NBER WORKING PAPER SERIES

\title{
CLIMATE RISKS AND MARKET EFFICIENCY
}

\author{
Harrison Hong \\ Frank Weikai Li \\ Jiangmin $\mathrm{Xu}$ \\ Working Paper 22890 \\ http://www.nber.org/papers/w22890
NATIONAL BUREAU OF ECONOMIC RESEARCH
1050 Massachusetts Avenue
Cambridge, MA 02138 \\ December 2016
}

We thank Stefano Giglio, Robert Engle, and seminar participants at the 2016 NBER Summer Institute Forecasting and Empirical Methods, the 2016 Symposium on Financial Engineering and Risk Management, the 2016 Research in Behavioral Finance Conference, the Volatility Institute at NYU, and the 2016 NBER Asset Pricing Meetings. The views expressed herein are those of the authors and do not necessarily reflect the views of the National Bureau of Economic Research.

NBER working papers are circulated for discussion and comment purposes. They have not been peer-reviewed or been subject to the review by the NBER Board of Directors that accompanies official NBER publications.

(C) 2016 by Harrison Hong, Frank Weikai Li, and Jiangmin Xu. All rights reserved. Short sections of text, not to exceed two paragraphs, may be quoted without explicit permission provided that full credit, including $\left({ }^{\circ}\right.$ notice, is given to the source. 
Climate Risks and Market Efficiency

Harrison Hong, Frank Weikai Li, and Jiangmin Xu

NBER Working Paper No. 22890

December 2016

JEL No. G0,G02,G12,Q0,Q5,Q54

\title{
ABSTRACT
}

We investigate whether stock markets efficiently price risks brought on or exacerbated by climate change. We focus on drought, the most damaging natural disaster for crops and food-company cash flows. We show that prolonged drought in a country, measured by the Palmer Drought Severity Index (PDSI) from climate studies, forecasts both declines in profitability ratios and poor stock returns for food companies in that country. A portfolio short food stocks of countries in drought and long those of countries not in drought generates a 9.2\% annualized return from 1985 to 2015 . This excess predictability is larger in countries having little history of droughts prior to the 1980s. Our findings support regulatory concerns of markets inexperienced with climate change underreacting to such risks.

\author{
Harrison Hong \\ Department of Economics \\ Columbia University \\ 1022 International Affairs Building \\ Mail Code 3308 \\ 420 West 118th Street \\ New York, NY 10027 \\ and NBER \\ hh2679@columbia.edu \\ Frank Weikai Li \\ Department of Finance \\ Hong Kong University of Science and Technology \\ Clear Water Bay, Kowloon, Hong Kong \\ wliaj@ust.hk
}

Jiangmin $\mathrm{Xu}$

Department of Finance

Guanghua School of Management

Peking University

jiangminxu@gsm.pku.edu.cn 


\section{Introduction}

Regulators are increasingly worried about the extent to which stock markets efficiently price climate change risks. Most notably, Mark Carney, the head of the Bank of England, recently linked these risks to financial stability (Carney (2015)). Such risks include energy corporations' exposure to carbon assets, which might be affected by future carbon prices or taxes. This so-called "stranded asset issue" has attracted the most discussion in regulatory and market circles at this point. ${ }^{1}$ But climate change risks need not be so narrowly confined to carbon exposures. Vulnerability of corporations' production processes to natural disasters such as prolonged drought, which is likely to be amplified by climate change and the focus of our paper, is also important and can impose significant damage to corporate profits (see, e.g., Trenberth, Dai, van der Schrier, Jones, Barichivich, Briffa, and Sheffield (2014)). ${ }^{2}$ In particular, regulators are concerned that markets have had little experience in dealing with such risks and might not pay enough attention and underreact to them as a result. Various regulatory bodies are promoting both voluntary and mandatory disclosures of corporations' climate risk exposures to address this issue. ${ }^{3}$ However, there is little systematic research on the topic of climate risks and market efficiency up to this point.

We tackle this important question by focusing on the efficiency with which the stock prices of food companies respond to information about drought. Our focus on drought has a few different motivations. First, among the natural disasters that might be amplified by climate change, including drought, heat waves, floods, and cold spells, drought is considered one of the most devastating for economic production. A recent study (Lesk, Rowhani, and Ramankutty (2016)) looks at 2,800 weather disasters along with data on 16 different cereals grown in over 100 countries. They found that droughts cut a country's crop production by ten percent, heat waves

\footnotetext{
${ }^{1}$ See, e.g., "The elephant in the atmosphere," Economist July 19th, 2014.

${ }^{2}$ Another recent study by Williams, Seager, Abatzoglou, Cook, Smerdon, and Cook (2015) argues that global warming caused by human emissions has most likely intensified the drought in California by 15 to 20 percent.

${ }^{3}$ Examples of the more prominent voluntary disclosure initiatives include the Carbon Standards Disclosure Board, Integrated Reporting, the Carbon Disclosure Project, and the UN Principles for Responsible Investment.
} 
by nine percent, but floods and cold spells had no effects on agricultural production levels. ${ }^{4}$

Second, a number of water engineering studies find that the food industry is the most reliant on water and hence the most sensitive to drought risk (Blackhurst, Hendrickson, and Vidal (2010)). ${ }^{5}$ Indeed, there are an increasing number of reports of dramatic short-falls in earnings and compressed profitability ratios or margins due to drought for agribusinesses such as Cargill, Tyson Foods, and Campbell Soup. ${ }^{6}$ For instance, Tyson Foods, a large multinational food processor, suffered steep profit drops due to the 2012 droughts in the main US agricultural states. $^{7}$

Third, drought is easy to quantify by using the Palmer Drought Severity Index (PDSI), a widely used monthly metric in climate studies (Palmer (1965)). PDSI combines information such as temperature and the amount of moisture in the soil to create an index that does an accurate job of measuring drought intensity. Less positive values of PDSI are associated with more drought-like conditions. While not perfect, it is by far the most widely used in climate studies and the most readily available (Alley (1984)). Globally, it is available at the country level and goes back to the 1870s. This data is available in the US by state going back to the 1890s.

We study the relationship between climate risks and stock markets in an international sample of countries. The time series of stock markets for most countries are much shorter than that of the US. The earliest start date is 1975 and much of our sample only begins in the early 1990s. ${ }^{8}$ We consider a sample of around 30 countries (including the US) with at least 10 food

\footnotetext{
${ }^{4}$ This is distinct from whether a warming climate is good or bad for crop yields (Mendelsohn, Nordhaus, and Shaw (1994)).

${ }^{5}$ The other major industry perhaps comparable to food companies in terms of water use is the power industry, but utilities are regulated and their profitability is largely unaffected by drought. The only other industry that also consumes a significant amount of water in its production process is the automative industry but its reliance on water is much less than that of the food industry.

${ }^{6}$ See "Feeding Ourselves Thirsty: How the Food Sector is Managing Global Water Risks", A Ceres Report, May 2015.

${ }^{7}$ See, e.g., "Meat Stocks Fall Tyson 8\% As Drought Hits Earnings", Investor's Business Daily August 6, 2012. Grain price is the main input cost for raising livestocks. The higher grain prices squeezed profit margins. Additionally, extreme reductions in output can also hurt food businesses relying on turnover as well as margins.

${ }^{8}$ However, the data for international markets includes 2015 in contrast to the US data which is only available
} 
companies during the entire period. In other words, our sample of countries are those with significant agricultural sectors. In robustness checks, we also separately analyze the US time series going back to 1927.

Our dependent variable of interests are the change in profitability ratios and the returns of the FOOD industry of each country. ${ }^{9}$ FOOD combines food processing and agricultural companies. We focus on this aggregated industry portfolio as opposed to the finer industry classifications, which separate FOOD into smaller components. The reason is that drought is likely to have a direct impact on the profits of both food processing and agricultural companies. ${ }^{10}$

First, we show that from roughly 1900 to now, when global temperatures exhibit a prominent increasing trend (see Figure 4), there is an increasing trend toward droughts across the countries in our sample. Climate studies typically focus on all places in the world, while we focus on just the countries that have large enough food industries. While not the focus of our paper, we provide evidence consistent with previous climate studies that suggest an association between global warming and droughts. It supports the premise behind our paper that drought is a channel through which a warming climate might impact the global economies and stock markets.

Second, we then show that droughts are problematic for food industry profitability, consistent with the anecdotes described earlier. Droughts are considered economically worrisome should the PDSI be elevated for a prolonged period. For short durations, drought has a negligible effect as production can adjust. It might even be helpful depending on when it occurs (before or after a harvest). But long periods of drought, running into years have negative consequences. Our main predictor variable will be a moving average of these PDSI series, averaged over horizons of anywhere from 12 months to 36 months (PDSI12m to PDSI36m). As our baseline, we focus on a 36-month moving average (PDSI36m). We pool together all the countries to run our up to 2014.

${ }^{9}$ We use Datastream industry classifications for the international sample excluding the US. For the US, we use the Fama and French (1997) 17-industry classification.

${ }^{10}$ Drought also creates water shortages which impact agricultural companies. While some of these cost increases can be temporarily passed onto consumers, prolonged drought ultimately also severely impacts agriculture as well. 
regressions and control for country fixed effects. We find that this moving average of the PDSI index strongly predicts changes in FOOD industry profitability ratios, as measured by industry net income over assets: low or negative values of PDSI for the previous 36 months are correlated with low or negative changes in food industry profitability ratios over the next 12 months.

Third, we then examine the relationship between this moving-average PDSI and food industry expected returns. Under the efficient market null hypothesis, we expect the coefficient on our independent variable of interest, the moving-average PDSI, to be zero (assuming there is no risk premium for drought) or negative (if there is a risk premium for drought). ${ }^{11}$ Yet to the extent that the market is underreacting to drought risk, as hypothesized by regulators, we expect the coefficient on the moving-average PDSI to be positive.

To see which is the case, we can construct a portfolio strategy that conditions on the PDSI information and consider the returns associated with this strategy. A strategy that longs the food industry portfolios of countries with high PDSI and shorts those with low PDSI in any given month and holds for one year generates an excess return of $0.77 \%$ per month with a $t$-statistic of 2.74. The Sharpe Ratio is $0.50 .{ }^{12}$ The results are similar whether we adjust the return spread using the global Sharpe (1964) CAPM, Fama and French (1993) three factor or Carhart (1997) four factor model as our long/short portfolio has little exposure to these common factors. These results support that there is underreaction in international markets since markets with drought do worst in the future than markets without drought. This underreaction is also symmetric with respect to negative and positive values of PDSI across countries. ${ }^{13}$

Another way to get at this same result is to use excess return predictability regressions. The portfolio results make clear that the predictability concerns food industry specific profitability and returns. As such, we extract the food industry specific returns in two ways. The first is that

\footnotetext{
${ }^{11}$ A lower PDSI level is associated with more uncertainty regarding future cash flows and hence should compensate investors with higher expected returns.

${ }^{12}$ Our portfolio analysis in contrast to our international sample regressions includes the US food stocks for purposes of investability.

${ }^{13}$ Our study assumes that even if the PDSI metric is not widely used until the 1970s producers and investors have always had access to temperature and other related information to form expectations of drought severity.
} 
we control in our predictive regressions, where the dependent variable is the FOOD portfolio return net of the risk-free rate, for a host of variables that are known to predict aggregate market returns. The second is that we can calculate the market portfolio net of FOOD stocks and then subtract from the FOOD returns the returns of the market portfolio purged of the FOOD sector. International cross-country regressions with country fixed effects yield a similar conclusion as our cross-country portfolio strategy.

Fourth, we can exploit exogenous variation in historical PDSI across countries to get at the experience mechanism behind regulatory concerns about market underreaction to climate change risks. Some countries in our sample have low PDSI scores in the past, while others have very high PDSI scores and little history with droughts. The main reason why regulators are worried that markets might be underreacting to climate change risks is that climate change represents a new phenomenon that markets do not have experience with. This scenario corresponds to the countries in our sample with high past PDSI scores. We find that the degree of underreaction for this subset of countries is more than twice that of other countries, consistent with regulatory concerns. Moreover, this underreaction is particularly strong for droughts or dry climate among these high past PDSI score countries.

We also conduct a series of robustness exercises, including separately analyzing the US sample where we have a long time series from 1927 to 2014 and where we have more detailed data on droughts. We can construct a measure of drought for the US by aggregating state-level drought measures for the top agricultural producing states. We find similar results as when we use a coarser measure of PDSI for the US, providing comfort that our international results are sensible. We also consider a number of extensions and robustness checks of our baseline specification, including (1) looking at short-horizon return predictability (1-month, 3-month and 6-month), and (2) seeing if our $t$-statistics are inflated due to persistent predictor variables since our PDSI measure is highly persistent (close to a random walk) by implementing the Campbell and Yogo (2006) test. We also show that our results are specific to the FOOD industry and this 
excess predictability is not apparent across other industries in the US.

Our findings are similar in spirit to the recent literature on attention and return predictability (see, e.g., Hong, Torous, and Valkanov (2007), DellaVigna and Pollet (2007), Cohen and Frazzini (2008)), whereby the market underreacts to many types of value relevant information such as industry news, demographic shifts, and upstream-downstream relationships. Even for these types of obviously relevant news, the market can be inattentive. Our analysis points to a similar underreaction to information on climate risks and suggests the value of exploring the corporate disclosure of exposure risk (Hirshleifer and Teoh (2003)).

Climate risk variables can be quantified and have been used successfully in the pricing of weather derivatives. ${ }^{14}$ However, the broader question of the extent to which information on such risks is appropriately discounted in stock markets has not received much attention to date. Our study of climate risks and market efficiency helps characterize the nature of the potential inefficiencies, which might inform regulatory responses and be useful for practitioners interested in the construction of quantitative risk-management models (Shiller (1994)).

There is a large literature on the economic analysis of how to design government policies to deal with climate change (see, e.g., Stern (2007), Nordhaus (1994)), be it through emissions trading (Montgomery (1972)) or taxes (Golosov, Hassler, Krusell, and Tsyvinski (2014)). In contrast, our analysis highlights the role of markets in potentially mitigating the risks brought on or exacerbated by climate change. Understanding the role of financial markets in pricing climate risks is a natural one, though work is limited at this point with some notable exceptions. Bansal, Kiku, and Ochoa (2014) argue that long-run climate risks as captured by temperature are priced into the market. Daniel, Litterman, and Wagner (2015) and Giglio, Maggiori, Stroebel, and Weber (2015) show how stock and real estate markets might help guide government policies assuming markets efficiently incorporate such climate risks. Our analysis suggests that such climate risk information, at least when it comes to natural disasters, is not efficiently priced.

\footnotetext{
${ }^{14}$ See, e.g., Roll (1984), Campbell and Diebold (2005).
} 


\section{Data, Variables and Summary Statistics}

\subsection{International Drought Measures}

Our data for the global (excluding the US) Palmer Drought Severity index comes from Dai, Trenberth, and Qian (2004). The index is a measurement of drought intensity based on a supply-and-demand model of soil moisture developed by Palmer (1965). The index takes into account not only temperature and the amount of moisture in the soil, but also hard-to-calibrate factors such as evapotranspiration and recharge rates. It is a widely used metric in climate studies. The index grades drought and moisture conditions in the following scale: -4 and below is extreme drought, -3.9 to -3 is severe drought, -2.9 to -2 is moderate drought, -1.9 to 1.9 is mid-range (normal), 2 to 2.9 is moderately moist, 3 to 3.9 is very moist, 4 and above is extremely moist. The extreme values for PDSI are -10 and 10 .

The data consists of the monthly PDSI over global land areas computed using observed or model monthly surface air temperature and precipitation. The global PDSI dataset is structured in terms of longitude and latitude coordinates and we extract each country's PDSI based on that country's geographic coordinates. The sample period of global PDSI is from January 1870 to December 2014.

We present the evolution of droughts in a number of countries from our international sample. Figure 1 plots the time series of monthly PDSI values for several countries, including Australia, India, Russia, Japan and Israel. The sample starts from 1927 and ends in 2014. We also identify some of the most severe drought episodes in the history, which correspond closely to very negative values of PDSI in the data. For example, the Millennium drought in Australia started from 1997 and continued for more than 10 years, which is recognized as the worst on record since settlement in Australia.

Since droughts that last for a few months are unlikely to do any harm to the food industry

(and under certain circumstances might even be helpful depending on whether it occurs before 
or after a harvest), we consider a moving average of these monthly drought measures, where the average is over years. As we discussed in the Introduction, prolonged droughts that last years are likely to substantially impair food industry cashflows and hence their stock prices. The idea is that by shortening or lengthening the window over which we do the average, we pick up more prolonged periods of drought. We will focus on the baseline 36 months moving average of PDSI (PDSI36m) for our countries. In robustness checks, we also consider shorter horizon moving averages, ranging from 12 months to 30 months.

To see why smoothing over long periods makes sense, consider that the monthly Palmer Drought Severity Index (PDSI) in month $t$ is computed based on the following equation:

$$
\mathrm{PDSI}_{t}=0.897 \mathrm{PDSI}_{t-1}+\frac{1}{3} Z_{t}
$$

where $\mathrm{PDSI}_{t}$ is the current $\mathrm{PDSI}$ in month $t, \mathrm{PDSI}_{t-1}$ is the $\mathrm{PDSI}$ in the previous month $t-1$, and $Z_{t}$ is called the "moisture anomaly index", which can be thought of as the moisture "shock" in month $t .{ }^{15}$ The initial monthly PDSI value at $(t=0)$ in a spell of dry or wet weather is

$$
\operatorname{PDSI}_{0}=\frac{1}{3} Z_{0}
$$

Hence the PDSI in a month depends on both the current-month moisture anomaly $Z_{t}$ and the previous-month PDSI value $\left(\mathrm{PDSI}_{t-1}\right)$. The value of $\mathrm{PDSI}_{t}$ in equation $(2.1)$ is not a weighted average of $\mathrm{PDSI}_{t-1}$ and $Z_{t}$, since the sum of the weights 0.897 and $1 / 3$ is strictly greater than $1 .^{16}$ This means the weight $(1 / 3)$ on the current moisture anomaly is too large, so that the monthly PDSI values respond too rapidly to monthly moisture shocks. This is one reason for why there are such large monthly fluctuations in PDSI in the graphs we showed before. As a result, practitioners often advocate smoothing by averaging over longer periods to get a more

\footnotetext{
${ }^{15}$ See, e.g., Alley (1984) and Karl (1986).

${ }^{16}$ If the weight on $Z_{t}$ were $1-0.897=0.103$, then (2.1) would have been an exponentially weighted moving average model.
} 
sensible result for a prolonged drought, which is what we do in the paper. ${ }^{17}$

Panel B of Table 2 shows the summary statistics for various drought measures in our international sample. Our main drought measure PDSI36m has a mean of -0.22 and a standard deviation of 1.13. The mean of PDSI measured over various horizons are quite similar and as expected, the standard deviation is smaller when PDSI is averaged over longer horizons.

\subsection{International Stock Market Data}

We obtain firm-level stock returns and accounting variables for a broad cross section of countries (except for the U.S.) from Datastream and Worldscope, respectively. The sample includes live as well as dead stocks, ensuring that the data are free of survivorship bias. We compute the stock returns in local currency using the return index (which includes dividends) supplied by Datastream and convert them to U.S. dollar returns using the conversion function built into Datastream. In some of our tests, we also use price-to-book ratio which is directly available from Worldscope database. Inflation rate for international countries is from the World Bank database.

We apply the following sequence of filters that are derived from the extensive data investigations by Ince and Porter (2006), Griffin, Kelly, and Nardari (2010) and Hou, Karolyi, and Kho (2011) as follows. First, we require that firms selected for each country are domestically incorporated based on their home country information (GEOGC). A single exchange with the largest number of listed stocks is chosen for most countries, whereas multiple exchanges are used for China (Shanghai and Shenzhen) and Japan (Tokyo and Osaka). We eliminate noncommon stocks such as preferred stocks, warrants, REITs, and ADRs. A cross-listed stock is included only in its home country sample. If a stock has multiple share classes, only the primary

\footnotetext{
${ }^{17}$ Another reason for smoothing is that the PDSI is not a real time measure but potentially delayed by a month or two so depending on whether climate models can accurately verify that a drought has ended or began. In practice, there is little difference between different versions of PDSI (which is available for the US and called PDMI).
} 
class is included. For example, we include only A-shares in the Chinese stock market and only bearer-shares in the Swiss stock market.

To filter out suspicious stock returns, we set returns to missing for stocks that rises by $300 \%$ or more within a month and drops by $50 \%$ or more in the following month (or falls and subsequently rises). We also treat returns as missing for stocks that rise by more than $1,000 \%$ within a month. Finally, in each month for each country, we winsorize returns at the 1st and the 99th percentiles, to reduce the impact of outliers on our results (McLean, Pontiff, and Watanabe (2009)). Datastream classifies industries according to Industrial Classification Benchmark (ICB). The food portfolio includes stocks in the food \& beverage supersector. ${ }^{18}$ Food portfolio returns are individual stock returns weighted by lagged market capitalization. In addition, to meaningfully identify the drought impact in our international sample, we further exclude countries with less than 10 stocks in the food portfolio in its entire time series. The final sample includes 30 countries, among which 15 are developed countries and 15 are developing countries.

Table 1 Panel A reports the summary statistics of our international sample. The average number of stocks in the food industry varies considerably across countries, from 7 in Finland to 108 in India. We also report the median firm market capitalization in the food industry within each country as of the end of 2013 in millions of U.S. dollars, as well as the mean and standard deviation of the monthly PDSI values for each country.

As we can also see from Panel A, the time series of stock returns for international countries are much shorter than for the US. As a result, we cannot conduct an individual time series exercise for each country. Instead, we will pool together all the international monthly observations and run a pooled regression. We control for country fixed effects to isolate the time series return predictability of lagged PDSI from the cross-country effect.

\footnotetext{
${ }^{18}$ ICB Supersector Level classifies industries as follows: Oil \& Gas, Chemicals, Basic Resources, Construction \& Materials, Industrial Goods \& Services, Automobiles \& Parts, Food \& Beverage, Personal \& Household Goods, Health Care, Retail, Media, Travel \& Leisure, Telecommunications, Utilities, Banks, Insurance, Real Estate, Financial Services, Equity/Non-Equity Investment Instruments, and Technology.
} 
Panel B of Table 1 reports the summary statistics for the control variables. The market predictor variables we have for the international sample include the lagged 12-month returns of the market (MRET12), the lagged inflation rate of the country (INF12), the dividend-to-price ratio of the country market index (DP12) and the market volatility (MVOL12). Food industryspecific controls include the price-to-book ratio of the food industry stocks (FOODPB12) and the 12-month food industry return (FOODRET12m). The mean annual market return is $7.98 \%$ with a standard deviation of $30.03 \%$. The mean annual inflation rate is $7.32 \%$, annual dividendto-price ratio is $2.98 \%$ and the mean annual market volatility is $23.12 \%$. The mean price-to-book ratio for the food stocks is 2.56 .

Finally, we report the summary statistics for the international FOOD industry portfolios return in Panel $\mathrm{C}$ of Table 1. The mean 12-month food industry return is $12.86 \%$ with a standard deviation of $41.30 \%$. We also report the change in the food industry profitability ratio in Panel $\mathrm{C}$. The change in the food industry profitability ratio in year $t$ is defined as $C P_{t}=N I_{t} / A_{t}-N I_{t-1} / A_{t-1}$, where $N I$ is the food industry net income and $A$ is the food industry total asset. The food industry net income and total asset are obtained respectively by aggregating the net income and the total asset of individual firms within the food industry. The cashflow variable CP has a median of $-.01 \%$ and a standard deviation of $3.34 \%$.

\subsection{US Drought Measures}

Our PDSI data for the US comes from the National Centers for Environmental Information (NCEI) of the US National Oceanic and Atmospheric Administration (NOAA). The PDSI is updated monthly on the NOAA's website, and the index value extends back to January 1895. We obtain the monthly PDSI data of all 48 contiguous states in the US (excluding Alaska and Hawaii because there is no data) from January 1927 to December 2014 as well as the aggregated US drought measure produced by US NOAA (PDSIUSA). PDSIUSA is essentially a land-area weighted average of the PDSI values from all climate divisions in the US. 
Figure 2 illustrates the historical evolution of this drought measure from January 1927 to December 2014, with its value shown on the vertical axis. The PDSIUSA measure identifies some of the most recognizable droughts in the US history. For example, we can see the infamous "Dust Bowl" period of prolonged droughts in the 1930s, and an extended period of severe droughts in the 1950s, with the PDSI value falling frequently below -2 and even breaking -8 . From the 1960 s to the 1980 s, the US experienced several spells of relatively shorter yet significant droughts. Since the turn of the 21st century, the US has been bombarded by various droughts that include the current ongoing drought in California. This might suggest that the climate risk due to global warming has intensified, as the droughts in the 1930s and 1950s could be (at least) partly attributed to bad soil management and exploitative farming techniques.

Because not every state in the US has significant croplands or an agricultural sector, we construct our own aggregated measures of drought for the US. The first one, PDSIWA, is the weighted average of the PDSI values from the top 10 food-producing states (in terms of gross cash income of the state's farm sector), using cropland area as weight. Data for both the cropland area and the gross cash income of the farm sector in each state are obtainable from the US Department of Agriculture. The top 10 food-producing states are (in alphabetic order): California, Illinois, Indiana, Iowa, Kansas, Minnesota, North Carolina, Nebraska, Texas, Wisconsin. This is our main drought measure in our robustness checks section.

Our second aggregate measure (PDSIASWA) is the weighted average of the PDSI values from all 48 contiguous states based on cropland area. We focus on the top 10 food producing states but a number of states have some croplands, and so we also consider this measure. Our third aggregate measure is PDSIASCAWA, which is simply the weighted average PDSI of the 48 states using gross cash income of the farm sector as weights.

For our main baseline measure PDSIWA, using the top 10 states, we consider moving averages from 12 months to 36 months (e.g. PDSIWA12m to PDSIWA36m). For our other three drought measures, we will just consider a 36-month moving average. In theory, we could average 
over much longer periods of time. The trade-off is that we then lose time series variation in our drought measure. As such, we consider 36-month (a 3 year drought) as a reasonable length to focus on and assess the sensitivity of our findings to differing lengths.

Panel A of Table 2 shows the summary statistics for our various drought measures. Our main drought measure PDSIWA36m has a mean of 0.17 and a standard deviation of 1.26. Moreover, the four drought measures are all positively correlated, as demonstrated in Panel D of Table 2. The PDSIUSA36m measure is less correlated not surprisingly with our other three measures since it weighs by land mass as opposed to cropland. Nonetheless, the correlation of PDSIUSA36m with PDSIWA36m is 0.88. As such we expect our baseline measure to be a better predictor of food stock returns than the PDSIUSA36m measure but this standard NOAA measure ought to still have information about food stock returns.

\subsection{US Stock Market Data}

Our second set of data comes from Kenneth French's website. ${ }^{19}$ It contains the monthly valueweighted returns for the Fama-French 17 industry portfolios from January 1927 to December $2014 .^{20}$ Our interest is in the FOOD industry, which includes agriculture firms, food products and food processing firms, candy and soda-producing firms, beer and liquor-producing firms, as well as related wholesale firms.

We take the raw continuously compounded monthly industry returns and net them off the one-month T-bill return to obtain the monthly excess returns for all industries. We denote the food industry excess return by FOODRET. We then take the FOODRET at 1-month, 3month, 6-month, and 12-month frequencies. Panel B of Table 2 shows the summary statistics

\footnotetext{
${ }^{19}$ http://mba.tuck.dartmouth.edu/pages/faculty/ken.french/data_library.html

${ }^{20}$ The 17 industries are: (1) Food, (2) Mining and Minerals, (3) Oil and Petroleum Products, (4) Textiles, Apparel and Footware, (5) Consumer Durables, (6) Chemicals, (7) Drugs, Soap, Perfumes, Tobacco, (8) Construction and Construction Materials, (9) Steel Works, (10) Fabricated Products, (11) Machinery and Business Equipment, (12) Automobiles, (13) Transportation, (14) Utilities, (15) Retail Stores, (16) Banks, Insurance Companies and Other Financials, (17) Other.
} 
for FOODRET. Our baseline dependent variable of interest, FOODRET12m, has a mean of $7.16 \%$ and a standard deviation of $17.45 \%$.

In addition to FOODRET12m, we create a FOOD industry return that nets the market portfolio. The problem is that the FOOD industry is also a big part of the market. As such, we create a market portfolio excluding the food stocks and then subtract the returns of this alternate market portfolio from the FOOD industry returns. We call this variable FOODXMRET12m. It has a mean of $1 \%$ and a standard deviation of $11.75 \%$. The cashflow variable CP has a mean of $-0.03 \%$ and a standard deviation of $0.77 \%$.

Our second data set also has the value-weighted average book-to-market ratio for each of the industries observed at annual frequency. We take the log value for all the industry book-tomarket ratios, and we denote this value for the food industry by FOODBM. Moreover, it has the monthly market excess returns (the CRSP value-weighted market portfolio excess return over the Treasury-bill), and we denote this variable by MRET.

Our third set of data comes from Amit Goyal's website. ${ }^{21}$ It contains the monthly data for all other market predictor variables that we will use. It includes the following variables: the inflation rate (INF), the log value of the dividend-price ratio of the S\&P 500 index (DP), the volatility of the S\&P 500 index (MVOL), the net equity expansion of the NYSE stocks (NTIS), the difference between BAA and AAA-rated corporate bond yields (DSPR), and the difference between the long term yield on government bonds and the Treasury-bill (TSPR). Panel C of Table 2 provides the summary statistics for all of our predictor variables (annualized and hence the appending of 12 (denoting 12-month) to the variable names) as well MRET12 and FOODBM12. We can see that the summary statistics of our variables are consistent with those in the literature. For instance, our market excess return MRET12 has a mean of $6 \%$ and a standard deviation of 20\% (see, e.g., Fama and French (2015)). Moreover, our annual inflation is $2.94 \%$ that is in line with the long-run inflation rate in the US. Panel D reports the

\footnotetext{
${ }^{21}$ http://www.hec.unil.ch/agoyal/docs/PredictorData2014.xlsx
} 
correlation matrix for these variables.

In Figure 3, we plot the time series of our independent variable of interest (PDSIWA36m) along with one of our dependent variable of interest (the future 12-month return of the food industry net of the market return, i.e. FOODXMRET12m). To the extent that the market is not efficiently pricing in the information about prolonged droughts, we expect a positive correlation between these two time series. This is indeed what we see. We have marked some of the main droughts in US history. Prolonged drought episodes are typically periods when future returns to the food portfolio is low. Similarly, periods when there is plentiful water (i.e. positive values of PDSI) are associated with higher than average returns to the food industry portfolio. As we will show in various ways below, the relationship between these two time series is positive and statistically significant.

\subsection{Climate Change and Droughts}

While not the focus of our paper, we briefly show here that for our sample of large FOOD

producing countries, a warming climate since 1900 (see Figure 4) is associated with an increasing trend toward droughts. Let the PDSI variable in question be PDSIvar. The PDSI variable can be the monthly median PDSI value of the international countries (including the US), the lower quartile (25th percentile) value, or the upper quartile (75th percentile) value. We can estimate the trend in drought, along with allowing for potential changes in this trend during the latter part of our sample, by estimating the following regression:

$$
\operatorname{PDSIvar}_{t}=\alpha_{0}+\beta_{0} t+\beta_{1}(t-\tau) D(t \geq \tau)+\varepsilon_{t},
$$

where $D(t \geq \tau)$ is a dummy variable that equals 1 if time $t$ is greater than or equal to January 1980 (198001), the break point. We choose 1980 as a natural breakpoint in trend because the global annual temperature anomaly measures (from Figure 4) typically take the 1950-1980 as 
the thirty-year average against which the anomaly in other time periods is measured. The coefficient $\beta_{1}$ captures the effect from the structural break in the time trend, i.e. the PDSI variable is trending at the speed of $\beta_{0}$ before 1980 but the speed rises to $\beta_{0}+\beta_{1}$ after $1980 .^{22}$ We estimate this equation by allowing the error term $\varepsilon$ to be serially correlated and heteroskedastic, and in doing so we adjust the standard errors of the estimates by using Newey-West (1992) HAC standard errors.

The estimation results are reported in Table 3. In Panel A, we first estimate the trend without allowing for a break. We can see that the coefficient $\beta_{0}$ is negative for all three measures of PDSI. It is statistically significant for the 25th and 50th percentile PDSI. Panel B of Figure 5 plots the series of the 50th percentile PDSI and the fitted trend line. We can see a prominent downward trend in the median PDSI. In Panel B, we allow for a break in trend. We can see that the coefficient $\beta_{1}$, the effect from the structural break in the time trend, is negative for all of the PDSI variables but only statistically significant for the 25 th percentile PDSI. To visualize this structural break in trend for the 25th percentile PDSI after 1980, we plot in Panel A of Figure 5 the time-series of monthly lower quartile of PDSI value of the international countries and the the fitted trend line that allows for a break after 1980. Overall, we provide evidence consistent with earlier climate studies that droughts have become worst over time, especially after 1980.

\footnotetext{
${ }^{22}$ However, we need to be careful before carrying out this structural break test for the deterministic time trend in PDSIvar because potentially, PDSIvar could be a unit root process. In other words, PDSIvar could be a random walk with drift

$$
\text { PDSIvar }_{t}=\theta+\text { PDSIvar }{ }_{t-1}+\epsilon_{t} \quad \text { (difference stationary), }
$$

instead of the trend stationary process that we specified above. If this is the case, then our structural break test for the time trend would be invalid. Therefore, we need to rule out the possibility that PDSIvar is a unit root process. To this end, we invoke the unit-root test of Zivot and Andrews (1992) that allows for a potential structural break in the intercept (constant) and/or the trend. This test is more appropriate than the traditional augmented Dicky-Fuller test (Dickey and Fuller (1979)) for unit root since potentially there can be a structural break, which would invalidate the augmented Dick-Fuller test. The null hypothesis of a unit root is rejected for all the PDSI variables at the $1 \%$ significance level. These results are available from the authors. Thus we can proceed with our time-trend structural break test.
} 


\section{Droughts and Food Industry Profitability}

We show how our drought measures impact the future profitability of the FOOD industry following the methodology set out in Fama and French (2000). The dependent variable is the future 1-year change in the food industry profitability ratio $(\mathrm{CP})$ in each country. The key explanatory variable is the 36-month moving average of country-level PDSI values (PDSI36m).

We specify this PDSI-food return relation for a given country $i$ as the linear regression

$$
\mathrm{CP}_{i, t}=\alpha_{i}+\beta_{i} \mathrm{PDSI}_{36 \mathrm{~m}_{i, t-1}}+\gamma_{i}^{\prime} X_{i, t-1}+e_{i, t}
$$

where $\mathrm{CP}_{i, t}$ is the future change in the food industry profitability over the next 12 months for country $i$, PDSI36m $\mathrm{m}_{i, t-1}$ is the moving average of PDSI over the previous 36 months and $X_{i, t-1}$ is a set of lagged predictors from the country's stock market.

To increase the power of our inferences in equation (3.1), we pool all countries together and estimate a panel regression that imposes the restriction

$$
\begin{aligned}
& \beta_{1}=\beta_{2}=\ldots=\beta \\
& \gamma_{1}=\gamma_{2}=\ldots=\gamma
\end{aligned}
$$

across all countries, so that $\beta$ reflects only the contribution of within-country time variation in PDSI36m. The $\alpha_{i}$ in equation (3.1) corresponds to country fixed effects when the restrictions in (3.2) and (3.3) are imposed across all countries. When we combine equation (3.1), (3.2) and (3.3), the regression is a panel regression with country fixed effects

$$
\mathrm{CP}_{i, t}=\alpha_{i}+\beta \operatorname{PDSI} 36 \mathrm{~m}_{i, t-1}+\gamma^{\prime} X_{i, t-1}+e_{i, t}
$$

Given country fixed effects, the OLS estimate $\hat{\beta}$ from this panel regression reflects only time- 
series variations in PDSI36m and food sector change in profitatbility. $\hat{\beta}$ is a weighted-average of the slope estimates from pure time-series regressions (Pastor, Stambaugh, and Taylor (2014)). This weighting scheme places larger weights on the time-series slopes of countries with more observations as well as countries whose PDSI fluctuates more over time. Following Petersen (2009), we cluster the standard errors at both the country and month dimensions.

Our hypothesis is that low PDSI would predict low future change in profitability within each country, so it is essentially a time-series relation between lagged PDSI and future food industry profitability. The result is reported in Table 4. In column (1), we report the coefficients for the market control variables, including MRET12, DP12, INF12, and MVOL12. MVOL12 comes in with a statistically significant coefficient. In column (2), we also add as control variables the lagged CP measure, FOODRET12m, and FOODPB12. These are industry specific controls from the literature. In column (2), we find that high lagged CP measure forecasts decreasing food industry profitability over the next year.

The coefficient of interest is in column (3) where we find that PDSI36m attracts a coefficient of 0.14 with a $t$-statistic of 1.8. Drought is associated with a decline in the food industry profitability over the next year. A one standard deviation move in our drought measure results in a $0.16 \%$ fall in $\mathrm{CP}$ (the standard deviation of PDSI36m is 1.13). This is $5 \%$ of the standard deviation of $\mathrm{CP}$, which is a substantial decrease.

In Figure 6, we show the scatterplot of the residual of $\mathrm{CP}$ generated from the predictive regression in column (2) and our drought measure. The univariate regression through the scatterplot has a coefficient of 0.08 with a $t$-statistic of 1.7 . In sum, our global markets result provides additional evidence that climate risks, such as prolonged droughts, could negatively impact the profitability of the food and agricultural sector. 


\section{Cross-Country Portfolio Strategy Based on PDSI}

In this section, we conduct a portfolio strategy test of market efficiency. We want to see if global markets are efficiently responding to drought information. To this end, we construct a trading strategy that is long the food portfolio in countries with high PDSI and short the food portfolio in countries with low PDSI in any given month. We expect this strategy to generate abnormal returns if markets indeed underreact to drought contained in the PDSI.

Our trading strategy is constructed as follows. To make the level of PDSI36m comparable across countries, we first standardize the PDSI36m by subtracting its mean and dividing by its standard deviation. We use the past 70 years of PDSI data to calculate a rolling mean and standard deviation of PDSI36m. This standardization uses only lagged drought information since we have long time series of drought for all countries. Every month, we sort the food-industry portfolios across all countries into quintiles based on the standardized PDSI36m (denoted as PDSI36m*) at the previous month. We then hold each portfolio for $K$ months (where $K$ can range anywhere from 1 month to 12 months) and returns are equally-weighted within each quintile portfolio. We follow Jegadeesh and Titman (1993) to construct the overlapping portfolios. For each quintile portfolio at month $t$, we have $K$ portfolios formed from month $t-1$ to $t-K$. Returns on the $K$ portfolios are then equally-weighted to get the average return for each quintile portfolio at month $t$. The quintile portfolios are rebalanced monthly as we replace $1 / K$ fraction of the portfolio that have reached the end of its holding horizons. In addition to the mean portfolio returns, we also report portfolio alphas adjusted using global factor models. ${ }^{23}$ Our sample starts from January 1985 when we have at least 10 countries to do the sorting exercise. The result is reported in Table 5 .

In Panel A, we report the monthly mean excess returns and factor-adjusted alphas for quintile portfolios with a holding horizon of $K=12$ months. The middle three portfolios are grouped

\footnotetext{
${ }^{23}$ The global market, size, book-to-market and momentum factors are the weighted average of the respective country-specific factors, where the weight is the lagged total market capitalization in that country.
} 
together by equal weighting their respective returns. In the first column, we report the mean standardized PDSI36m for each quintile portfolio. By construction, mean PDSI36m* increases monotonically from low to high PDSI36m* countries. Interestingly, we see from column (2) that portfolio returns also increase from low to high PDSI36m* countries. The mean excess return for countries in the bottom quintile of PDSI36m* is $0.38 \%$ per month, and for countries in the top quintile, the number is $1.15 \%$. The return spread for the long/short strategy is $0.77 \%$ per month and significant at $1 \%$ level $(\mathrm{t}=2.74)$. The row "Middle - Low" shows that the bottom portfolio underperform the middle portfolio by $0.33 \%$, while the row "High - Middle" shows that the top quintile portfolio outperforms the middle by $0.44 \%$. The difference between these two numbers is not significant $(\mathrm{t}=0.1)$. In the last column, we also report the portfolio alphas adjusted using a global Carhart (1997) four factor model. Our results are not affected as the long/short strategy generates a monthly alpha of $0.83 \%(\mathrm{t}=2.87)$. In untabulated tables, we show that a value-weighted long/short portfolio using the lagged total market capitalization of the food sector in that country as weight generates a monthly excess return of $0.72 \%(\mathrm{t}=1.95)$ and a four-factor alpha of $0.68 \%(t=1.82) .{ }^{24}$

In Panel B, we report the return spread as well as factor-adjusted alphas on this long/short portfolio with holding horizons varying from $K=1$ month to $K=12$ months. The mean excess returns are positive and significant across all holding horizons. Consistent with our time-series return predictability result, the return spread becomes more pronounced when we increase the holding horizon, indicating that it takes time for market to fully incorporate the information about drought into stock prices. For example, the mean monthly excess return on this long/short strategy for the 12-month holding horizon is $0.77 \%$, with an annualized Sharpe ratio of 0.50 . The return decreases to $0.74 \%$ when we only hold the portfolio for three months, and further decreases to $0.57 \%$ when the holding horizon is 1 month. The results are similar whether we adjust the return spread using a global Sharpe (1964) CAPM, Fama and French

\footnotetext{
${ }^{24}$ Such a value-weighted portfolio is dominated by the food sector from the US since the total market capitalization of the food industry is much larger in the US than in other countries.
} 
(1993) three factor or Carhart (1997) four factor model as our long/short portfolio has little exposure to these common factors.

\section{Droughts and Food Industry Excess Return Predictabil- ity}

We now conduct an excess return predictability regression analog of our portfolio strategy above. We examine whether droughts forecast food stock returns in international markets. ${ }^{25}$ In Table 6, we consider how PDSI averaged over 36 months predict future food industry returns. To increase the power of our test, we pool all countries together, and run a panel regression by including a country fixed effect. We specify this PDSI-food return relation for a given country $i$ as the linear regression

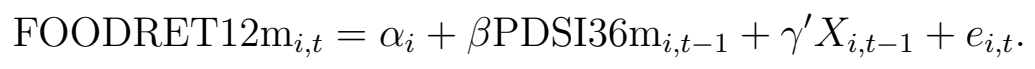

Given country fixed effects, the OLS estimate $\hat{\beta}$ from this panel regression again reflects only time-series variations in PDSI36m and food sector returns. $\hat{\beta}$ is a weighted-average of the slope estimates from pure time-series regressions.

In column (1), the coefficient on MRET12 is statistically insignificant. The coefficient on INF12 is positive. A higher dividend-price ratio forecasts lower returns. Over this sample period, this variable is highly statistically significant. Lagged market volatility attracts a positive sign. The $R^{2}$ of this time series regression is $16.7 \%$. As such, we believe that this expected return model for the market does an adequate job of explaining the systematic component of FOOD industry returns.

\footnotetext{
${ }^{25}$ For the international return predictability regressions, we include the US in the international sample. We will also do the return predictability for the US separately as we have a much longer US time-series sample of the return starting from 1927. But removing the US from the international sample does not change the main conclusion at all. This result is available from the authors.
} 
In column (2), we add in two FOOD industry specific variables in the form of the lagged past 12-month FOOD industry returns (FOODRET12m) and the book-to-market ratio of the FOOD industry portfolio (FOOBM12). These FOOD industry specific return predictors are motivated by momentum or positive serial correlation in industry portfolios (Moskowitz and Grinblatt (1999), Hong, Torous, and Valkanov (2007)) and the potential conditioning information in the cost of equity by industries (Fama and French (1997)). Both variables come in with the expected signs. They increase the $R^{2}$ from $16.7 \%$ in column (1) to $19.5 \%$ in column (2).

In column (3), we then add in our variable of interest PDSI36m and find that it has significant incremental forecasting power for the future returns of the food portfolio. The coefficient estimate of PDSI36m is 3.48 with a $t$-statistic of 2.26 , which is significant at the $5 \%$ statistical significance level. It increases the $R^{2}$ from $19.5 \%$ in column (2) to $21.3 \%$ in column (3). Moreover, notice that the coefficients in front of the previous market and industry predictor variables from columns (1) and (2) are largely unchanged. This is to be expected from our discussion regarding the contemporaneous correlations of the PDSI36m with the standard market and industry predictor variables. Our variable of interest is not significantly correlated with these predictors. As a result, adding our variable of interest has little effect on the coefficients in columns (1) and (2). Hence we can be assured that our drought variable is not picking up the traditional market predictors nor is it priced into the book-to-market ratio of the FOOD industry. If the information in drought were priced in, we might expect it to be captured by the FOOD past returns and book-to-market ratio in column (2).

To the extent markets are efficient, we would expect zero excess return forecastability on the moving average of PDSI36m for the food portfolio. However, our baseline result of strong forecastability suggests that markets are under-reacting to climate risks from droughts. Moreover, the sign on the coefficient of interest suggests that this is not a risk premium mechanism at work. If it were risk, we would expect that more intense drought results in higher as opposed to lower expected returns. Moreover, we might expect that if markets were efficient in pricing 
drought, the information in drought would be captured by the FOOD industry book-to-market ratio introduced in column (2).

The implied economic significance of our PDSI variable is large. The mean return of this portfolio is $12.86 \%$. Hence the decrease in returns associated with a one standard deviation increase in drought is roughly $31 \%$ of the mean. The economic magnitude from our international sample is large. Another way to gauge the economic significance of our drought variable is to compare it to the predictive power of the traditional market predictors. In column (3), the two most powerful predictors are the FOODPB12 and DP12. Our drought effect is about $60 \%$ of that of the FOODPB12 and $40 \%$ of that of the DP12.

To visualize the regression results in Table 6, we produce a scatterplot in Figure 7 of the FOOD returns residualized from the predictive model given in column (2) against our PDSI36m measure. That is, we are plotting the FOOD returns in excess of the expected returns as captured by the traditional market predictor and industry predictor variables with our drought measure. We then run a simple univariate regression on these residuals. The coefficient is 2.16 with a $t$-statistic of 3.69. The coefficient is not identical to column (3) since there are non-zero covariances between PDSI36m and the other variables. But since these covariances are not too large, the coefficients are similar in magnitude. Furthermore, the appealing aspect of this scatterplot analysis is that we can see that our drought effect is coming from both negative values of PDSI as well as positive values of PDSI. That is, since PDSI measures the combined moisture in soil and temperature, we expect that when there is less drought (i.e. more moist conditions), we also get higher returns or more profits for the FOOD industry. This difference in the mean FOOD industry returns across drought conditions is visible in the scatterplot.

Our focus on 12-month horizon returns for FOOD brings up the usual worries of longhorizon excess return predictability (Valkanov (2003)). These worries are alleviated somewhat in our setting since our $t$-statistic is around 2 and the scatterplot analysis points to a pronounced decline in expected returns with drought. Nonetheless, to fully address such concerns, we repeat 
our analysis (column (3) of the previous table) but now using short (1 month) to intermediate horizon returns (3 and 6 months).

In Table 7, we examine the excess return predictability at shorter horizons from 1 month to 6 months. In column (1), we consider the 1-month return results. Our FOODPB12, MRET12 and MVOL12 are economically and statistically significant. Our coefficient of interest is 0.175 with a $t$-statistic of 2.0. A one standard deviation increase in PDSI36m (1.13) leads to a higher expected return of $.20 \%$ next month. The mean 1 -month return is $1.04 \%$. This is nearly $19 \%$ of the mean.

In columns (2) and (3), we consider intermediate horizon returns of 3 months and 6 months. In column (2), the coefficient of interest is .597 with a $t$-statistic of 2.38. A one standard deviation decrease in PDSI36m leads to a decline of $.67 \%$ in next quarter returns, which is around $21 \%$ of the mean FOOD return. Among the traditional predictors, only FOODPB12 are more significant than our variable.

In column (3), the coefficient of interest is 1.30 with a $t$-statistic of 2.12 . The implied economic effect for drought as a fraction of the mean return of FOOD is similar but as a fraction of the standard deviation of FOOD returns, it is smaller than the 12-month case (at around $6 \%$ ). Overall, we conclude that the economic significance of our drought variable is there at short, intermediate and long horizons.

In Table 8, we use a FOOD industry portfolio return that is net of the market portfolio of that country. The market portfolio for each country is calculated, as in the case of the US, by excluding food industry stocks. In column (1), we show the monthly return results. The coefficient is 0.136 with a $t$-statistic of 1.83 . All the specifications as we go further out in horizon are economically significant. The columns that are not statistically significant are the 3- and 6 -month horizon results. The coefficients are sizeable but only attracts a $t$-statistic of 1.44 and 1.43 , respectively.

In Appendix Table 1, we explore the extent to which different horizons of our baseline PDSI 
(from 12-month moving average to 30-month moving average) forecast food portfolio returns over the next 12 months. We always use the specification with the full list of control variables from column (3) of Table 6.

In columns (1) and (2), we use a moving average of 12 months and 18 months. We can think of this short-horizon moving average as capturing shorter episodes of drought. The coefficients are positive but marginally insignificant. It is in column (3), at the 24-month moving average horizon, that we see a statistically significant result. The coefficient of interest is 2.58 with a t-statistic of 1.74. Similarly, in column (4), the coefficient is even larger and significant at the $5 \%$ level of significance. Overall, the predictability of FOOD returns by drought information increases the more prolonged the drought is.

\section{How Excess Predictability Varies Across Countries De- pending on Experience with Droughts}

Up to now, our goal has been to establish that stock markets underreact to the implications of drought for future food industry profitability. In this section, we want to address more directly regulatory concerns. The main reason why regulators are worried that markets might be underreacting to climate risks is that climate change represents a new phenomenon that markets do not have experience with. There is a literature in behavioral economics and finance which supports a related idea, namely that investors might pay limited or not enough attention to information that is not salient (see, e.g., Klibanoff, Lamont, and Wizman (1998)).

To this end, we exploit exogenous variation in PDSI across countries. The key for us is that some countries in our sample have very high PDSI scores in the past, while others have very low PDSI scores. As such, we expect that investors in countries with previously temperate climates would underreact more to drought information in the 1975 onward sample than investors in countries with previous experience with drought. This would be a way of testing the regula- 
tory hypothesis that markets are underreacting to climate change risks that they do not have experience with.

We take our sample of international countries with PDSI monthly values going back to the 1900s. We can see from Panel A of Table 9 that there is significant dispersion in PDSI (mean PDSI36m values) measured up to 1975 across countries. In Panel B of Table 9, we then re-calculate our results from Table 6 but now split the countries into three groups: high, medium and low past PDSI terciles (based on the past mean PDSI36m values). Recall that our excess predictability regressions are ran from 1975 onwards. We drop the middle group from our analysis and focus on a comparison of the high and low tercile countries. In the first column, for the low PDSI tercile sub-sample, we see that the coefficient of PDSI36m is 2.83 and the $t$-statistic is 1.48. In the second column, for the high PDSI tercile sub-sample, we find that the coefficient is 5.90 and the $t$-statistic is 2.54. Therefore, our findings from Table 6 on underreaction in international markets are coming from the sub-sample of countries with previously temperate climates and little history with droughts.

In the final column, we conduct a formal statistical test of this difference by introducing an additional covariate PDSI36m*HighPDSI, which is an interaction term involving PDSI36m and a dummy variable HighPDSI that equals one if a country is in the highest tercile of PDSI. The coefficient on the interaction term is 3.82 and statistically significant. In short, we find that the degree of under-reaction for this subset of high PDSI countries is more than twice that of other countries.

To further examine whether markets underreact more to drought in countries with previous temperate climates, we create two dummies dry and wet when the PDSI value is below or above certain threshold. We first demean PDSI36m by subtracting its sample mean estimated using past 70 years of data. Dry is a dummy equals one when the demeaned PDSI36m is less than -1 , and wet is a dummy equals one when the demeaned PDSI36m is greater than +1 . In Panel $\mathrm{C}$ of Table 9, we show the return predictability results using the dry and wet dummy instead 
of PDSI36m for low and high past PDSI countries separately. As we can see, the coefficient on Dry and Wet are larger in magnitude and more significant for countries with high past PDSI score. So there is more underreaction in general (to both Dry and Wet conditions) in previously temperate countries. But the coefficient is particularly large for Dry conditions. The results strongly support the idea that the degree of under-reaction to drought is related to the countries' previous drought history.

In Figure 8, we show a scatterplot of the relationship between residualized future 12-month FOOD returns and PDSI for the two sub-samples: the blue dots represent the observations for the countries in the highest PDSI tercile and the red dots represent the observations for the countries in the lowest tercile. We also draw the fitted line for these two subsamples respectively, with the standard errors of the coefficient estimates clustered at the country level. We can see that there is a more pronounced upward slope for the blue dots of the highest PDSI tercile sub-sample. The coefficients are not identical to columns (1) and (2) of Panel B in Table 9 because we do not include country fixed effects for purposes of showing the fitted lines.

\section{Robustness: US Time Series}

In this section, we show that these conclusions from the international sample hold when we just consider the long US time series going back to 1927. For this long US sample, we focus on the 36-month moving average of the PDSIWA using the top 10 food producing US states (PDSIWA36m) as our baseline drought measure. ${ }^{26}$ This stands in contrast to coarser measures which we used in the international sample. But the results are very similar in the US regardless of the measure we use, which is reassuring.

\footnotetext{
${ }^{26}$ All of the predictive regressions for FOOD returns and cash flows using the US sample have been repeated with the alternative Modified Palmer Drought Severity Index (PMDI) as the drought measure instead of the PDSI, i.e. we use PMDIWA36m, the 36-month moving average of weighted PMDI values (PMDIWA), as the main explanatory variable in the predictive regressions. The corresponding results are shown in Appendix Table 9, which are similar to the results using PDSIWA36m.
} 


\subsection{Excess Return Predicatbility}

In Appendix Table 2, we use this variable to forecast FOODRET12m, the excess returns of the FOOD industry portfolio (net of the risk-free rate) FOODRET over the next 12 months. Our sample period is from 1927 to 2014. The empirical specification is

$$
\text { FOODRET } 12 \mathrm{~m}_{t}=\alpha+\beta \text { PDSIWA36 } \mathrm{m}_{t-1}+\gamma^{\prime} X_{t-1}+\varepsilon_{t},
$$

where FOODRET $12 \mathrm{~m}_{t}$ denotes the future non-overlapping FOOD return over the next 12 months, PDSIWA36 $\mathrm{m}_{t-1}$ is the moving average of PDSIWA over the previous 36 months, and $X_{t-1}$ includes market and food industry specific controls. ${ }^{27}$

In column (3), we add in our variable of interest PDSIWA36m and find that it has significant incremental forecasting power for the future returns of the food portfolio. The coefficient estimate of PDSIWA36m is 2 with a $t$-statistic of 2.5 , which is significant at the $5 \%$ statistical significance level. It increases the $R^{2}$ from $24 \%$ in column (2) to $26 \%$ in column (3).

The implied economic significance of our PDSI variable is large. It means that if the average weighted PDSI value of the top 10 food-producing states over the previous 36 months falls by 1 standard deviation (about 1.26 from Table 2), the average excess return of the food industry portfolio over the risk-free rate in the next 12 months (FOODRET12m) will decrease by about 2.5\%. From Table 2, the mean FOODRET $12 \mathrm{~m}$ is $7.16 \%$ with a standard deviation of $17.45 \%$. Thus the implied economic effect is about $35 \%$ of the mean of the food portfolio return and about $15 \%$ of the standard deviation of FOODRET12m, which are both economically significant results.

\footnotetext{
${ }^{27}$ We use the traditional market predictor variables, including the lagged 12-month aggregate market return MRET (see, e.g., Poterba and Summers (1988)), the inflation rate INF (see, e.g., Fama and Schwert (1977)), the log value of the dividend-price ratio of the aggregate market DP (see, e.g.,Campbell and Shiller (1988)), the volatility of the aggregate market MVOL (see, e.g., French, Schwert, and Stambaugh (1987)), the net equity expansion of the aggregate market NTIS (see, e.g., Baker and Wurgler (2000)), a corporate bond spread (DSPR), and a treasury yield spread TSPR (Fama and French (1989)).All of these market predictor variables have a suffix of 12 to denote they are annualized values over the past 12 months.
} 
To visualize the regression results in Appendix Table 2, we produce a scatterplot in Appendix Figure 1 of the FOOD returns residualized from the predictive model given in column (2) against our PDSIWA36m measure. That is, we are plotting the FOOD returns in excess of the expected returns as captured by the traditional market predictor and industry predictor variables with our drought measure. We then run a simple univariate regression on these residuals. The coefficient is 1.61 with a $t$-statistic of 2 .

One important concern is that the $t$-statistics of our predictability regressions are inflated due to persistent predictor variables since our PDSIWA36m is highly persistent (close to a random walk). To deal with this concern, we implement the Campbell and Yogo (2006) test. For this test in our baseline case, we do the following. First, we carry out the following two regressions:

$$
\begin{gathered}
\text { FOODRET12m } m_{t}=\alpha+\beta \text { PDSIWA36m } m_{t-1}+e_{t}, \\
\operatorname{PDSIWA36m}_{t}=\gamma+\rho \text { PDSIWA36m } \mathrm{m}_{t-1}+u_{t},
\end{gathered}
$$

where FOODRET12m $\mathrm{m}_{t}$ denotes the future non-overlapping FOOD return over the next 12 months, PDSIWA36m $\mathrm{m}_{t-1}$ is the moving average of PDSIWA over the previous 36 months, and PDSIWA36m $\mathrm{m}_{t}$ is the one-step ahead value of PDSIWA36m $\mathrm{m}_{t-1}$ (i.e. the contemporaneous value of PDSIWA36m corresponding to FOODRET12 $\mathrm{m}_{t}$ ). We obtain the residuals from regressions (7.2) and (7.3), and denote them as $e_{t}$ and $u_{t}$ respectively. Then we calculate the correlation between the residuals $e_{t}$ and $u_{t}$. The correlation turns out to be merely -0.001 . As shown in Campbell and Yogo (2006), the bias in $t$-statistics would be a concern if the residuals $e_{t}$ and $u_{t}$ are highly negatively correlated. This is not the case in our sample. Furthermore, as demonstrated in their Table 4 and 5 in Campbell and Yogo (2006), when the correlation is very close to zero as opposed to being close to -1 , the confidence intervals for the standard $t$-test are almost unaffected. Therefore, based on the (extremely) low correlation we find in our sample, 
we are on safe ground in proceeding with the standard $t$-test in our analysis and not adjusting the $t$-statistics values.

\subsection{Short and Intermediate Horizon Predictability}

Our focus on 12-month horizon returns for FOOD brings up the usual worries of long-horizon excess return predictability (Valkanov (2003)). These worries are alleviated somewhat in our setting since our $t$-statistic is around 2.5 and the scatterplot analysis points to a pronounced decline in expected returns with drought. Nonetheless, to fully address such concerns, we repeat our analysis (column (3) of Appendix Table 2) in Appendix Table 3 but now using short (1 month) to intermediate horizon returns (3 and 6 months). Our results are qualitatively similar to the 12 month results.

\subsection{Different Horizon Drought Measures}

In Appendix Table 4, we explore the extent to which different horizons of our baseline PDSIWA (from 12-month moving average to 30-month moving average) forecast food portfolio returns over the next 12 months. We always use the specification with the full list of control variables from column (3) of Appendix Table 2.

In columns (1) and (2), we use a moving average of 12 months and 18 months. We can think of this short-horizon moving average as capturing shorter episodes of drought. The coefficients are positive as before but are not statistically significant. Take the 0.673 coefficient in column (1). A standard deviation of PDSIWA12m is 1.6, which is as expected larger than the standard deviation of 1.26 for our baseline PDSIWA36m measure. Thus a one standard deviation increase in this short-horizon drought measure translates to around a $1 \%$ increase in FOOD returns. This economic magnitude is about $40 \%$ of that of our 36 -month moving average measure. The economic effect is smaller, as we hypothesized, since short duration droughts should have less of an effect on the FOOD industry, all else equal. Indeed, if we took the view that information 
about a prolonged 36-month drought is much more salient than a 12-month drought and ought to be more readily priced in by the market, then the difference in the predictability generated by the long versus the short-horizon drought measures are even more pronounced.

It is in column (3), at the 24-month moving average horizon, that we see a statistically significant result. The coefficient of interest is 1.264 with a $t$-statistic of 2.25 . Similarly, in column (4), the coefficient is even larger and significant at the $1 \%$ level of significance. The implied economic magnitudes are nonetheless smaller than our 36-month moving average baseline measure. Overall, the predictability of FOOD returns by drought information increases the more prolonged the drought is.

\subsection{PDSI at Different Levels of Granularity}

In Appendix Table 5, we use 36-month moving averages of alternative PDSI measures as the predictor in our baseline regression specification to forecast 12-month FOOD returns. In column (1), the alternative measure is the PDSI using the 48 contiguous US states weighted by cropland area. The coefficient of interest is 2.5 with a $t$-statistic of 2.4 . In column (2), the measure is the PDSI aggregated across the US but weighted by the food cash receipts produced by that state. The coefficient of interest is 2.5 with a $t$-statistic of 1.9 . In column (3), we use the PDSI measure produced by NOAA. The coefficient is 1.26 with a $t$-statistic of 1.77 .

All of the alternative drought measures carry comparable statistically significant forecasting power on food portfolio returns. The implied economic effects are also comparable to our top 10 agricultural producing states measure. It is comforting that we can find predictability results even using a coarse PDSIUSA measure since for our international analysis below we only have access to such a coarse measure. 


\subsection{Food Returns Net of the Market}

We now use our second approach to calculate FOOD returns in excess of the market. In Appendix Table 6, we do just this. From column (3), our estimate in front of our coefficient of interest is 1.23 with a $t$-statistic of 3.01. A one standard deviation increase in PDSIWA36m leads to a $1.55 \%$ higher return over the next 12 months for FOODXMRET. The mean of FOODXMRET $12 \mathrm{~m}$ is $1 \%$ with a standard deviation of $11.75 \%$. The economic significance is comparable to our first method. The corresponding plot of this regression is in Figure 3.

\subsection{US Cashflows}

In Appendix Table 7, we perform the following regression of forecasting the future 1-year change in $\mathrm{CP}$ :

$$
C P_{t+1}=\alpha+\beta \text { PDSIWA36m } t+\gamma^{\prime} X_{t}+\varepsilon_{t+1},
$$

where $X$ denotes the control variables apart from PDSIWA36m. This specification is similar to the one used in Fama and French (2000). The one modification of our control variables is that we include in columns (2) and (3) of Appendix Table 7 the previous 1-year change in the food industry profitability (i.e. $C P_{t}$ ). Otherwise, the control variables are the same as before, which include all of the controls as specified in column (3) of Appendix Table 2.

The coefficient of interest is in column (3) where we find that PDSIWA36m attracts a coefficient of 0.10 with a $t$-statistic of 2.41. Drought is associated with a decline in the food industry profitability over the next year. The standard deviation of CP is $0.77 \%$. Hence, a one standard deviation move in our drought measure results in a $0.12 \%$ fall in $\mathrm{CP}$ (the standard deviation of PDSIWA36m in our regression (7.4) is 1.2). This is nearly $16 \%$ of the standard deviation of $\mathrm{CP}$, which is a substantial decrease.

In Appendix Figure 2, we show the scatterplot of the residual of $\mathrm{CP}$ generated from the predictive regression in column (2) and our drought measure. The univariate regression through 
the scatterplot has a coefficient of 0.08 with a $t$-statistic of 2.47 . In short, we confirm that our interpretation of the excess FOOD return predictability regressions is due to the market underreacting to the implications of drought for FOOD industry cash flow-related news.

\section{7 $\quad$ Other Industries}

We have focused on the returns of the food industry since it is the most directly linked to crops, agricultural production and drought. Our prior is that drought should not significantly predict returns of other industries. To see if this is the case, we run the same predictive regression for each industry in the Fama-French 17-industry categories. Appendix Table 8 reports the coefficient estimates and $t$-statistics of PDSIWA36m for the Fama-French 17 industries and the ranking is based on the magnitude of the $t$-statistics. As we can see, the Food industry is ranked 1st among all 17 industries for return horizons over future 1 to 12 months. For convenience, we report the coefficients and $t$-statistics for FOOD, which are the same as those presented earlier. Notice for the 1-month horizon returns, no other industry is significant besides FOOD. The same is true for the 3-month horizon returns and the 6-month horizon returns. At 12 months, Steel is significant besides FOOD but attracts a negative sign. In short, drought only significantly predicts FOOD, consistent with our priors.

Having said this, we are working with very aggregate portfolios. It is possible that perhaps when we consider disaggregated industry portfolios, such as the Fama-French 48 industries categorization, we might see different results. Drought might predict some sub-industries with a positive sign (i.e. they are hurt by drought) and others with a negative sign (i.e. they benefit from drought). 


\section{Conclusion}

We show that stock markets are inefficient with respect to information about prolonged drought, one of the most important climate risks that are brought on or exacerbated by climate change. Using a global dataset of the widely-used Palmer Drought Severity Index (PDSI) from climate studies, we show that prolonged drought spells in a country, as measured by a 3-year moving average of PDSI, forecast poor returns for a portfolio comprised of food stocks in that country. This predictability is stronger in countries with previously temperate climates and little history of droughts.

Our findings have a number of implications for policymakers and practitioners. First, our findings confirm regulatory worries about markets underreacting to climate risks and suggest further exploration of the value of corporate disclosure of exposure risk. Second, our findings show that PDSI might be a very useful metric of drought to form portfolios and manage risks. We leave these topics for future research. 


\section{References}

Alley, W. M., 1984, "The Palmer drought severity index: limitations and assumptions," Journal of Climate and Applied Meteorology, 23(7), 1100-1109.

Baker, M., and J. Wurgler, 2000, "The equity share in new issues and aggregate stock returns," The Journal of Finance, 55(5), 2219-2257.

Bansal, R., D. Kiku, and M. Ochoa, 2014, "Climate change and growth risks," working paper, Duke University.

Blackhurst, B. M., C. Hendrickson, and J. S. i. Vidal, 2010, "Direct and indirect water withdrawals for US industrial sectors," Environmental Science \& Technology, 44(6), 2126-2130.

Campbell, J. Y., and R. J. Shiller, 1988, "The dividend-price ratio and expectations of future dividends and discount factors," Review of Financial Studies, 1(3), 195-228.

Campbell, J. Y., and M. Yogo, 2006, "Efficient tests of stock return predictability," Journal of Financial Economics, 81(1), 27-60.

Campbell, S. D., and F. X. Diebold, 2005, "Weather Forecasting for Weather Derivatives," Journal of the American Statistical Association, pp. 6-16.

Carhart, M. M., 1997, "On persistence in mutual fund performance," The Journal of Finance, $52(1), 57-82$.

Carney, M., 2015, "Breaking the Tragedy of the Horizon-Climate Change and Financial Stability," Speech given at Lloyd's of London (29 September).

Cohen, L., and A. Frazzini, 2008, "Economic links and predictable returns," The Journal of Finance, 63(4), 1977-2011. 
Dai, A., K. E. Trenberth, and T. Qian, 2004, "A global dataset of Palmer Drought Severity Index for 1870-2002: Relationship with soil moisture and effects of surface warming," Journal of Hydrometeorology, 5(6), 1117-1130.

Daniel, K., R. B. Litterman, and G. Wagner, 2015, "Applying asset pricing theory to calibrate the price of climate risk," working paper, Mimeo.

DellaVigna, S., and J. M. Pollet, 2007, "Demographics and industry returns," The American Economic Review, pp. 1667-1702.

Dickey, D. A., and W. A. Fuller, 1979, "Distribution of the Estimators for Autoregressive Time Series With a Unit Root," Journal of the American Statistical Association, 74(366), 427-431.

Fama, E. F., and K. R. French, 1989, "Business conditions and expected returns on stocks and bonds," Journal of Financial Economics, 25(1), 23-49.

— 1993 , "Common risk factors in the returns on stocks and bonds," Journal of Financial Economics, 33(1), 3-56.

— , 1997, "Industry costs of equity," Journal of Financial Economics, 43(2), 153-193.

— , 2000, "Forecasting Profitability and Earnings," The Journal of Business, 73(2), 161175.

Fama, E. F., and K. R. French, 2015, "A five-factor asset pricing model," Journal of Financial Economics, 116(1), 1-22.

Fama, E. F., and G. W. Schwert, 1977, "Asset returns and inflation," Journal of Financial Economics, 5(2), 115-146.

French, K. R., G. W. Schwert, and R. F. Stambaugh, 1987, "Expected stock returns and volatility," Journal of Financial Economics, 19(1), 3-29. 
Giglio, S., M. Maggiori, J. Stroebel, and A. Weber, 2015, "Climate change and long-run discount rates: Evidence from real estate," working paper, National Bureau of Economic Research.

Golosov, M., J. Hassler, P. Krusell, and A. Tsyvinski, 2014, "Optimal taxes on fossil fuel in general equilibrium," Econometrica, 82(1), 41-88.

Griffin, J. M., P. J. Kelly, and F. Nardari, 2010, "Do Market Efficiency Measures Yield Correct Inferences? A Comparison of Developed and Emerging Markets," Review of Financial Studies, pp. $3225-3277$.

Hirshleifer, D., and S. H. Teoh, 2003, "Limited attention, information disclosure, and financial reporting," Journal of Accounting and Economics, 36(1), 337-386.

Hong, H., W. Torous, and R. Valkanov, 2007, "Do industries lead stock markets?," Journal of Financial Economics, 83(2), 367-396.

Hou, K., G. A. Karolyi, and B.-C. Kho, 2011, "What factors drive global stock returns?," Review of Financial Studies, 24(8), 2527-2574.

Ince, O. S., and R. B. Porter, 2006, "Individual equity return data from Thomson Datastream: Handle with care!," Journal of Financial Research, 29(4), 463-479.

Jegadeesh, N., and S. Titman, 1993, "Returns to buying winners and selling losers: Implications for stock market efficiency," The Journal of Finance, 48(1), 65-91.

Klibanoff, P., O. Lamont, and T. A. Wizman, 1998, "Investor reaction to salient news in closedend country funds," The Journal of Finance, 53(2), 673-699.

Lesk, C., P. Rowhani, and N. Ramankutty, 2016, "Influence of extreme weather disasters on global crop production," Nature, 529(7584), 84-87.

McLean, R. D., J. Pontiff, and A. Watanabe, 2009, "Share issuance and cross-sectional returns: International evidence," Journal of Financial Economics, 94(1), 1-17. 
Mendelsohn, R., W. D. Nordhaus, and D. Shaw, 1994, "The impact of global warming on agriculture: a Ricardian analysis," The American Economic Review, pp. 753-771.

Montgomery, W. D., 1972, "Markets in licenses and efficient pollution control programs," Journal of Economic Theory, 5(3), 395-418.

Moskowitz, T. J., and M. Grinblatt, 1999, "Do industries explain momentum?," The Journal of Finance, 54(4), 1249-1290.

Nordhaus, W. D., 1994, Managing the global commons: the economics of climate change, vol. 31. MIT press Cambridge, MA.

Palmer, W. C., 1965, Meteorological drought, vol. 30. US Department of Commerce, Weather Bureau Washington, DC, USA.

Pastor, L., R. F. Stambaugh, and L. A. Taylor, 2014, "Do Funds Make More When They Trade More?," working paper, National Bureau of Economic Research.

Petersen, M. A., 2009, "Estimating standard errors in finance panel data sets: Comparing approaches," Review of Financial Studies, 22(1), 435-480.

Poterba, J. M., and L. H. Summers, 1988, "Mean reversion in stock prices: Evidence and implications," Journal of Financial Economics, 22(1), 27-59.

Roll, R., 1984, "Orange juice and weather," The American Economic Review, 74(5), 861-880.

Sharpe, W. F., 1964, "Capital asset prices: A theory of market equilibrium under conditions of risk," The Journal of Finance, 19(3), 425-442.

Shiller, R. J., 1994, Macro markets: Creating institutions for managing society's largest economic risks. Oxford University Press. 
Stern, N., 2007, The economics of climate change: the Stern review. Cambridge University Press.

Trenberth, K. E., A. Dai, G. van der Schrier, P. D. Jones, J. Barichivich, K. R. Briffa, and J. Sheffield, 2014, "Global warming and changes in drought," Nature Climate Change, 4(1), $17-22$.

Valkanov, R., 2003, "Long-horizon regressions: theoretical results and applications," Journal of Financial Economics, 68(2), 201-232.

Williams, A. P., R. Seager, J. T. Abatzoglou, B. I. Cook, J. E. Smerdon, and E. R. Cook, 2015, "Contribution of anthropogenic warming to California drought during 2012-2014," Geophysical Research Letters, 42(16), 6819-6828.

Zivot, E., and D. W. Andrews, 1992, "Further Evidence on the Great Crash, the Oil-Price Shock, and the Unit-Root Hypothesis," Journal of Business and Economic Statistics, 10(3), $251-270$. 


\section{Table 1: Summary Statistics of the International Sample}

This table reports summary statistics of the sample of 30 international countries, including 15 developed countries and 15 developing countries. We report the average number of stocks in the food industry, the median firm market captitalization in US dollars, the mean and standard deviation of the PDSI value and the starting date for each country. Countries with missing variables and less than 10 stocks in the food industry in the whole sample are excluded. The overall sample runs from 1975 to 2015. Stock return data and accounting information for international countries are taken from Datastream and Worldscope, respectively.

\begin{tabular}{|c|c|c|c|c|c|}
\hline \multicolumn{6}{|c|}{ Panel A } \\
\hline $\begin{array}{c}\text { Country } \\
\text { Developed Countries }\end{array}$ & $\begin{array}{c}\text { Average \# } \\
\text { of Stocks }\end{array}$ & $\begin{array}{l}\text { Median Firm Size } \\
\text { (Million USD) }\end{array}$ & $\begin{array}{l}\text { Palmer Drought } \\
\text { Mean }\end{array}$ & $\begin{array}{l}\text { Severity Index } \\
\text { Std. }\end{array}$ & $\begin{array}{c}\text { Start } \\
\text { date }\end{array}$ \\
\hline Australia & 25 & 37.65 & -0.98 & 2.16 & 197501 \\
\hline Belgium & 12 & 49.06 & 0.16 & 2.27 & 198601 \\
\hline Canada & 16 & 266.58 & -0.40 & 1.75 & 197501 \\
\hline Switzerland & 12 & 163.44 & -0.64 & 2.25 & 197501 \\
\hline Germany & 15 & 125.31 & -0.66 & 1.84 & 198410 \\
\hline Denmark & 9 & 94.01 & 0.58 & 2.41 & 198804 \\
\hline Finland & 7 & 154.74 & 0.87 & 2.07 & 199008 \\
\hline France & 26 & 71.13 & -0.58 & 2.15 & 197501 \\
\hline United Kingdom & 56 & 23.70 & -0.05 & 2.27 & 197501 \\
\hline Greece & 24 & 33.32 & -0.53 & 2.45 & 198801 \\
\hline Israel & 23 & 22.93 & 0.00 & 1.78 & 198601 \\
\hline Japan & 90 & 158.62 & -0.35 & 2.40 & 197501 \\
\hline Netherlands & 12 & 261.64 & 0.26 & 2.40 & 197501 \\
\hline New Zealand & 10 & 29.25 & -0.94 & 2.03 & 198801 \\
\hline Portugal & 9 & 10.32 & -0.60 & 2.45 & 198801 \\
\hline \multicolumn{6}{|l|}{ Developing Countries } \\
\hline Brazil & 14 & 160.94 & -1.05 & 1.78 & 199001 \\
\hline Chile & 20 & 75.68 & -0.46 & 2.06 & 198907 \\
\hline China & 54 & 306.79 & -3.08 & 2.18 & 199311 \\
\hline Indonesia & 22 & 56.50 & -0.41 & 1.35 & 199006 \\
\hline India & 108 & 2.86 & 0.94 & 2.88 & 199001 \\
\hline South Korea & 39 & 58.96 & -0.24 & 2.24 & 198407 \\
\hline Mexico & 9 & 128.17 & 0.21 & 1.85 & 199107 \\
\hline Malaysia & 50 & 49.64 & 1.17 & 2.55 & 198601 \\
\hline Peru & 19 & 19.67 & -1.34 & 2.18 & 199112 \\
\hline Philippines & 11 & 39.99 & 0.29 & 2.84 & 199308 \\
\hline Poland & 22 & 35.22 & -0.58 & 1.68 & 199410 \\
\hline Russian Federation & 10 & 101.14 & 1.27 & 1.84 & 200601 \\
\hline Thailand & 32 & 31.10 & -1.23 & 2.10 & 198701 \\
\hline Turkey & 17 & 24.74 & 2.21 & 3.04 & 199011 \\
\hline South Africa & 15 & 162.98 & -0.34 & 3.05 & 198703 \\
\hline
\end{tabular}




\section{Summary Statistics of the International Sample, Continued}

This table continues with the summary statistics for the variables in our international sample with all countries pooled together. Panel B shows the summary statistics of our main drought measure and other control variables. PDSI12m to PDSI36m are the 12-month to 36-month moving average of the PDSI for international countries. MRET12, INF12, FOODPB12, DP12 and MVOL12 denote respectively the market excess return, the inflation rate, the price-to-book ratio of the food portfolio, the dividend-to-price ratio and the market volatility over 12 months. Panel $\mathrm{C}$ shows the summary statistics of non-overlapping returns of the food portfolio over different horizons. CP is the annual change in the food industry profitability ratio. FOODRET to FOODRET12m denote, respectively, the non-overlapping return over 1 month, 3 months, 6 months and 12 months. FOODXMRET12m is the food portfolio return net of the return of the market excluding food portfolio over 12 months.

Panel B: Drought measure and other controls

\begin{tabular}{cccccc}
\hline & Mean & S.D. & Median & Min & Max \\
\hline PDSI12m & -0.20 & 1.71 & -0.26 & -3.75 & 3.83 \\
PDSI18m & -0.20 & 1.53 & -0.26 & -3.27 & 3.41 \\
PDSI24m & -0.20 & 1.37 & -0.27 & -2.95 & 3.01 \\
PDSI30m & -0.21 & 1.24 & -0.27 & -2.72 & 2.62 \\
PDSI36m & -0.22 & 1.13 & -0.26 & -2.52 & 2.27 \\
MRET12 (\%) & 7.98 & 30.03 & 9.14 & -70.31 & 83.83 \\
INF12 (\%) & 7.32 & 6.57 & 5.13 & 1.08 & 26.19 \\
FOODPB12 & 2.56 & 1.29 & 2.28 & 0.84 & 5.82 \\
DP12 (\%) & 2.98 & 2.21 & 2.35 & 0.73 & 9.84 \\
MVOL12 (\%) & 23.12 & 13.74 & 19.74 & 6.47 & 82.27 \\
\hline
\end{tabular}

Panel C: Food Portfolio Non-overlapping Returns

\begin{tabular}{cccccc}
\hline & Mean & S.D. & Median & Min & Max \\
\hline CP (\%) & 0.00 & 3.34 & -0.01 & -14.71 & 15.49 \\
FOODRET (\%) & 1.04 & 8.74 & 0.88 & -105.17 & 143.33 \\
FOODRET3m (\%) & 3.22 & 16.93 & 2.80 & -87.83 & 237.11 \\
FOODRET6m (\%) & 6.42 & 26.16 & 5.86 & -108.33 & 420.44 \\
FOODRET12m (\%) & 12.86 & 41.30 & 11.91 & -132.06 & 528.09 \\
FOODXMRET12m (\%) & 2.93 & 24.04 & 2.02 & -65.53 & 99.91 \\
\hline
\end{tabular}




\section{Table 2: Summary Statistics of the US Sample}

This table reports the summary statistics for the variables in our sample. The sample is from January 1927 to December 2014 and comprises monthly observations of all variables except FOODBM which is observed annually. Panel A shows PDSIUSA, the Palmer Drought Severity Index (PDSI) of USA produced directly by the US National Oceanic and Atmospheric Administration. PDSIUSA36m is the the 36-month moving average of the PDSIUSA. The alternative drought measure PDSIWA is the weighted average PDSI values for the top 10 food-producing states (in terms of cash value) in the US. PDSIWA12m to PDSIWA36m denote, respectively, the moving average of the PDSIWA values over 12 months, 18 months, 24 months, 30 months and 36 months. It also shows the 36-month moving average of 2 other alternative drought measures: PDSIASWA is the weighted average (based on cropland areas) of the PDSI values of all 48 contiguous US states (excluding Alaska, Hawaii, and Washington D.C. because of no data), and PDSIASCA is the weighted average PDSI of all 48 states with the gross cash income of the farm sector in each state as weight. Panel B shows the Fama-French 17-industry food industry portfolio non-overlapping excess returns over various horizons. FOODRET is the monthly excess return (net of the 1-month T-bill rate), FOODRET3m to FOODRET12m denote the excess returns over 3 months, 6 months and 12 months respectively, and FOODXMRET12m is the food portfolio return net of the return of the market excluding food (MXF) portfolio over 12 months. CP is the annual change in the food industry profitability ratio. Panel $\mathrm{C}$ shows the non-overlapping values for other control variables over 12 months. FOODBM is the log value of the value-weighted average of the book-to-market ratios of the firms in the food industry portfolio. MRET is the CRSP value-weighted market portfolio excess return. INF is the CPI inflation rate. DP is the log value of the dividend-price ratio of the S\&P 500 index. MVOL is the market volatility (volatility of the S\&P 500 index). NTIS is the net equity expansion of the NYSE stocks. DSPR is the default yield spread, the difference between BAA and AAA-rated corporate bond yields. TSPR is the term spread, the difference between the long term yield on government bonds and the Treasury-bill. Panel D gives the correlations among the variables of interest in Panel (A) to (C).

\begin{tabular}{lccccc}
\hline \multicolumn{7}{c}{ Panel A: Palmer Drought Severity Index (PDSI) } & Values & \\
\hline & Mean & S.D. & Median & Min & Max \\
\hline PDSIUSA36m & 0.17 & 1.96 & 0.33 & -4.44 & 4.11 \\
PDSIWA12m & 0.17 & 1.60 & 0.54 & -4.25 & 4.10 \\
PDSIWA18m & 0.16 & 1.55 & 0.51 & -3.79 & 3.64 \\
PDSIWA24m & 0.17 & 1.41 & 0.42 & -3.40 & 2.99 \\
PDSIWA30m & 0.16 & 1.36 & 0.29 & -3.24 & 2.83 \\
PDSIWA36m & 0.17 & 1.26 & 0.29 & -3.12 & 2.53 \\
PDSIASWA36m & 0.15 & 1.06 & 0.22 & -2.35 & 2.07 \\
PDSIASCAWA36m & 0.07 & 0.89 & 0.19 & -1.95 & 1.77 \\
\hline \hline
\end{tabular}

Panel B: Fama-French 17-Industry Food Portfolio Non-overlapping Returns and Cashflow Measure

\begin{tabular}{lccccc}
\hline & Mean & S.D. & Median & Min & Max \\
\hline FOODRET (\%) & 0.60 & 4.80 & 0.87 & -33.35 & 28.61 \\
FOODRET3m (\%) & 1.79 & 9.37 & 2.51 & -42.59 & 52.88 \\
FOODRET6m (\%) & 3.58 & 12.78 & 4.51 & -42.48 & 54.73 \\
FOODRET12m (\%) & 7.16 & 17.45 & 8.68 & -43.63 & 39.81 \\
FOODXMRET12m (\%) & 1.01 & 11.75 & 1.37 & -37.19 & 30.87 \\
CP (\%) & -0.03 & 0.77 & 0.07 & -2.26 & 2.24 \\
\hline \hline
\end{tabular}

Panel C: Other Control Variables, Non-overlapping

\begin{tabular}{lccccc}
\hline & Mean & S.D. & Median & Min & Max \\
\hline FOODBM12 & -0.67 & 0.46 & -0.64 & -1.77 & 0.26 \\
MRET12 (\%) & 6.02 & 20.07 & 9.87 & -59.11 & 45.04 \\
INF12 (\%) & 2.94 & 3.96 & 2.77 & -10.93 & 16.44 \\
DP12 & -3.36 & 0.47 & -3.34 & -4.48 & -2.29 \\
MVOL12 (\%) & 13.91 & 8.78 & 10.94 & 5.54 & 50.43 \\
NTIS12 (\%) & 1.85 & 2.63 & 1.76 & -4.19 & 16.35 \\
DSPR12 (\%) & 1.20 & 0.79 & 0.96 & 0.34 & 5.10 \\
TSPR12 (\%) & 1.61 & 1.42 & 1.64 & -3.50 & 4.53 \\
\hline
\end{tabular}




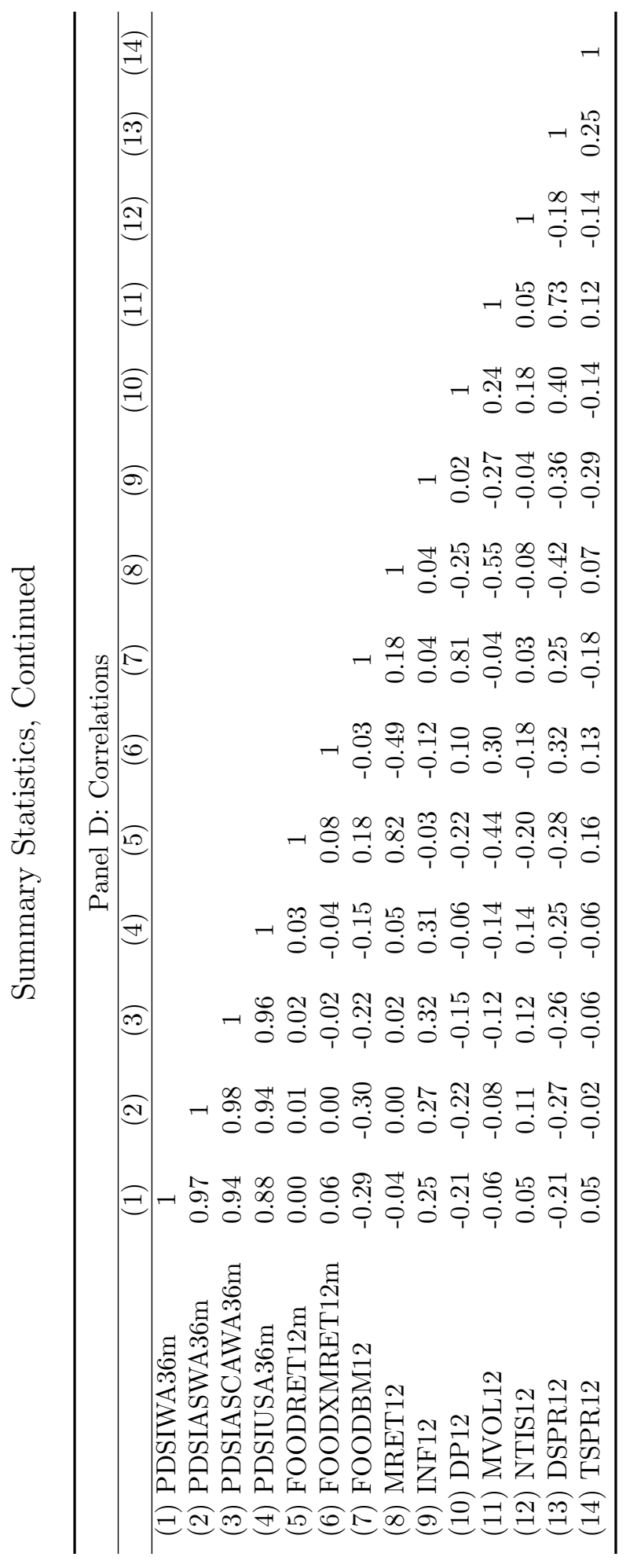




\section{Table 3: Trend in Global PDSI Variables}

This table shows the results for estimating a time trend in several global PDSI variables. The dependent variables, PDSI25\%ile, PDSI50\%ile, and PDSI75\%ile denote the monthly 25th percentile (lower quartile) PDSI value of all international countries (including the US), the 50th percentile (median) value, and the 75 th percentile (upper quartile) value respectively. Panel A estimates the trend model PDSIvar ${ }_{t}=\alpha_{0}+\beta_{0} t+\varepsilon_{t}$ where PDSIvar is PDSI25\%ile, PDSI50\%ile, or PDSI75\%ile. Panel B estimates the model PDSIvar ${ }_{t}=\alpha_{0}+\beta_{0} t+\beta_{1}(t-\tau) D(t \geq$ $\tau)+\varepsilon_{t}$ where we allow for a structural break in trend at time $\tau$. The explanatory variable $t$ denotes the time trend. $D(t \geq \tau)$ is a dummy variable that equals to 1 if time $t$ is greater than or equal to the break point $\tau$. The break point $\tau$ is January 1980 (198001). $\alpha_{0}$ is the constant term. The parameter in brackets after the corresponding explanatory variable denotes the coefficient in front of that variable. $t$-statistics based on NeweyWest HAC standard errors are shown in parentheses, with a lag order of 12 months for all of the regressions. *, **, ${ }^{* * *}$ denote statistical significance at $10 \%, 5 \%, 1 \%$ respectively. The $R^{2}$ for each regression is also reported. $N$ is the number of observation points in each regression. The sample is from 190001 (January 1900) to 201412 (December 2014).

\begin{tabular}{|c|c|c|c|}
\hline \multicolumn{4}{|c|}{ Panel A: Estimating a Time Trend in Global PDSI Variables } \\
\hline & $(1)$ & $(2)$ & $(3)$ \\
\hline & \multicolumn{3}{|c|}{ Dependent Variable } \\
\hline & PDSI25\%ile & PDSI50\%ile & PDSI75\%ile \\
\hline$t \quad\left(\beta_{0}\right)$ & $-0.0004^{* * *}$ & $-0.0003^{* * *}$ & -0.0001 \\
\hline$\alpha_{0}$ & $\begin{array}{c}(-.0 .010) \\
-1.3086^{* * *} \\
(-14.773)\end{array}$ & $\begin{array}{c}(-.0816) \\
0.08168)\end{array}$ & $\begin{array}{c}1.5709^{* * *} \\
(18.281)\end{array}$ \\
\hline$R^{2}$ & 0.07 & 0.03 & 0.01 \\
\hline$N$ & 1380 & 1380 & 1380 \\
\hline
\end{tabular}

Panel B: Allowing for a Structural Break in Trend at Jan 1980

\begin{tabular}{|c|c|c|c|}
\hline & (1) & $(2)$ & (3) \\
\hline & \multicolumn{3}{|c|}{ Dependent Variable } \\
\hline & PDSI25\%ile & PDSI50\%ile & PDSI75\%ile \\
\hline$t \quad\left(\beta_{0}\right)$ & -0.0000 & -0.0002 & -0.0000 \\
\hline & $(-0.089)$ & $(-1.040)$ & $(-0.248)$ \\
\hline$(t-\tau) \times D(t \geq \tau)$ & $\begin{array}{c}-0.0004^{* * *} \\
(-2.806)\end{array}$ & $\begin{array}{l}-0.0001 \\
(-0.787)\end{array}$ & $\begin{array}{l}-0.0001 \\
(-0.437)\end{array}$ \\
\hline$\alpha_{0}$ & $\begin{array}{c}-1.4544^{* * * *} \\
(-14.202)\end{array}$ & $\begin{array}{l}0.0348 \\
(0.289)\end{array}$ & $\begin{array}{c}1.5459^{* * *} \\
(16.499)\end{array}$ \\
\hline$R^{2}$ & 0.10 & 0.04 & 0.01 \\
\hline$N$ & 1380 & 1380 & 1380 \\
\hline
\end{tabular}


Table 4: International Evidence: Predicting 1-year Food Industry Change in Profitability (CP) with 36-month Moving Average of PDSI

This table presents the results from forecasting the future 1-year CP, the change in profitability of the food industry over the next year, using the 36-month moving average of the PDSI values (PDSI36m). The dependent variable (forecast) is the $\mathrm{CP}$, the future change in the food industry profitability, over the next year. The key explanatory (forecasting) variable, PDSI36m, is the moving average of the PDSI values over the previous 3 years (36 months). Other control variables, CP1y, FOODRET12m, FOODPB12, MRET12, INF12, DP12 and MVOL12 denote, respectively, the change in the food industry profitability, the food industry portfolio return (FOODRET), the log of the food industry price-to-book ratio (FOODPB), the market excess return (MRET), the inflation rate (INF), the log of the market dividend price ratio (DP) and the market volatility (MVOL). We control for country fixed effects in the regression and standard errors are double clustered along the country and month dimensions. ${ }^{*}, * *, * * *$ denote statistical significance at $10 \%, 5 \%, 1 \%$ respectively. The sample period is 1975 to 2015.

\begin{tabular}{cccc}
\hline & \multicolumn{3}{c}{$\begin{array}{c}\text { Dependent Variable: Future 1-year } \\
\text { Change in Food Industry Profitability }\end{array}$} \\
\hline PDSI36m & $(1)$ & $(2)$ & $(3)$ \\
& & & $0.141^{*}$ \\
CP1y & & $-1.812)$ \\
& & $-13.458^{* * *}$ & $-0.453^{* * *}$ \\
FOODRET12m & 0.005 & $(-10.661)$ \\
& & $(0.646)$ & 0.002 \\
FOODPB12 & -0.099 & $(0.309)$ \\
& & $-0.475)$ & -0.091 \\
MRET12 & -0.001 & $(-0.517)$ \\
& -0.002 & $(-0.137)$ & 0.001 \\
DP12 & -0.018 & $(0.256)$ \\
& $-0.404)$ & $(-0.844)$ & -0.020 \\
INF12 & -0.001 & $(-0.878)$ \\
MVOL12 & $(-1.303)$ & $(-0.819)$ & -0.001 \\
& -0.000 & 0.039 & $(-0.572)$ \\
Ave. R-sq & $(-1.526)$ & $(1.618)$ & $0.042^{*}$ \\
N. of Obs. & $0.073^{* * *}$ & 0.209 & $(1.808)$ \\
& $(4.548)$ & 704 & 0.204 \\
& 0.019 & & 670 \\
\hline
\end{tabular}




\section{Table 5: Return to Portfolio Strategies Sorted on Standardized PDSI36m}

This table presents the returns and alphas (in percentage) to country food portfolios sorted on lagged PDSI36m. PDSI36m is first standardized by substracting its mean and dividing by its standard deviation. We estimate the rolling mean and standard deviation of PDSI36m with past 70 years of data. Each month all country foodindustry portfolios are sorted into quintiles based on their standardized PDSI36m (denoted as PDSI36m*) from the previous month end and held for various horizons from 1 month to 12 months. In panel A, we report the mean PDSI36m*, excess returns and Carhart (1997) four factor alphas for quintile portfolios with a holding period of 12 months. We group the middle three portfolios together by equal weighting their respective returns. Row "Middle - Low" shows the return difference between middle portfolio and lowest PDSI36m* portfolio. "High - Middle" and "High - Low" follows the similar definition. Row "DiD" shows the difference between "High Middle" and "Middle - Low". In panel B, we report the long/short return spread and factor-adjusted alphas from 1 month to 12 months. The alphas are adjusted using global Sharpe (1964) CAPM, Fama and French (1993) three factors and Carhart (1997) four factors model following the methodology of constructing local factors. The sample period is from January 1985 to December 2015.

Panel A: Quintile Portfolios sorted on standardized PDSI36m

\begin{tabular}{cccccc}
\hline Portfolio & PDSI36m* & Excess Return & t-stat & 4-factor alpha & t-stat \\
\hline Low PDSI & -1.60 & 0.38 & 1.31 & 0.27 & 1.04 \\
Middle PDSI & 0.25 & 0.71 & 3.03 & 0.59 & 3.14 \\
High PDSI & 1.37 & 1.15 & 3.87 & 1.10 & 4.28 \\
Middle - Low & 1.32 & 0.33 & 1.82 & 0.33 & 1.85 \\
High - Middle & 1.61 & 0.44 & 2.14 & 0.51 & 2.41 \\
DiD & 0.30 & 0.10 & 0.35 & 0.18 & 0.58 \\
High - Low & 2.97 & 0.77 & 2.74 & 0.83 & 2.87 \\
\hline
\end{tabular}




\section{Table 5 Continued}

Panel B: L/S Portfolios sorted on standardized PDSI36m for various holding horizons

\begin{tabular}{|c|c|c|c|c|}
\hline \multicolumn{5}{|c|}{ 12-month Holding Period } \\
\hline & Excess Return & CAPM alpha & Three-factor alpha & Four-factor alpha \\
\hline Mean & 0.77 & 0.76 & 0.80 & 0.83 \\
\hline t-stat & 2.74 & 2.69 & 2.78 & 2.87 \\
\hline Std.Dev & 5.34 & & & \\
\hline Sharpe Ratio & 0.50 & & & \\
\hline No.of obs. & 360 & & & \\
\hline \multicolumn{5}{|c|}{ 6-month Holding Period } \\
\hline & Excess Return & CAPM alpha & Three-factor alpha & Four-factor alpha \\
\hline Mean & 0.74 & 0.73 & 0.75 & 0.81 \\
\hline t-stat & 2.49 & 2.45 & 2.46 & 2.63 \\
\hline Std.Dev & 5.68 & & & \\
\hline Sharpe Ratio & 0.45 & & & \\
\hline No.of obs. & 360 & & & \\
\hline \multicolumn{5}{|c|}{ 3-month Holding Period } \\
\hline & Excess Return & CAPM alpha & Three-factor alpha & Four-factor alpha \\
\hline Mean & 0.72 & 0.71 & 0.72 & 0.80 \\
\hline t-stat & 2.38 & 2.34 & 2.35 & 2.58 \\
\hline Std.Dev & 5.74 & & & \\
\hline Sharpe Ratio & 0.43 & & & \\
\hline No.of obs. & 360 & & & \\
\hline \multicolumn{5}{|c|}{ 1-month Holding Period } \\
\hline & Excess Return & CAPM alpha & Three-factor alpha & Four-factor alpha \\
\hline Mean & 0.57 & 0.56 & 0.56 & 0.66 \\
\hline t-stat & 1.84 & 1.81 & 1.79 & 2.09 \\
\hline Std.Dev & 5.86 & & & \\
\hline Sharpe Ratio & 0.34 & & & \\
\hline No.of obs. & 360 & & & \\
\hline
\end{tabular}


Table 6: International Evidence: Predicting 12-month Non-overlapping Food Portfolio Return

This table presents the results from forecasting the food industry portfolio excess returns over future 12 months, using the moving averages of the PDSI values over the past 36 months (PDSI36m). The regressions are run by pooling all countries together and including a country fixed effect. The dependent variable is the food return over the future 12 months. The returns are non-overlapping. All of the regressions include these other forecasting variables over the past 12 months: lagged food industry return (FOODRET12m), lagged market return (MRET12), lagged inflation rate (INF12), log of food industry price-to-book ratio (FOODPB12), the log of the market dividend price ratio (DP12) and the market volatility (MVOL12). Standard errors are clustered at both the country and month dimensions. ${ }^{*},{ }^{* *},{ }^{* * *}$ denote statistical significance at $10 \%, 5 \%, 1 \%$ respectively. The sample period is from January 1975 to December 2015.

\begin{tabular}{cccc}
\hline \multicolumn{3}{c}{ Dependent Variable: Future 12-month FOODRET, Non-overlapping } \\
\hline & $(1)$ & $(2)$ & $(3)$ \\
PDSI36m & & & $3.4796^{* *}$ \\
& & -0.0777 & $(2.26)$ \\
FOODRET12m & $(-0.74)$ & -0.0714 \\
FOODPB12 & & $-12.2938^{* *}$ & $(-0.64)$ \\
& & $(-2.61)$ & $-12.5436^{* * *}$ \\
MRET12 & 0.2025 & 0.2351 & $(-2.92)$ \\
& $(0.85)$ & $(0.84)$ & 0.2388 \\
INF12 & 2.4152 & 2.1613 & $(0.74)$ \\
& $(1.37)$ & $(1.35)$ & 1.8519 \\
DP12 & $-0.2435^{* * *}$ & $-0.3446^{* * *}$ & $(1.24)$ \\
& $(-5.99)$ & $(-12.41)$ & $-0.3512^{* * *}$ \\
MVOL12 & $1.9336^{* *}$ & $1.9493^{* *}$ & $(-5.34)$ \\
& $(2.08)$ & $(2.11)$ & $1.9918^{*}$ \\
Ave.R-sq & 0.167 & 0.195 & $(1.99)$ \\
N.of Obs. & 624 & 612 & 0.213 \\
\hline
\end{tabular}


Table 7: International Evidence: Predicting Food Industry Portfolio Non-overlapping Returns over Different Horizons

This table presents the results from forecasting the food industry portfolio excess returns (FOODRETs) at various horizons, using the moving averages of the PDSI values over the past 36 months (PDSI36m). The regressions are run by pooling all countries together and including a country fixed effect. The dependent variable $1 \mathrm{~m}$ is the food return over the next month, and those dependent variables of $3 \mathrm{~m}$ to $6 \mathrm{~m}$ are the food returns over the next 3 months and 6 months, respectively. The returns are non-overlapping. All of the regressions include these other forecasting variables over the past 12 months: lagged food industry return (FOODRET12m), lagged market return (MRET12), lagged inflation rate (INF12), log of food industry price-to-book ratio (FOODPB12), the $\log$ of the market dividend price ratio (DP12), the market volatility (MVOL12). Standard errors are clustered at both the country and month dimensions. * , **,*** denote statistical significance at 10\%, $5 \%, 1 \%$ respectively. The sample period is from January 1975 to December 2015.

\begin{tabular}{cccc}
\hline \multicolumn{2}{c}{ Dependent Variable: Future FOODRET over $1 \mathrm{~m}, 3 \mathrm{~m}$ and $6 \mathrm{~m}$, Non-overlapping } \\
\hline & $1 \mathrm{~m}$ & $3 \mathrm{~m}$ & $6 \mathrm{~m}$ \\
\hline PDSI36m & $0.1752^{*}$ & $0.5970^{* *}$ & $1.3033^{* *}$ \\
& $(2.00)$ & $(2.38)$ & $(2.12)$ \\
FOODRET12m & -0.0016 & 0.0078 & 0.0424 \\
& $(-0.31)$ & $(0.42)$ & $(0.98)$ \\
FOODPB12 & $-0.9897^{* * *}$ & $-2.9013^{* * *}$ & $-4.9145^{* *}$ \\
& $(-3.25)$ & $(-3.24)$ & $(-2.70)$ \\
MRET12 & $0.0375^{*}$ & 0.0903 & 0.1260 \\
& $(1.87)$ & $(1.34)$ & $(0.84)$ \\
INF12 & 0.1239 & 0.5134 & 0.4594 \\
& $(1.14)$ & $(1.43)$ & $(0.69)$ \\
DP12 & $-0.0106^{*}$ & -0.0288 & $-0.1583^{* * *}$ \\
& $(-1.73)$ & $(-1.37)$ & $(-3.25)$ \\
MVOL12 & $0.1197^{*}$ & $0.5046^{*}$ & $1.0844^{* *}$ \\
Ave.R-sq & $(1.70)$ & $(1.83)$ & $(2.37)$ \\
N.of Obs. & 0.055 & 0.134 & 0.174 \\
& 6918 & 2310 & 1154 \\
\hline
\end{tabular}


Table 8: International Evidence: Predicting Non-overlapping Food Portfolio net of Market Return over Different Horizons

This table presents the results from forecasting the future non-overlapping FOODXMRET, the food portfolio return net of the return of the market excluding food (MXF) portfolio, using the 36-month moving average of the weighted PDSI values (PDSI36m). The dependent variable (forecast) is the non-overlapping FOODXMRET, the food portfolio return net of the return of the market excluding food (MXF) portfolio, over the next 1 months to 12 months. The returns are non-overlapping. All of the regressions include these other forecasting variables over the past 12 months: lagged food industry return net of market return (FOODXMRET12m), lagged market return (MRET12), lagged inflation rate (INF12), log of food industry price-to-book ratio (FOODPB12), the log of the market dividend price ratio (DP12) and the market volatility (MVOL12). Standard errors are clustered at both the country and month dimensions. ${ }^{*}, * *, * * *$ denote statistical significance at $10 \%, 5 \%, 1 \%$ respectively. The sample period is from January 1975 to December 2015.

\begin{tabular}{ccccc}
\hline \multicolumn{4}{c}{ Dependent Variable: Future FOODXMRE } & over $1 \mathrm{~m}, 3 \mathrm{~m}, 6 \mathrm{~m}$ and $12 \mathrm{~m}$, Non-overlapping \\
\hline & $1 \mathrm{~m}$ & $3 \mathrm{~m}$ & $6 \mathrm{~m}$ & $12 \mathrm{~m}$ \\
\hline PDSI36m & $0.1360^{*}$ & 0.2882 & 0.5881 & $1.3526^{* *}$ \\
& $(1.83)$ & $(1.44)$ & $(1.43)$ & $(2.09)$ \\
FOODXMRET12m & -0.0225 & -0.0180 & -0.0384 & 0.0034 \\
& $(-1.34)$ & $(-0.83)$ & $(-0.75)$ & $(0.05)$ \\
FOODPB12 & $-0.5487^{* *}$ & $-1.2048^{*}$ & -2.3425 & -4.1423 \\
& $(-2.04)$ & $(-1.81)$ & $(-1.65)$ & $(-1.48)$ \\
MRET12 & -0.0039 & 0.0043 & 0.0082 & $0.0312^{*}$ \\
& $(-0.87)$ & $(0.59)$ & $(0.41)$ & $(1.81)$ \\
INF12 & -0.0043 & 0.1437 & -0.0100 & -0.5649 \\
& $(-0.09)$ & $(1.29)$ & $(-0.05)$ & $(-1.14)$ \\
DP12 & -0.0143 & -0.0137 & -0.0101 & -0.0376 \\
& $(-1.18)$ & $(-0.61)$ & $(-0.80)$ & $(-1.04)$ \\
MVOL12 & 0.0342 & 0.1563 & 0.0665 & -0.1167 \\
& $(1.28)$ & $(1.45)$ & $(0.27)$ & $(-0.31)$ \\
Ave.R-sq & 0.009 & 0.020 & 0.036 & 0.062 \\
N.of Obs. & 6909 & 2290 & 1134 & 564 \\
\hline
\end{tabular}


Table 9: International Evidence: Predicting 12-month Non-overlapping Food Portfolio Return in subsamples based on Past Mean PDSI36m

This table presents the results from forecasting the food industry portfolio excess returns over future 12 months, using the moving averages of the PDSI values over the past 36 months (PDSI36m). Panel A reports the mean PDSI36m for each country using data up to 1974. Panel B reports the return predictability of PDSI36m for 3 groups of countries based on the past mean PDSI36m. Panel C reports the return predictability of Dry/Wet dummy for low and high past PDSI countries. Dry (Wet) is a dummy equal to one when the demeand PDSI36m is less (greater) than $-1(+1)$. The result for countries with mean PDSI36m in the lowest (highest) tercile is reported under Column "Low PDSI tercile" ("High PDSI tercile"). The regressions are run by pooling all countries within a group together and including a country fixed effect. In column (3) of Panel B, We interact PDSI36m with a dummy HighPDSI indicating a country is in the highest past PDSI36m tercile. We do not include countries in the middle tercile of PDSI in Column (3). The dependent variable is the food return over the future 12 months. The returns are non-overlapping. All of the regressions include these other forecasting variables over the past 12 months: lagged food industry return (FOODRET12m), lagged market return (MRET12), lagged inflation rate (INF12), log of food industry price-to-book ratio (FOODPB12), the log of the market dividend price ratio (DP12) and the market volatility (MVOL12). The sample period is from January 1975 to December 2015. Standard errors are clustered at both the country and month dimensions. ${ }^{*},{ }^{* *}, * * *$ denote statistical significance at $10 \%, 5 \%, 1 \%$ respectively.

Panel A: Mean PDSI36m

\begin{tabular}{cc}
\hline Country & Mean PDSI36m \\
\hline Israel & 3.023 \\
Peru & 0.624 \\
Chile & 0.594 \\
Thailand & 0.513 \\
Turkey & 0.438 \\
Poland & 0.429 \\
Malaysia & 0.400 \\
Finland & 0.365 \\
Netherlands & 0.364 \\
Belgium & 0.364 \\
Brazil & 0.290 \\
Japan & 0.219 \\
Greece & 0.183 \\
Philippines & 0.164 \\
Denmark & 0.024 \\
Switzerland & 0.017 \\
Germany & 0.015 \\
United Kingdom & -0.014 \\
South Africa & -0.107 \\
France & -0.168 \\
United States of America & -0.174 \\
Indonesia & -0.188 \\
Norway & -0.195 \\
Russian Federation & -0.273 \\
South Korea & -0.315 \\
India & -0.368 \\
Mexico & -0.697 \\
Canada & -0.712 \\
Portugal & -0.804 \\
China & -0.979 \\
New Zealand & -1.000 \\
Australia & -1.074 \\
\hline & \\
\hline & Pod
\end{tabular}




\section{Table 9 Continued}

Panel B: Subsample Return Predictability of PDSI

\begin{tabular}{cccc}
\hline & Low PDSI tercile & High PDSI tercile & \\
\hline PDSI36m & 2.8261 & $5.9049^{* *}$ & 1.7059 \\
& $(1.48)$ & $(2.54)$ & $(0.73)$ \\
PDSI36m*HighPDSI & & & $3.8232^{*}$ \\
& & & $(1.93)$ \\
FOODRET12m & 0.0685 & -0.2061 & -0.1088 \\
& $(0.62)$ & $(-1.13)$ & $(-0.63)$ \\
FOODPB12 & $-10.4033^{*}$ & $-15.1159^{*}$ & $-14.0648^{* *}$ \\
& $(-2.13)$ & $(-2.18)$ & $(-2.47)$ \\
MRET12 & -0.2008 & 0.4941 & 0.2989 \\
& $(-1.46)$ & $(1.02)$ & $(0.70)$ \\
INF12 & $-96.5665^{* *}$ & 1.7356 & 2.0021 \\
& $(-2.50)$ & $(0.60)$ & $(0.75)$ \\
DP12 & -0.4874 & $-0.4716^{* *}$ & $-0.4061^{* * *}$ \\
& $(-0.42)$ & $(-2.84)$ & $(-3.46)$ \\
MVOL12 & 0.9775 & 2.4168 & 2.4785 \\
& $(0.77)$ & $(1.69)$ & $(1.72)$ \\
Ave.R-sq & 0.097 & 0.363 & 0.260 \\
N.of Obs. & 159 & 198 & 357 \\
\hline
\end{tabular}




\section{Table 9 Continued}

Panel C: Subsample Return Predictability of Dry/Wet Dummy

\begin{tabular}{ccc}
\hline & Low PDSI tercile & High PDSI tercile \\
\hline Dry & -7.2535 & $-12.7872^{*}$ \\
& $(-1.02)$ & $(-2.18)$ \\
Wet & 5.6888 & $7.5794^{*}$ \\
& $(0.59)$ & $(1.96)$ \\
FOODRET12 & 0.0710 & -0.1822 \\
& $(0.65)$ & $(-0.84)$ \\
FOODPB12 & $-10.2587^{*}$ & $-14.8729^{*}$ \\
& $(-2.13)$ & $(-1.91)$ \\
MRET12 & -0.2114 & 0.4767 \\
& $(-1.08)$ & $(0.86)$ \\
INF12 & $-97.8097^{* *}$ & 1.7718 \\
& $(-2.53)$ & $(0.59)$ \\
DP12 & -0.5193 & $-0.4368^{*}$ \\
& $(-0.41)$ & $(-2.11)$ \\
MVOL12 & 0.8883 & 2.2851 \\
& $(0.66)$ & $(1.44)$ \\
Ave.R-sq & 0.100 & 0.357 \\
N.of Obs. & 159 & 198 \\
\hline
\end{tabular}




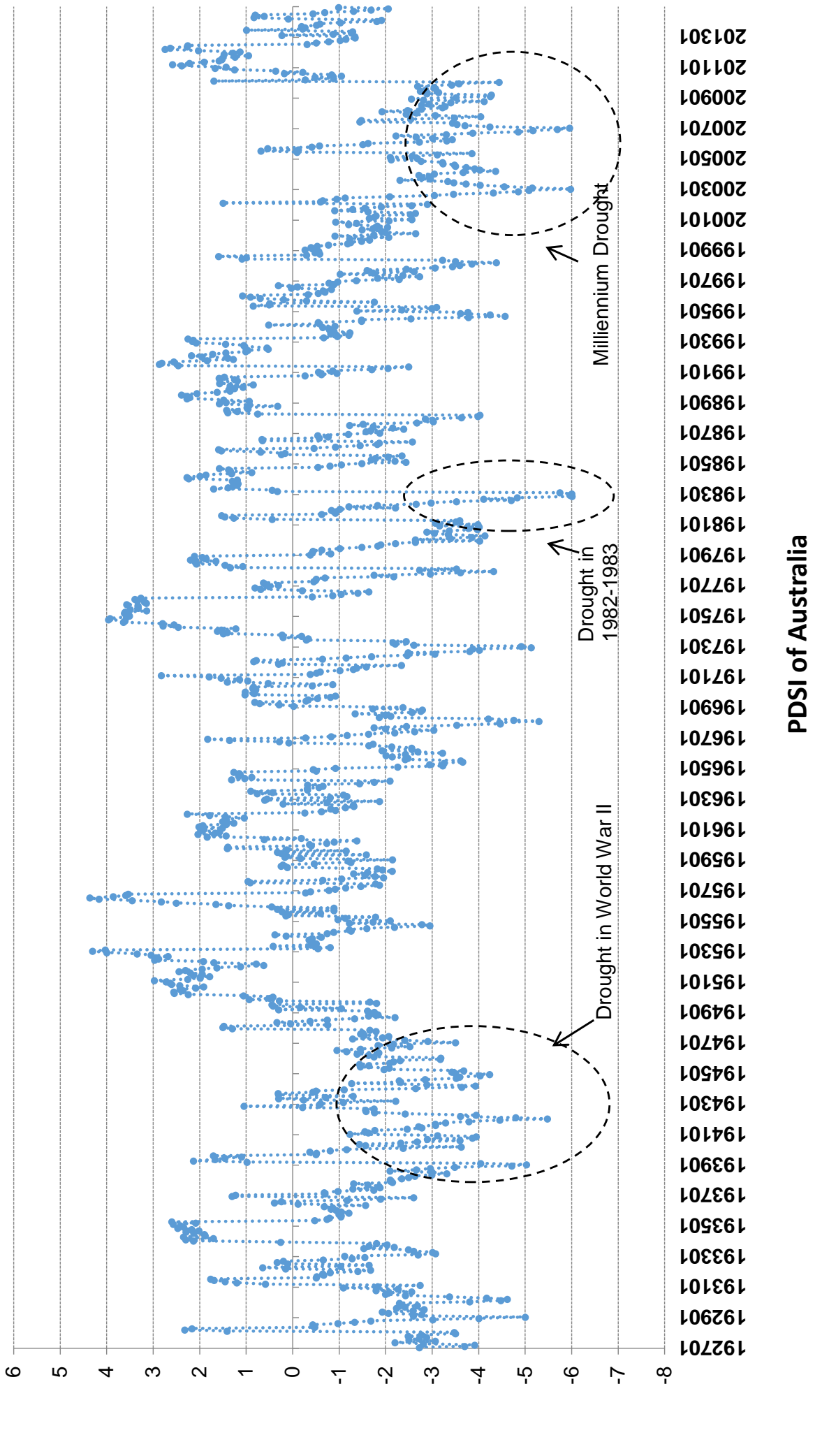




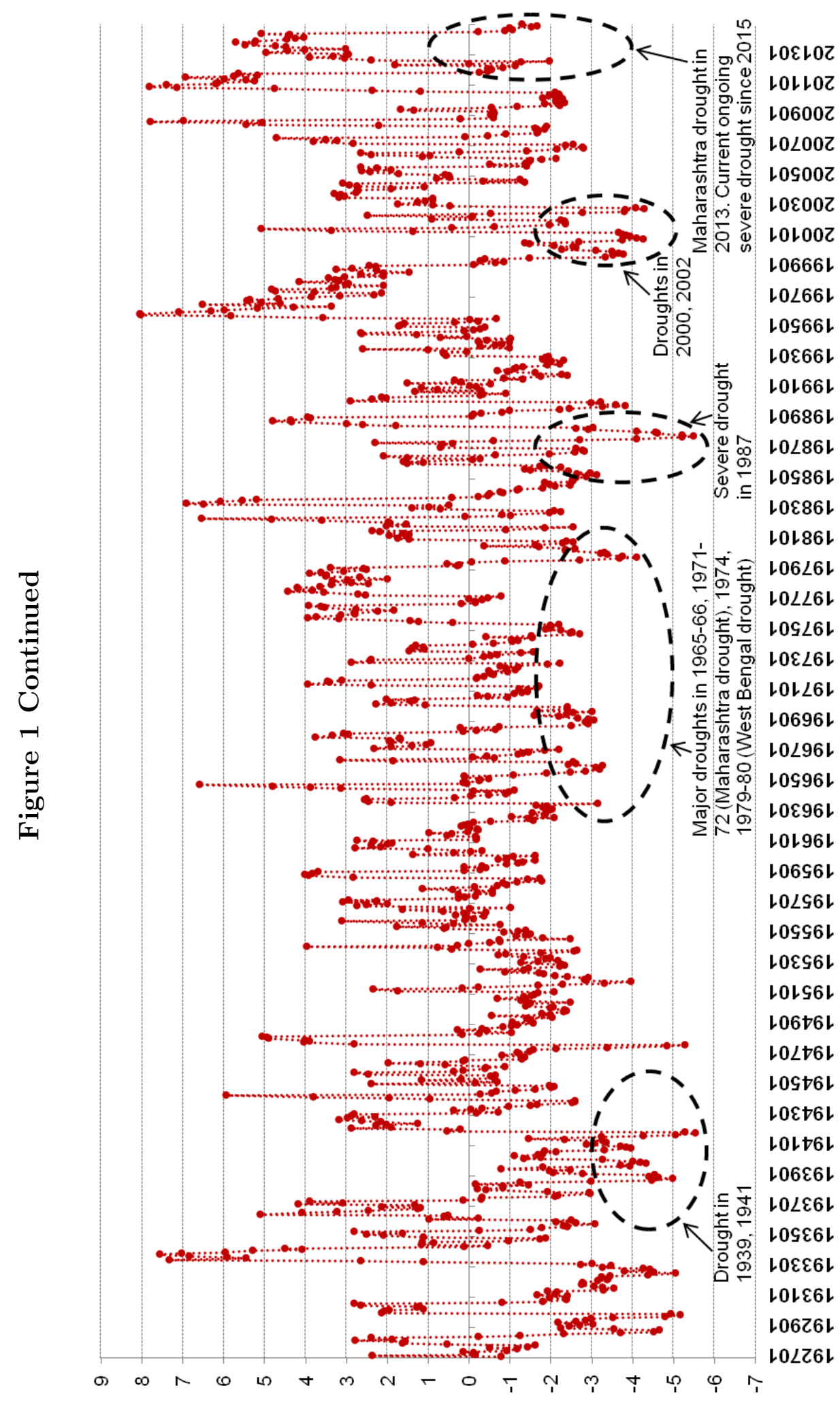




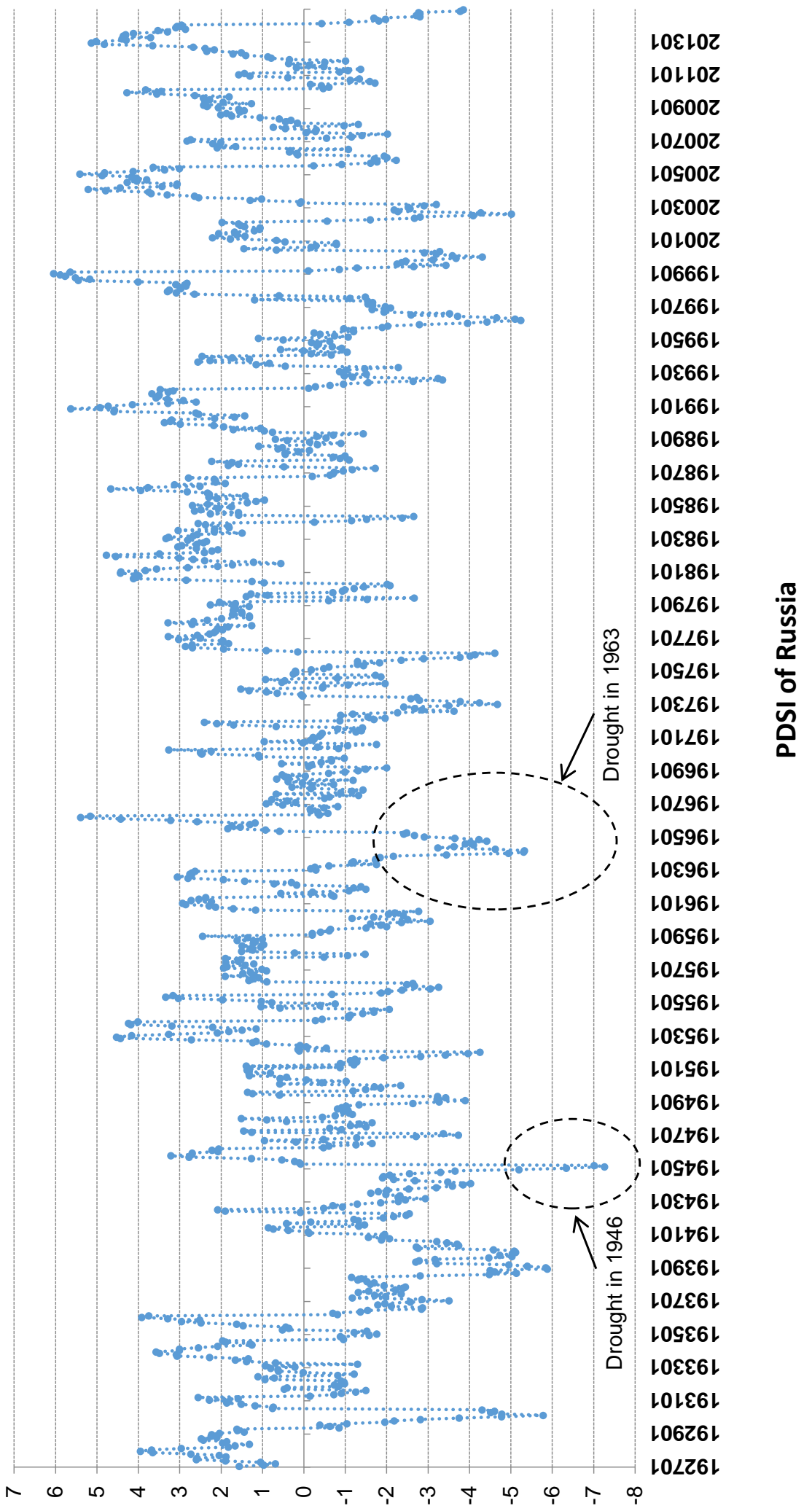




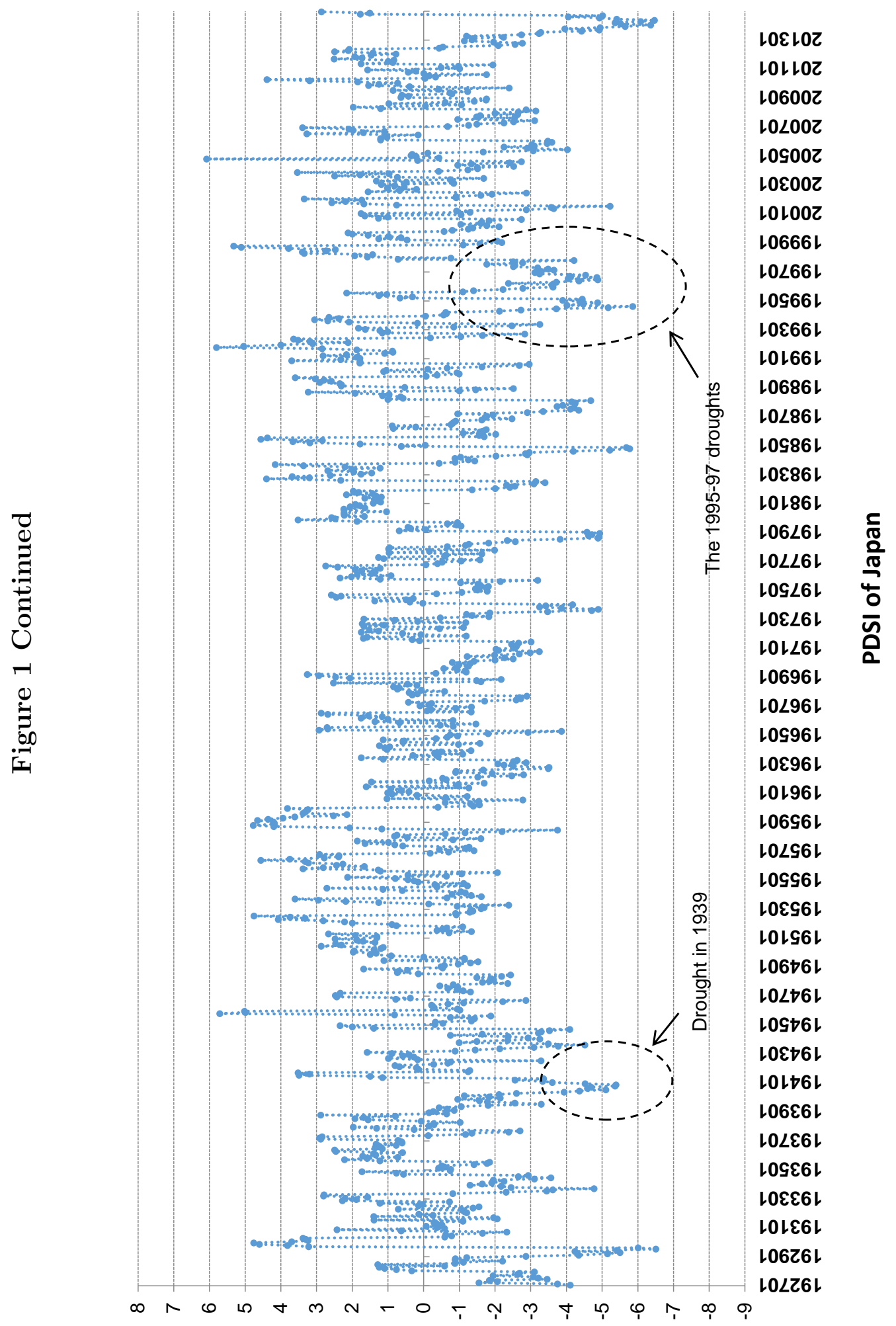




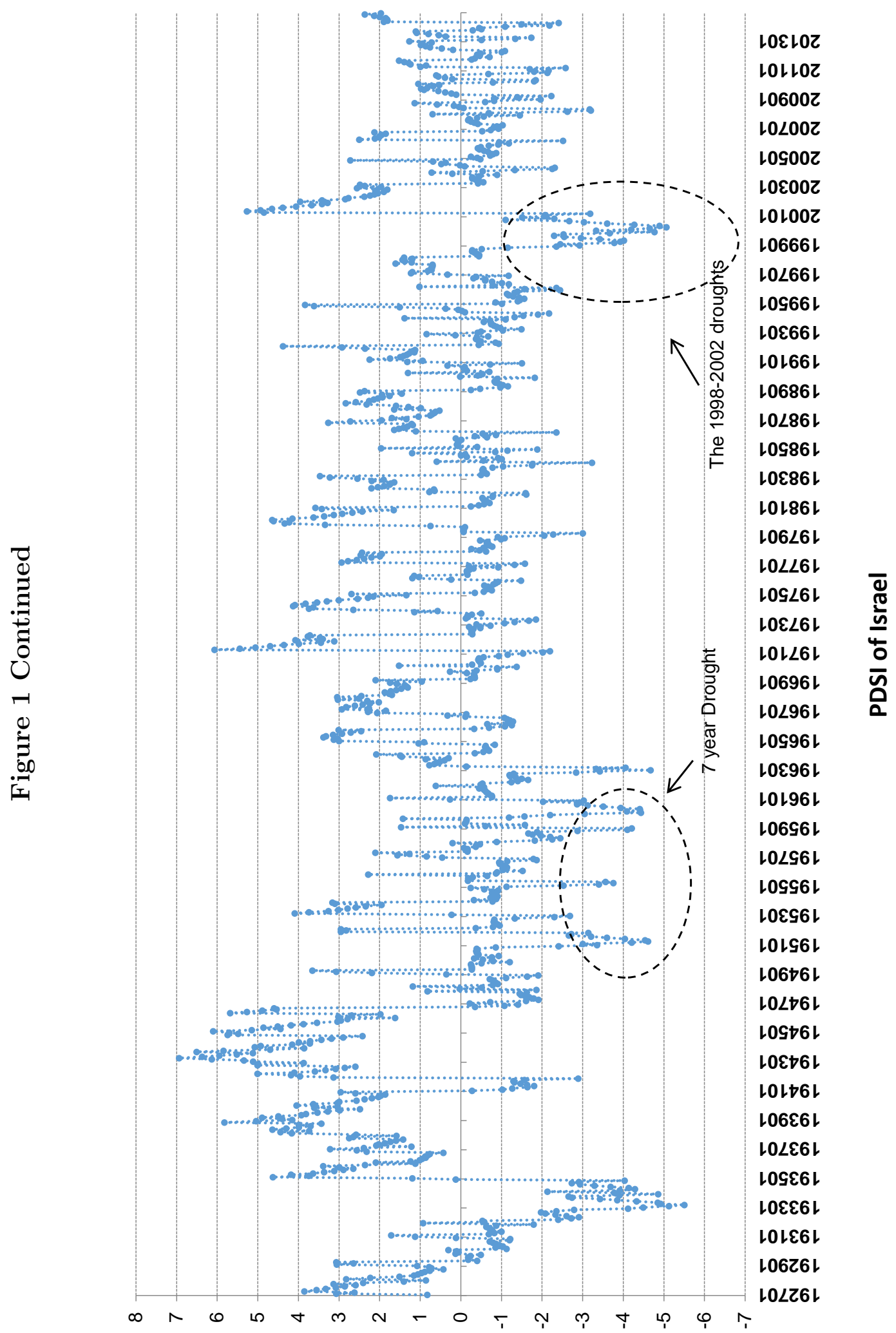



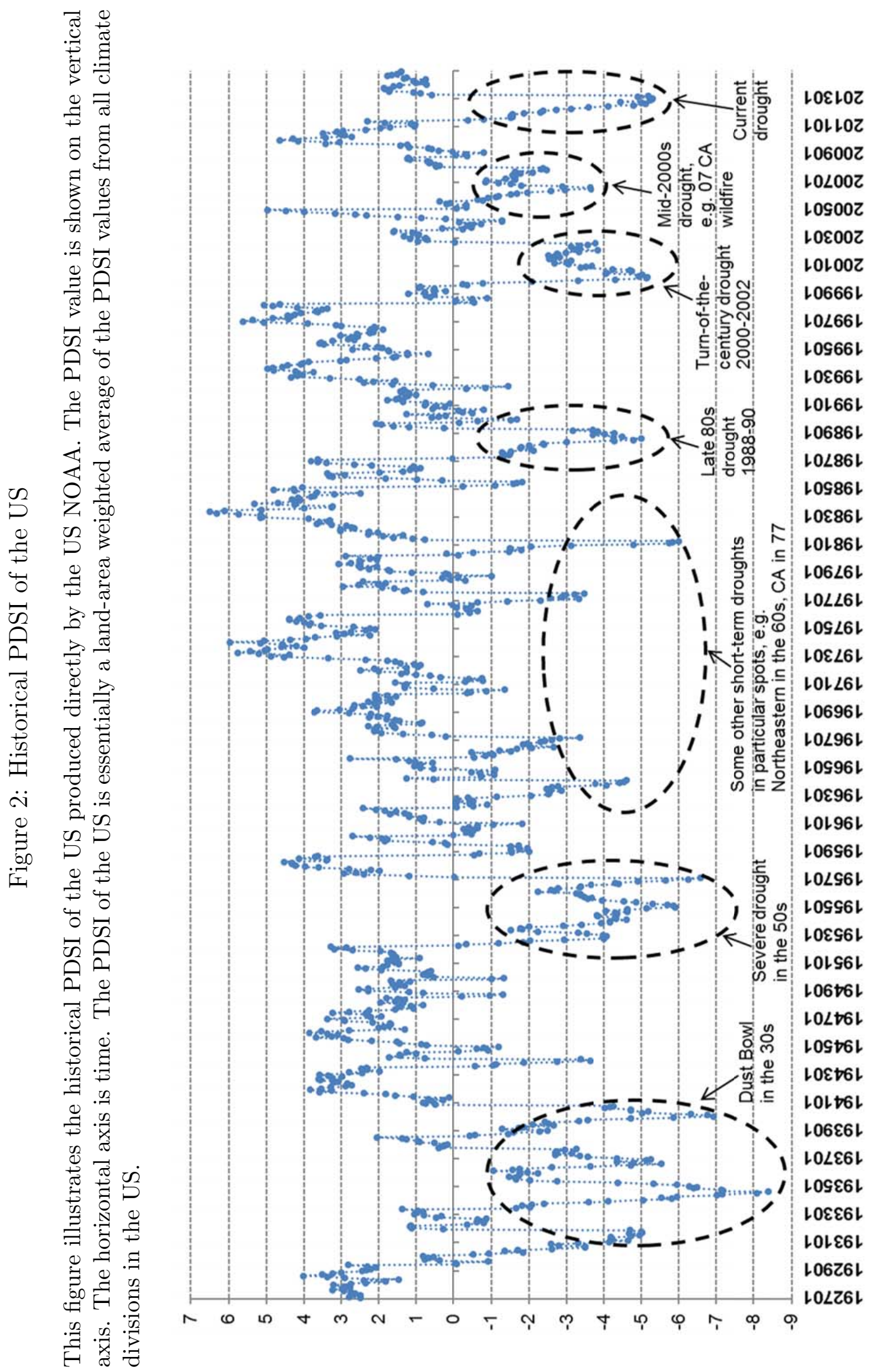
Figure 3: Future Non-overlapping 12-month Return of Food net of Market Portfolio and Past 36-month Moving Average of PDSIWA, Time-series Plot

This figure depicts the time-series plot of the future non-overlapping 12-month return of the food net of market portfolio against our main predictor variable PDSIWA36m, the past 36-month moving average of the weighted average (by cropland area) PDSI value of the top 10 food-producing states in the US. The sample period is January 1927 to December 2014. The plot starts in December 1929 as the first 36 months are used to obtain the first value of PDSIWA36m.

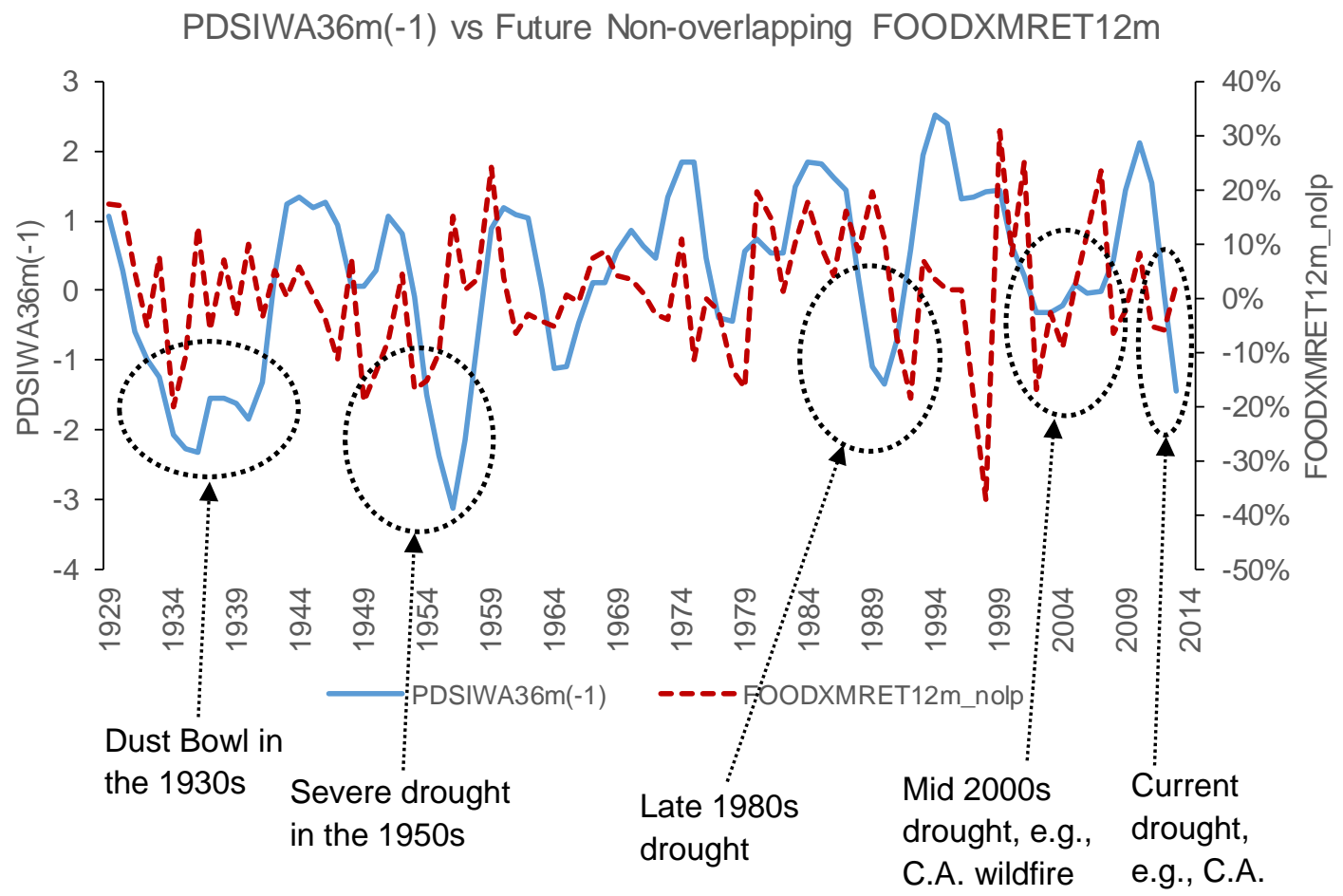


Figure 4: Global Annual Temperature Anomaly, 1880 to 2014

This figure shows the global annual temperature anomalies from 1880 to 2014 as recorded by NASA (red line), NOAA (green line), the Japan Meteorological Agency (purple line), and the Met Office Hadley Centre in the UK (blue line), downloaded from NASA's website (source: http://earthobservatory.nasa.gov/Features/ WorldOfChange/decadaltemp.php). The vertical axis is the annual temperature anomaly and the horizontal axis is time.

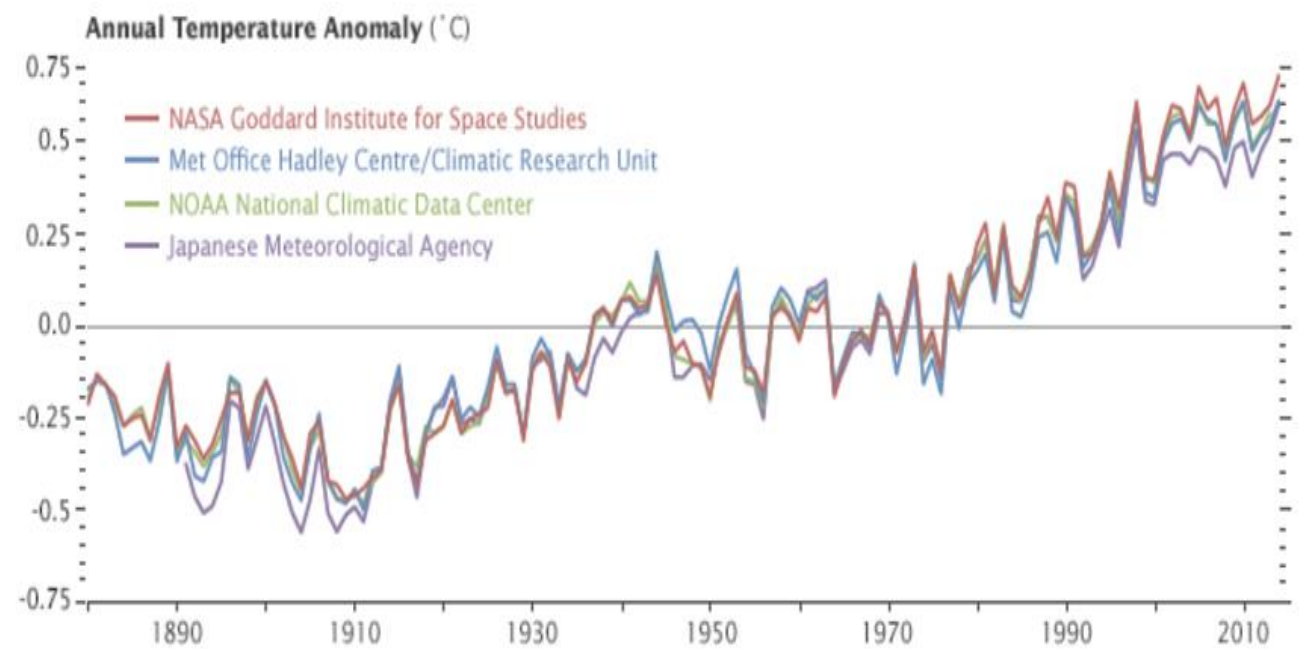


Figure 5: Monthly Quartile PDSI Values of International Countries over Time

This figure depicts the monthly lower quartile (25th percentile) PDSI value of international countries (including the US) over time. The vertical axis is the corresponding PDSI variable value, and the horizontal axis is time. We also plot the best-fitted linear trend line and allow for a structural break in trend at Jan 1980. The orange dotted line and the red dashed line in the graph are the best-fitted linear trend lines before the structural break in trend (before Jan 1980) and after the structural break in trend (after Jan 1980) respectively. The sample period is from 190001 (January 1900) to 201412 (December 2014).

Panel $(A)$

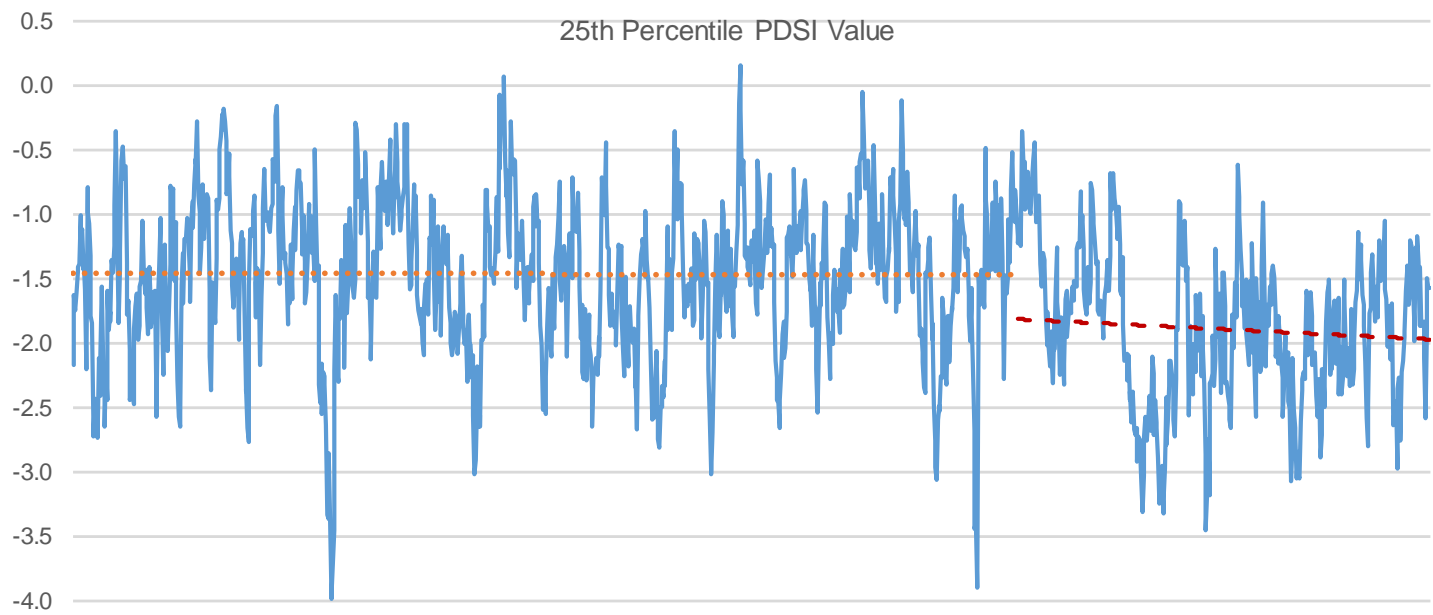

$-4.5$

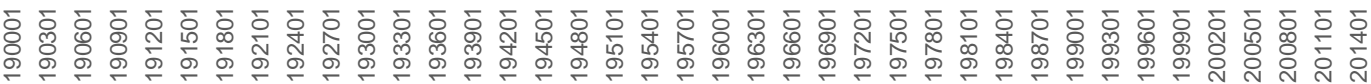

Panel (B)

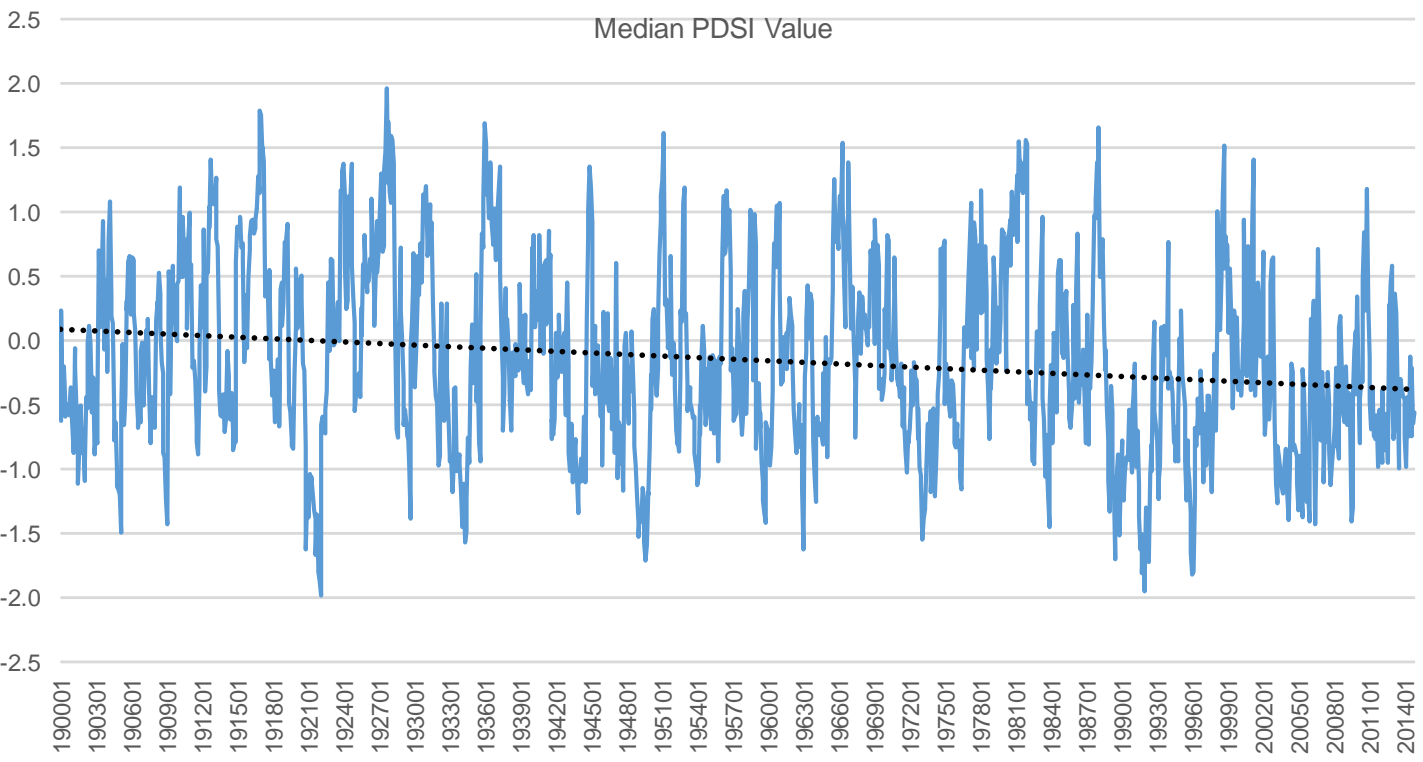


Figure 6: International Evidence: Future 1-year Change in Food Industry Profitability (CP) Residual and Past 36-month Moving Average of PDSI, Scatter Plot

This figure depicts the scatter plot of the future 1-year change in the food industry profitability (CP) residual against our main predictor variable PDSI36m, the past 36-month moving average of PDSI value, for our international sample including the US. The sample period is from January 1975 to December 2015.

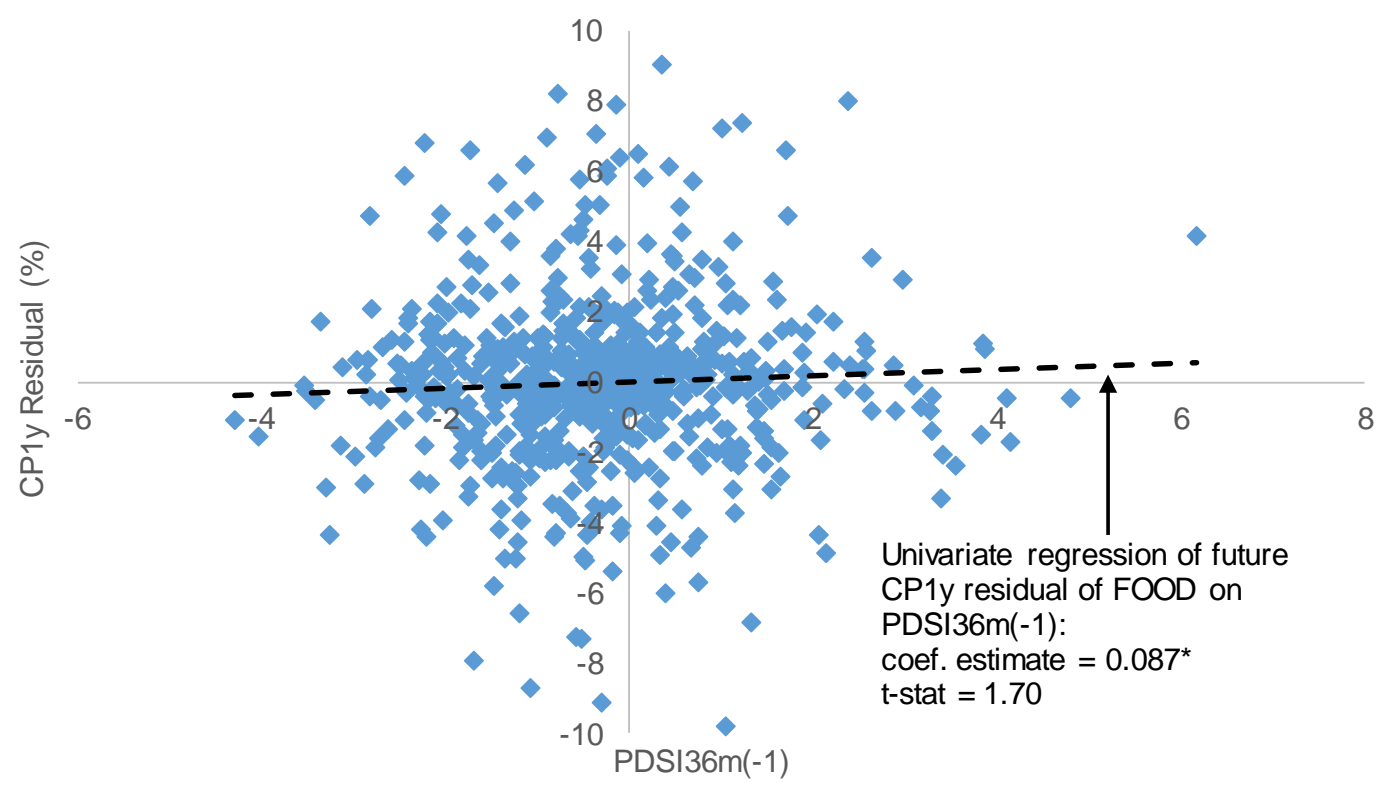


Figure 7: International Evidence: Future Non-overlapping 12-month Food Portfolio Return Residual and Past 36-month Moving Average of PDSI, Scatter Plot

This figure depicts the scatter plot of the future non-overlapping 12-month food portfolio return residual against our main predictor variable PDSI36m, the past 36-month moving average of PDSI value. The sample period is from January 1975 to December 2015.

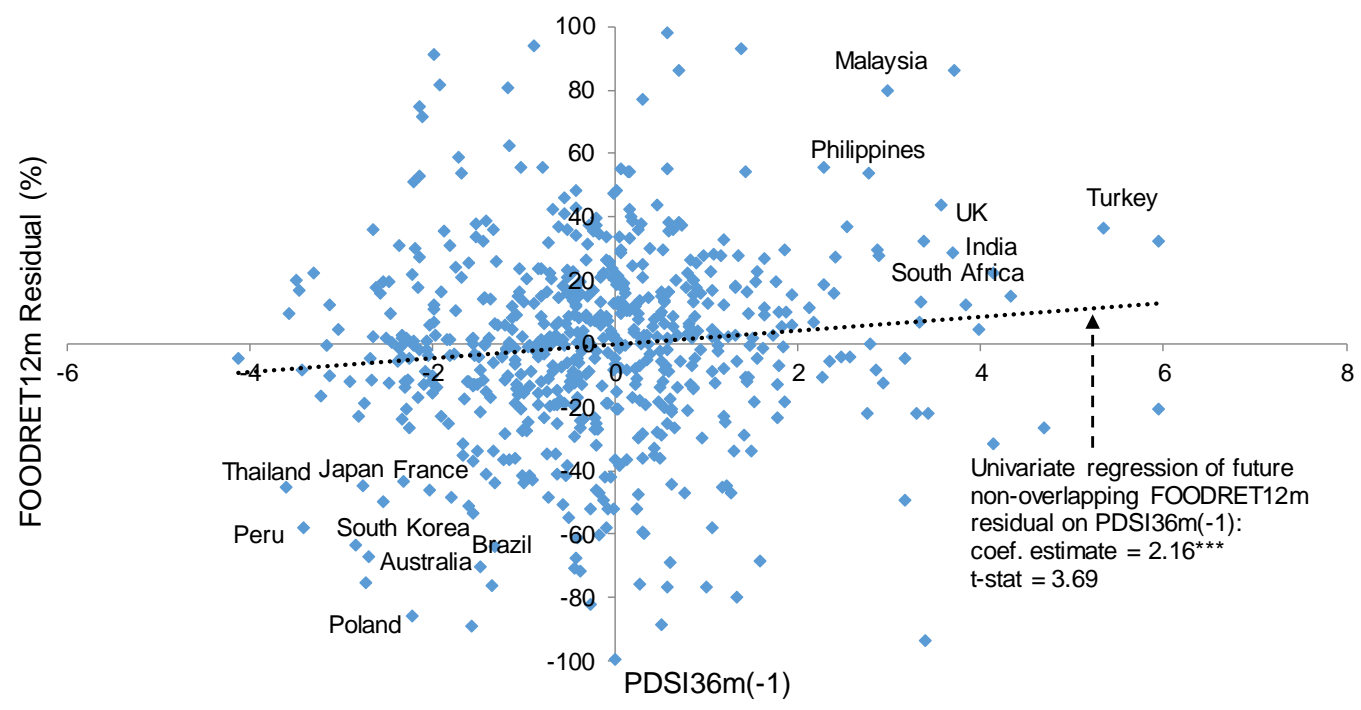


Figure 8: International Evidence: Future Non-overlapping 12-month Food Portfolio Return Residual and Past 36-month Moving Average of PDSI, Subsamples based on Past Mean PDSI36m

This figure depicts the scatter plot of the future non-overlapping 12-month food portfolio return residual against our main predictor variable PDSI36m, the past 36-month moving average of PDSI value. The blue circle indicates countries whose past mean PDSI36m values are in the highest tercile (high tercile group), while the red diamond indicates countries whose past mean PDSI36m values are in the lowest tercile (low tercile group). The sample period is from January 1975 to December 2015.

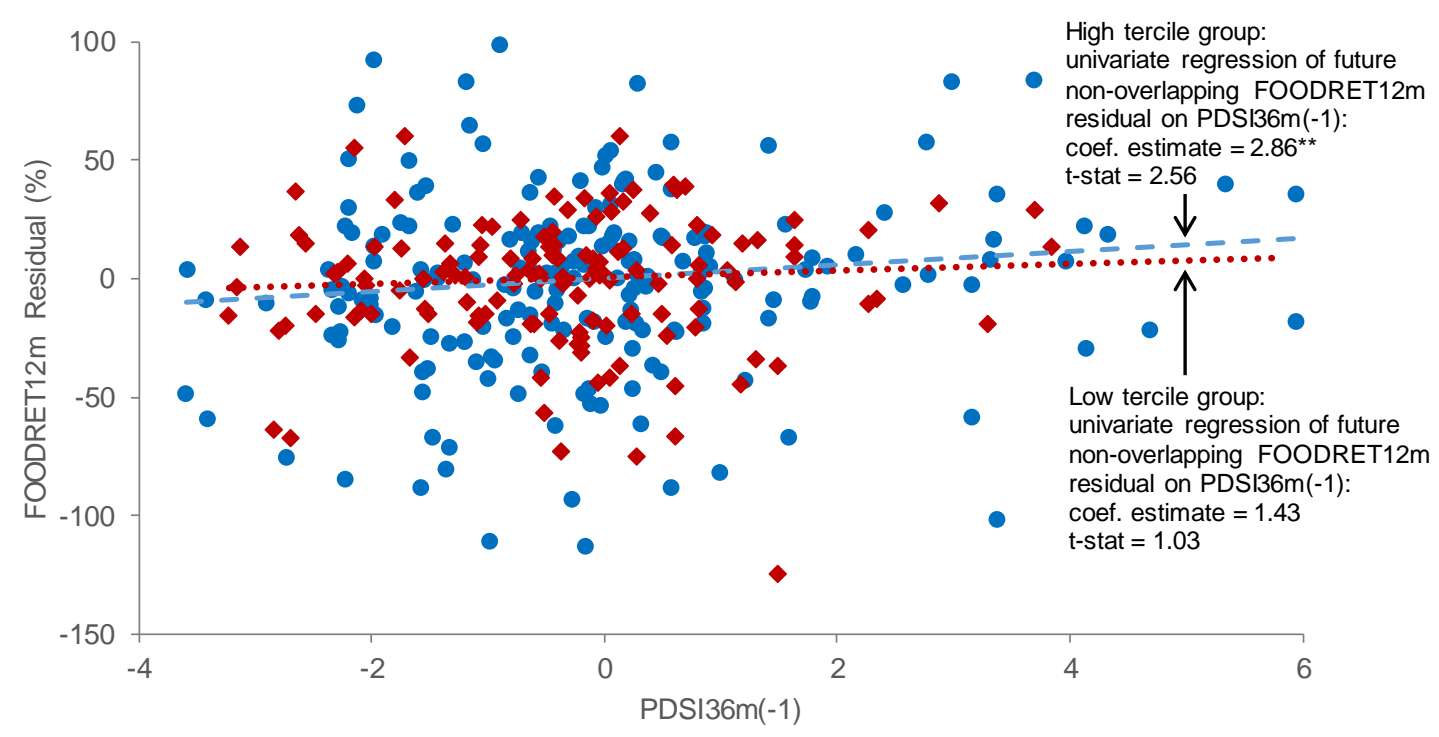




\section{Internet Appendix For Online}

\section{Publication Only}




\section{Appendix Tables and Figures}

Appendix Table 1: International Evidence: Predicting 12-month Non-overlapping Food Portfolio Return with Moving Average of PDSI at Different Frequencies

This table presents the results from forecasting the food industry portfolio excess returns over future 12 months, using the moving averages of the PDSI values over different frequencies. The regressions are run by pooling all countries together and including a country fixed effect. The dependent variable is the food return over the future 12 months. PDSI $12 \mathrm{~m}$ to PDSI30m are the moving average of the PDSI values over the previous 12 months, 18 months, 24 months and 30 months, respectively. The returns are non-overlapping. All of the regressions include these other forecasting variables over the past 12 months: lagged food industry return (FOODRET12m), lagged market return (MRET12), lagged inflation rate (INF12), log of food industry price-to-book ratio (FOODPB12), the $\log$ of the market dividend price ratio (DP12) and the market volatility (MVOL12). Standard errors are clustered at both the country and month dimensions. *, **,*** denote statistical significance at $10 \%, 5 \%, 1 \%$ respectively. The sample period is from January 1975 to December 2015.

\begin{tabular}{|c|c|c|c|c|}
\hline \multicolumn{5}{|c|}{ Dependent Variable: Future 12-month FOODRET, Non-overlapping } \\
\hline & $(1)$ & $(2)$ & $(3)$ & (4) \\
\hline PDSI12m & $\begin{array}{l}1.8019 \\
(1.42)\end{array}$ & & & \\
\hline PDSI18m & & $\begin{array}{l}1.9335 \\
(1.40)\end{array}$ & & \\
\hline PDSI24m & & & $\begin{array}{c}2.5839^{*} \\
(1.74)\end{array}$ & \\
\hline PDSI30m & & & & $\begin{array}{c}3.1015^{* *} \\
(2.07)\end{array}$ \\
\hline FOODRET12 & $\begin{array}{c}-0.0642 \\
(-0.59)\end{array}$ & $\begin{array}{c}-0.0649 \\
(-0.59)\end{array}$ & $\begin{array}{c}-0.0679 \\
(-0.62)\end{array}$ & $\begin{array}{c}-0.0705 \\
(-0.64)\end{array}$ \\
\hline FOODPB12 & $\begin{array}{c}-12.3973^{* * *} \\
(-2.96)\end{array}$ & $\begin{array}{c}-12.5065^{* * *} \\
(-2.91)\end{array}$ & $\begin{array}{c}-12.6034^{* * *} \\
(-2.89)\end{array}$ & $\begin{array}{c}-12.5605^{* * *} \\
(-2.91)\end{array}$ \\
\hline MRET12 & $\begin{array}{c}0.2351 \\
(0.76)\end{array}$ & $\begin{array}{c}0.2340 \\
(0.75)\end{array}$ & $\begin{array}{c}0.2362 \\
(0.76)\end{array}$ & $\begin{array}{c}0.2393 \\
(0.75)\end{array}$ \\
\hline INF12 & $\begin{array}{l}1.9168 \\
(1.26)\end{array}$ & $\begin{array}{c}1.9174 \\
(1.26)\end{array}$ & $\begin{array}{l}1.8901 \\
(1.24)\end{array}$ & $\begin{array}{c}1.8570 \\
(1.22)\end{array}$ \\
\hline DP12 & $\begin{array}{c}-0.3365^{* * *} \\
(-14.02)\end{array}$ & $\begin{array}{c}-0.3348^{* * *} \\
(-12.81)\end{array}$ & $\begin{array}{c}-0.3341^{* * *} \\
(-8.91)\end{array}$ & $\begin{array}{c}-0.3430^{* * *} \\
(-6.70)\end{array}$ \\
\hline MVOL12 & $\begin{array}{c}2.0001^{* *} \\
(2.07)\end{array}$ & $\begin{array}{c}1.9964^{* *} \\
(2.05)\end{array}$ & $\begin{array}{c}2.0033^{* *} \\
(2.07)\end{array}$ & $\begin{array}{c}2.0032^{*} \\
(2.04)\end{array}$ \\
\hline Ave.R-sq & 0.209 & 0.208 & 0.211 & 0.213 \\
\hline N.of Obs. & 584 & 584 & 584 & 584 \\
\hline
\end{tabular}


Appendix Table 2: Predicting 12-month Non-overlapping Food Portfolio Return with 36-month Moving Average of PDSIWA

This table presents the results from forecasting the future non-overlapping food industry portfolio excess returns (FOODRET) at the 12-month horizon, using the 36-month moving average of the weighted PDSI values (PDSIWA). The dependent variable (forecast) is the non-overlapping food portfolio excess return (FOODRET) over the next 12 months. The key explanatory (forecasting) variable, PDSIWA36m, is the moving average of the weighted PDSI values (PDSIWA) over the previous 36 months. The weighted average is over the top 10 food-producing states using cropland area as weight. Other control variables, FOODRET12m, FOODBM12, MRET12, INF12, DP12, MVOL12, NTIS12, DSPR12 and TSPR12 denote, respectively, the FOODRET, the $\log$ of the food industry book-to-market ratio (FOODBM), the market excess return (MRET), the inflation rate (INF), the log of the market dividend price ratio (DP), the market volatility (MVOL), the net equity expansion ratio (NTIS), the default spread (DSPR) and the term spreads (TSPR), all over the previous 12 months. CONST is the constant term. $t$-statistics based on Newey-West HAC standard errors are shown in parentheses, with a lag order of 36 for all of the regressions. *, **, *** denote statistical significance at $10 \%, 5 \%, 1 \%$ respectively. The $R^{2}$ for each regression is also reported. $N$ is the number of observation points in each regression. The sample period is January 1927 to December 2014. Estimations start in December 1929 as the first 36 months are used to obtain the first value of PDSIWA36m.

\begin{tabular}{|c|c|c|c|}
\hline & \multicolumn{3}{|c|}{$\begin{array}{c}\text { Dependent Variable: Future 12-month } \\
\text { FOODRET, Non-overlapping }\end{array}$} \\
\hline & $(1)$ & $(2)$ & $(3)$ \\
\hline PDSIWA36m & & & $\begin{array}{l}2.005^{* *} \\
(2.532)\end{array}$ \\
\hline FOODRET12m & & $\begin{array}{c}0.012 \\
(0.118)\end{array}$ & $\begin{array}{l}-0.022 \\
(-0.186)\end{array}$ \\
\hline FOODBM12 & & $\begin{array}{l}14.709 \\
(0.970)\end{array}$ & $\begin{array}{l}16.899 \\
(1.016)\end{array}$ \\
\hline MRET12 & $\begin{array}{l}-0.080 \\
(-1.098)\end{array}$ & $\begin{array}{l}-0.224 \\
(-1.125)\end{array}$ & $\begin{array}{l}-0.206 \\
(-1.105)\end{array}$ \\
\hline INF12 & $\begin{array}{c}0.189 \\
(0.738)\end{array}$ & $\begin{array}{c}0.199 \\
(0.987)\end{array}$ & $\begin{array}{c}0.031 \\
(0.125)\end{array}$ \\
\hline DP12 & $\begin{array}{c}7.782^{* * *} \\
(6.537)\end{array}$ & $\begin{array}{l}-4.707 \\
(-0.384)\end{array}$ & $\begin{array}{l}-5.511 \\
(-0.411)\end{array}$ \\
\hline MVOL12 & $\begin{array}{l}-0.463^{*} \\
(-1.805)\end{array}$ & $\begin{array}{l}-0.343 \\
(-1.235)\end{array}$ & $\begin{array}{l}-0.362 \\
(-1.373)\end{array}$ \\
\hline NTIS12 & $\begin{array}{l}-2.376^{* * *} \\
(-6.921)\end{array}$ & $\begin{array}{l}-2.204^{* * *} \\
(-6.707)\end{array}$ & $\begin{array}{l}-2.263^{* * *} \\
(-6.990)\end{array}$ \\
\hline DSPR12 & $\begin{array}{c}1.573 \\
(0.686)\end{array}$ & $\begin{array}{c}-0.193 \\
(-0.061)\end{array}$ & $\begin{array}{c}0.222 \\
(0.083)\end{array}$ \\
\hline TSPR12 & $\begin{array}{c}2.300^{* * *} \\
(5.937)\end{array}$ & $\begin{array}{c}2.926^{* * *} \\
(4.267)\end{array}$ & $\begin{array}{c}2.761^{* * *} \\
(3.631)\end{array}$ \\
\hline CONST & $\begin{array}{c}37.938 * * * \\
(5.768)\end{array}$ & $\begin{array}{c}5.600 \\
(0.178)\end{array}$ & $\begin{array}{c}4.750 \\
(0.137)\end{array}$ \\
\hline$R^{2}$ & 0.22 & 0.24 & 0.26 \\
\hline$N$ & 85 & 85 & 85 \\
\hline
\end{tabular}


Appendix Table 3: Predicting Non-overlapping Food Portfolio Returns over Different Horizons with 36-month Moving Average of PDSIWA

This table presents the results from forecasting the future non-overlapping food industry portfolio excess returns (FOODRET) over different horizons, using the 36-month moving average of the weighted PDSI values (PDSIWA). The dependent variables (forecasts) are the non-overlapping food portfolio excess returns (FOODRET) over the next 1 month, 3 months and 6 months in columns $1 \mathrm{~m}, 3 \mathrm{~m}$ and $6 \mathrm{~m}$ respectively. The key explanatory (forecasting) variable, PDSIWA36m, is the moving average of the weighted PDSI values (PDSIWA) over the previous 36 months. The weighted average is over the top 10 food-producing states using cropland area as weight. Other control variables, FOODRET12m, FOODBM12, MRET12, INF12, DP12, MVOL12, NTIS12, DSPR12 and TSPR12 denote, respectively, the FOODRET, the log of the food industry book-to-market ratio (FOODBM), the market excess return (MRET), the inflation rate (INF), the log of the market dividend price ratio (DP), the market volatility (MVOL), the net equity expansion ratio (NTIS), the default spread (DSPR) and the term spreads (TSPR), all over the previous 12 months. CONST is the constant term. $t$-statistics based on Newey-West HAC standard errors are shown in parentheses, with a lag order of 36 for all of the regressions. $*, * *, * * *$ denote statistical significance at $10 \%, 5 \%, 1 \%$ respectively. The $R^{2}$ for each regression is also reported. $N$ is the number of observation points in each regression. The sample period is January 1927 to December 2014.

\begin{tabular}{|c|c|c|c|}
\hline & \multicolumn{3}{|c|}{$\begin{array}{c}\text { Dependent Variables: Future FOODRET } \\
\text { over } 1 \mathrm{~m}, 3 \mathrm{~m} \text { and } 6 \mathrm{~m} \text {, Non-overlapping }\end{array}$} \\
\hline & $1 \mathrm{~m}$ & $3 \mathrm{~m}$ & $6 \mathrm{~m}$ \\
\hline \multirow[t]{2}{*}{ PDSIWA36m } & $0.185^{*}$ & 0.558 & $1.062^{* *}$ \\
\hline & $(1.648)$ & $(1.620)$ & $(2.260)$ \\
\hline \multirow[t]{2}{*}{ FOODRET12m } & -0.001 & -0.027 & -0.011 \\
\hline & $(-0.038)$ & $(-0.491)$ & $(-0.125)$ \\
\hline \multirow[t]{2}{*}{ FOODBM12 } & 0.488 & 1.929 & 6.604 \\
\hline & $(0.716)$ & $(0.676)$ & $(1.171)$ \\
\hline \multirow[t]{2}{*}{ MRET12 } & 0.004 & -0.011 & -0.111 \\
\hline & $(0.235)$ & $(-0.212)$ & $(-1.371)$ \\
\hline \multirow[t]{2}{*}{ INF12 } & -0.058 & -0.143 & $-0.340^{* *}$ \\
\hline & $(-0.897)$ & $(-0.856)$ & $(-2.091)$ \\
\hline \multirow[t]{2}{*}{ DP12 } & 0.428 & 1.135 & -0.048 \\
\hline & $(0.702)$ & $(0.475)$ & $(-0.010)$ \\
\hline \multirow[t]{2}{*}{ MVOL12 } & -0.008 & -0.039 & $-0.308^{* * *}$ \\
\hline & $(-0.274)$ & $(-0.613)$ & $(-2.791)$ \\
\hline \multirow[t]{2}{*}{ NTIS12 } & $-0.237^{* * *}$ & $-0.877^{* * *}$ & $-1.345^{* * *}$ \\
\hline & $(-3.003)$ & $(-3.837)$ & $(-3.576)$ \\
\hline \multirow[t]{2}{*}{ DSPR12 } & -0.102 & -0.389 & -0.600 \\
\hline & $(-0.280)$ & $(-0.458)$ & $(-0.490)$ \\
\hline \multirow[t]{2}{*}{ TSPR12 } & 0.139 & $0.456^{* *}$ & $1.382^{*}$ \\
\hline & $(1.618)$ & $(2.134)$ & $(1.883)$ \\
\hline \multirow[t]{2}{*}{ CONST } & 2.856 & 9.138 & 14.329 \\
\hline & $(1.545)$ & $(1.422)$ & $(1.133)$ \\
\hline$R^{2}$ & 0.02 & 0.06 & 0.14 \\
\hline$N$ & 1020 & 340 & 170 \\
\hline
\end{tabular}


Appendix Table 4: Predicting 12-month Non-overlapping Food Portfolio Return with Moving Averages of PDSIWA at Different Frequencies

This table shows the results from forecasting the future non-overlapping food industry portfolio excess returns (FOODRET) at the 12-month horizon, using the moving averages of the weighted PDSI values (PDSIWA) over different frequencies. The dependent variable (forecast) is the non-overlapping food portfolio excess return (FOODRET) over the next 12 months. The key explanatory (forecasting) variables, PDSIWA12m to PDSIWA30m, are the moving averages of the weighted PDSI values (PDSIWA) over the previous 12 months, 18 months, 24 months and 30 months respectively. The weighted average is over the top 10 food-producing states using cropland area as weight. Other control variables, FOODRET12m, FOODBM12, MRET12, INF12, DP12, MVOL12, NTIS12, DSPR12 and TSPR12 denote, respectively, the FOODRET, the log of the food industry book-to-market ratio (FOODBM), the market excess return (MRET), the inflation rate (INF), the log of the market dividend price ratio (DP), the market volatility (MVOL), the net equity expansion ratio (NTIS), the default spread (DSPR) and the term spreads (TSPR), all over the previous 12 months. CONST is the constant term. $t$-statistics based on Newey-West HAC standard errors are shown in parentheses, with a lag order of 36 for all of the regressions. *,**,*** denote statistical significance at $10 \%, 5 \%, 1 \%$ respectively. The $R^{2}$ and the number of observations $(N)$ in each regression are also reported. The sample period is January 1927 to December 2014. Estimations start in December 1929 to be consistent with our baseline Table 2.

\begin{tabular}{|c|c|c|c|c|}
\hline & \multicolumn{4}{|c|}{ Dep. Var.: Future 12-month Non-overlapping FOODRET } \\
\hline & $(1)$ & $(2)$ & $(3)$ & (4) \\
\hline PDSIWA12m & $\begin{array}{c}0.673 \\
(0.454)\end{array}$ & & & \\
\hline PDSIWA18m & & $\begin{array}{c}0.752 \\
(0.907)\end{array}$ & & \\
\hline PDSIWA24m & & & $\begin{array}{c}1.264^{* *} \\
(2.245)\end{array}$ & \\
\hline PDSIWA30m & & & & $\begin{array}{c}1.749^{* * * *} \\
(2.719)\end{array}$ \\
\hline FOODRET12m & $\begin{array}{c}0.003 \\
(0.025)\end{array}$ & $\begin{array}{c}0.002 \\
(0.022)\end{array}$ & $\begin{array}{c}-0.004 \\
(-0.040)\end{array}$ & $\begin{array}{c}-0.015 \\
(-0.130)\end{array}$ \\
\hline FOODBM12 & $\begin{array}{l}15.681 \\
(0.914)\end{array}$ & $\begin{array}{l}15.719 \\
(0.966)\end{array}$ & $\begin{array}{l}16.154 \\
(1.012)\end{array}$ & $\begin{array}{l}16.651 \\
(1.024)\end{array}$ \\
\hline MRET12 & $\begin{array}{l}-0.224 \\
(-1.190)\end{array}$ & $\begin{array}{c}-0.224 \\
(-1.178)\end{array}$ & $\begin{array}{c}-0.220 \\
(-1.172)\end{array}$ & $\begin{array}{c}-0.209 \\
(-1.131)\end{array}$ \\
\hline INF12 & $\begin{array}{c}0.110 \\
(0.491)\end{array}$ & $\begin{array}{l}0.099 \\
(0.485)\end{array}$ & $\begin{array}{c}0.051 \\
(0.219)\end{array}$ & $\begin{array}{c}0.018 \\
(0.074)\end{array}$ \\
\hline DP12 & $\begin{array}{c}-5.246 \\
(-0.391)\end{array}$ & $\begin{array}{c}-5.161 \\
(-0.402)\end{array}$ & $\begin{array}{c}-5.273 \\
(-0.412)\end{array}$ & $\begin{array}{c}-5.370 \\
(-0.411)\end{array}$ \\
\hline MVOL12 & $\begin{array}{c}-0.357 \\
(-1.452)\end{array}$ & $\begin{array}{c}-0.357 \\
(-1.375)\end{array}$ & $\begin{array}{c}-0.362 \\
(-1.351)\end{array}$ & $\begin{array}{c}-0.355 \\
(-1.326)\end{array}$ \\
\hline NTIS12 & $\begin{array}{c}-2.233^{* * *} \\
(-6.906)\end{array}$ & $\begin{array}{c}-2.246^{* * *} \\
(-6.934)\end{array}$ & $\begin{array}{c}-2.265^{* * *} \\
(-7.040)\end{array}$ & $\begin{array}{c}-2.280^{* * *} \\
(-7.089)\end{array}$ \\
\hline DSPR12 & $\begin{array}{l}-0.057 \\
(-0.021)\end{array}$ & $\begin{array}{l}-0.064 \\
(-0.022)\end{array}$ & $\begin{array}{c}0.019 \\
(0.007)\end{array}$ & $\begin{array}{c}0.072 \\
(0.026)\end{array}$ \\
\hline TSPR12 & $\begin{array}{c}2.840^{* * *} \\
(4.626)\end{array}$ & $\begin{array}{c}2.855^{* * *} \\
(4.040)\end{array}$ & $\begin{array}{c}2.811^{* * *} \\
(3.700)\end{array}$ & $\begin{array}{c}2.792^{* * *} \\
(3.649)\end{array}$ \\
\hline CONST & $\begin{array}{c}4.882 \\
(0.146)\end{array}$ & $\begin{array}{c}5.224 \\
(0.161)\end{array}$ & $\begin{array}{c}5.279 \\
(0.161)\end{array}$ & $\begin{array}{c}5.200 \\
(0.155)\end{array}$ \\
\hline$R^{2}$ & 0.25 & 0.25 & 0.25 & 0.26 \\
\hline$N$ & 85 & 85 & 85 & 85 \\
\hline
\end{tabular}


Appendix Table 5: Predicting 12-month Non-overlapping Food Portfolio Return with Alternative PDSIWA Measures

This table presents the results from forecasting the future non-overlapping food industry portfolio excess returns (FOODRET) at the 12-month horizon, using the 36-month moving averages of alternative PDSIWA measures. The dependent variable (forecast) is the non-overlapping food portfolio excess return (FOODRET) over the next 12 months. The key explanatory (forecasting) variables in columns (1) to (3) are the 36-month moving averages of, respectively, the weighted average (based on cropland areas) of the PDSI values of all 48 contiguous US states (PDSIASWA), the weighted average PDSI of all 48 states with the gross cash income of the farm sector in each state as weight (PDSIASCAWA), and the PDSI of USA produced directly by the US NOAA (PDSIUSA). Other control variables, FOODRET12m, FOODBM12, MRET12, INF12, DP12, MVOL12, NTIS12, DSPR12 and TSPR12 denote, respectively, the FOODRET, the log of the food industry book-to-market ratio (FOODBM), the market excess return (MRET), the inflation rate (INF), the log of the market dividend price ratio (DP), the market volatility (MVOL), the net equity expansion ratio (NTIS), the default spread (DSPR) and the term spreads (TSPR), all over the previous 12 months. CONST is the constant term. $t$-statistics based on NeweyWest HAC standard errors are shown in parentheses, with a lag order of 36 for all of the regressions. $*, * *, * * *$ denote statistical significance at $10 \%, 5 \%, 1 \%$ respectively. The $R^{2}$ for each regression is also reported. $N$ is the number of observation points in each regression. The sample period is January 1927 to December 2014.

\begin{tabular}{|c|c|c|c|}
\hline & \multicolumn{3}{|c|}{$\begin{array}{l}\text { Dependent Variable: Future 12-month } \\
\text { FOODRET, Non-overlapping }\end{array}$} \\
\hline & (1) & $(2)$ & $(3)$ \\
\hline PDSIASWA36m & $\begin{array}{l}2.510^{* *} \\
(2.392)\end{array}$ & & \\
\hline PDSIASCAWA36m & & $\begin{array}{l}2.516^{*} \\
(1.939)\end{array}$ & \\
\hline PDSIUSA36m & & & $\begin{array}{l}1.263^{*} \\
(1.774)\end{array}$ \\
\hline FOODRET12m & $\begin{array}{l}-0.018 \\
(-0.154)\end{array}$ & $\begin{array}{l}-0.012 \\
(-0.108)\end{array}$ & $\begin{array}{l}-0.015 \\
(-0.131)\end{array}$ \\
\hline FOODBM12 & $\begin{array}{l}17.122 \\
(1.022)\end{array}$ & $\begin{array}{l}16.599 \\
(1.006)\end{array}$ & $\begin{array}{l}17.578 \\
(1.061)\end{array}$ \\
\hline MRET12 & $\begin{array}{l}-0.217 \\
(-1.198)\end{array}$ & $\begin{array}{l}-0.220 \\
(-1.217)\end{array}$ & $\begin{array}{c}-0.231 \\
(-1.354)\end{array}$ \\
\hline INF12 & $\begin{array}{c}0.022 \\
(0.086)\end{array}$ & $\begin{array}{c}0.024 \\
(0.100)\end{array}$ & $\begin{array}{c}0.015 \\
(0.063)\end{array}$ \\
\hline DP12 & $\begin{array}{l}-5.616 \\
(-0.416)\end{array}$ & $\begin{array}{l}-5.572 \\
(-0.420)\end{array}$ & $\begin{array}{l}-6.923 \\
(-0.525)\end{array}$ \\
\hline MVOL12 & $\begin{array}{l}-0.379 \\
(-1.404)\end{array}$ & $\begin{array}{l}-0.352 \\
(-1.246)\end{array}$ & $\begin{array}{l}-0.337 \\
(-1.196)\end{array}$ \\
\hline NTIS12 & $\begin{array}{c}-2.309^{* * *} \\
(-7.351)\end{array}$ & $\begin{array}{c}-2.310^{* * *} \\
(-7.385)\end{array}$ & $\begin{array}{c}-2.321^{* * *} \\
(-7.498)\end{array}$ \\
\hline DSPR12 & $\begin{array}{c}0.404 \\
(0.150)\end{array}$ & $\begin{array}{c}0.062 \\
(0.022)\end{array}$ & $\begin{array}{l}-0.008 \\
(-0.003)\end{array}$ \\
\hline TSPR12 & $\begin{array}{c}2.875^{* * *} \\
(3.611)\end{array}$ & $\begin{array}{c}2.923^{* * *} \\
(3.747)\end{array}$ & $\begin{array}{c}2.946^{* * *} \\
(3.503)\end{array}$ \\
\hline CONST & $\begin{array}{c}4.516 \\
(0.130)\end{array}$ & $\begin{array}{c}4.445 \\
(0.130)\end{array}$ & $\begin{array}{c}0.471 \\
(0.014)\end{array}$ \\
\hline$R^{2}$ & 0.26 & 0.26 & 0.26 \\
\hline$N$ & 85 & 85 & 85 \\
\hline
\end{tabular}


Appendix Table 6: Predicting 12-month Non-overlapping Food Portfolio net of Market Return with 36-month Moving Average of PDSIWA

This table presents the results from forecasting the future non-overlapping FOODXMRET, the food portfolio return net of the return of the market excluding food (MXF) portfolio, at the 12-month horizon, using the 36-month moving average of the weighted PDSI values (PDSIWA). The dependent variable (forecast) is the non-overlapping FOODXMRET, the food portfolio return net of the return of the market excluding food (MXF) portfolio, over the next 12 months. The key explanatory (forecasting) variable, PDSIWA36m, is the moving average of the weighted PDSI values (PDSIWA) over the previous 36 months. The weighted average is over the top 10 food-producing states using cropland area as weight. Other control variables, FOODXMRET12m, FOODBM12, MRET12, INF12, DP12, MVOL12, NTIS12, DSPR12 and TSPR12 denote, respectively, the FOODXMRET, the $\log$ of the food industry book-to-market ratio (FOODBM), the market excess return (MRET), the inflation rate (INF), the log of the market dividend price ratio (DP), the market volatility (MVOL), the net equity expansion ratio (NTIS), the default spread (DSPR) and the term spreads (TSPR), all over the previous 12 months. CONST is the constant term. $t$-statistics based on Newey-West HAC standard errors are shown in parentheses, with a lag order of 36 for all of the regressions. *, **, *** denote statistical significance at $10 \%, 5 \%, 1 \%$ respectively. The $R^{2}$ for each regression is also reported. $N$ is the number of observation points in each regression. The sample period is January 1927 to December 2014.

\begin{tabular}{|c|c|c|c|}
\hline & \multicolumn{3}{|c|}{$\begin{array}{l}\text { Dependent Variable: Future 12-month } \\
\text { FOODXMRET, Non-overlapping }\end{array}$} \\
\hline & $(1)$ & $(2)$ & $(3)$ \\
\hline PDSIWA36m & & & $\begin{array}{c}1.230^{* * *} \\
(3.013)\end{array}$ \\
\hline FOODXMRET12m & & $\begin{array}{c}0.011 \\
(0.127)\end{array}$ & $\begin{array}{c}-0.008 \\
(-0.092)\end{array}$ \\
\hline FOODBM12 & & $\begin{array}{l}9.413^{* * *} \\
(2.764)\end{array}$ & $\begin{array}{c}10.737^{* *} \\
(2.601)\end{array}$ \\
\hline MRET12 & $\begin{array}{l}-0.111^{* *} \\
(-2.609)\end{array}$ & $\begin{array}{c}-0.194^{* * *} \\
(-3.068)\end{array}$ & $\begin{array}{c}-0.203^{* * *} \\
(-2.983)\end{array}$ \\
\hline INF12 & $\begin{array}{c}0.097 \\
(0.864)\end{array}$ & $\begin{array}{c}0.105 \\
(0.732)\end{array}$ & $\begin{array}{c}0.001 \\
(0.010)\end{array}$ \\
\hline DP12 & $\begin{array}{l}-5.240 \\
(-1.609)\end{array}$ & $\begin{array}{c}-13.237^{* * *} \\
(-2.669)\end{array}$ & $\begin{array}{l}-13.710^{* *} \\
(-2.387)\end{array}$ \\
\hline MVOL12 & $\begin{array}{l}-0.334^{* *} \\
(-2.166)\end{array}$ & $\begin{array}{l}-0.257^{*} \\
(-1.688)\end{array}$ & $\begin{array}{l}-0.269^{*} \\
(-1.761)\end{array}$ \\
\hline NTIS12 & $\begin{array}{c}0.240 \\
(0.241)\end{array}$ & $\begin{array}{c}0.354 \\
(0.356)\end{array}$ & $\begin{array}{c}0.318 \\
(0.319)\end{array}$ \\
\hline DSPR12 & $\begin{array}{c}4.675^{* * *} \\
(2.890)\end{array}$ & $\begin{array}{c}3.542^{* *} \\
(2.437)\end{array}$ & $\begin{array}{c}3.804^{* * *} \\
(2.718)\end{array}$ \\
\hline TSPR12 & $\begin{array}{c}-0.794 \\
(-1.381)\end{array}$ & $\begin{array}{c}-0.397 \\
(-0.756)\end{array}$ & $\begin{array}{c}-0.499 \\
(-1.028)\end{array}$ \\
\hline CONST & $\begin{array}{l}-16.251 \\
(-1.139)\end{array}$ & $\begin{array}{c}-36.973^{* *} \\
(-2.007)\end{array}$ & $\begin{array}{c}-37.445^{*} \\
(-1.821)\end{array}$ \\
\hline$R^{2}$ & 0.07 & 0.09 & 0.10 \\
\hline$N$ & 85 & 85 & 85 \\
\hline
\end{tabular}


Appendix Table 7: Predicting 1-year Food Industry Change in Profitability (CP) with 36-month Moving Average of PDSIWA

This table presents the results from forecasting the future 1-year CP, the change in profitability of the food industry over the next year, using the 36-month moving average of the weighted PDSI values (PDSIWA). The dependent variable (forecast) is the CP, the future change in the food industry profitability, over the next year. The key explanatory (forecasting) variable, PDSIWA $36 \mathrm{~m}$, is the moving average of the weighted PDSI values (PDSIWA) over the previous 3 years (36 months). The weighted average is over the top 10 food-producing states using cropland area as weight. Other control variables, CP1y, FOODRET12m, FOODBM12, MRET12, INF12, DP12, MVOL12, NTIS12, DSPR12 and TSPR12 denote, respectively, the change in the food industry profitability, the food industry portfolio return (FOODRET), the log of the food industry book-to-market ratio (FOODBM), the market excess return (MRET), the inflation rate (INF), the log of the market dividend price ratio (DP), the market volatility (MVOL), the net equity expansion ratio (NTIS), the default spread (DSPR) and the term spreads (TSPR), all over the previous year (12 months). CONST is the constant term. $t$-statistics based on Newey-West HAC standard errors are shown in parentheses, with a lag order of 36 for all of the regressions. $*, * *, * * *$ denote statistical significance at $10 \%, 5 \%, 1 \%$ respectively. The $R^{2}$ for each regression is also reported. $N$ is the number of observation points in each regression. The sample period is 1950 to 2014 .

\begin{tabular}{lccc}
\hline & \multicolumn{3}{c}{ Dependent Variable: Future 1-year } \\
& \multicolumn{2}{c}{ Change in Food Industry Profitability } \\
\hline PDSIWA36m & & $(1)$ & $(3)$ \\
CP1y & & & $0.100^{* *}$ \\
& & -0.101 & $(2.412)$ \\
FOODRET12m & & -0.125 \\
& & $-0.016^{* * *}$ & $(-0.969)$ \\
FOODBM12 & & $(-3.668)$ & $-0.017^{* * *}$ \\
MRET12 & & $-4.455)$ \\
& & $(0.7148$ & 0.299 \\
INF12 & -0.003 & $0.008^{*}$ & $(1.388)$ \\
& $(-0.633)$ & $(1.788)$ & 0.008 \\
DP12 & $-0.078^{* * *}$ & $-0.084^{* * *}$ & $-0.094^{* * *}$ \\
& $(-3.101)$ & $(-3.198)$ & $(-3.480)$ \\
MVOL12 & 0.157 & 0.033 & -0.068 \\
& $(1.648)$ & $(0.142)$ & $(-0.282)$ \\
NTIS12 & $0.031^{* * *}$ & $0.027^{* * *}$ & $0.026^{* * *}$ \\
DSPR12 & $(3.227)$ & $(3.761)$ & $(2.804)$ \\
& $0.119^{* *}$ & $0.089^{*}$ & $0.088^{* *}$ \\
TSPR12 & $(2.518)$ & $(1.978)$ & $(2.018)$ \\
& 0.285 & $0.319^{*}$ & 0.280 \\
CONST & $(1.396)$ & $(1.796)$ & $(1.453)$ \\
& -0.002 & 0.020 & 0.009 \\
$R^{2}$ & $(-0.105)$ & $(0.666)$ & $(0.283)$ \\
$N$ & 0.026 & -0.192 & -0.361 \\
& $(0.065)$ & $(-0.299)$ & $(-0.528)$ \\
& 0.22 & 0.27 & 0.29 \\
& 63 & 63 & 63 \\
\hline
\end{tabular}




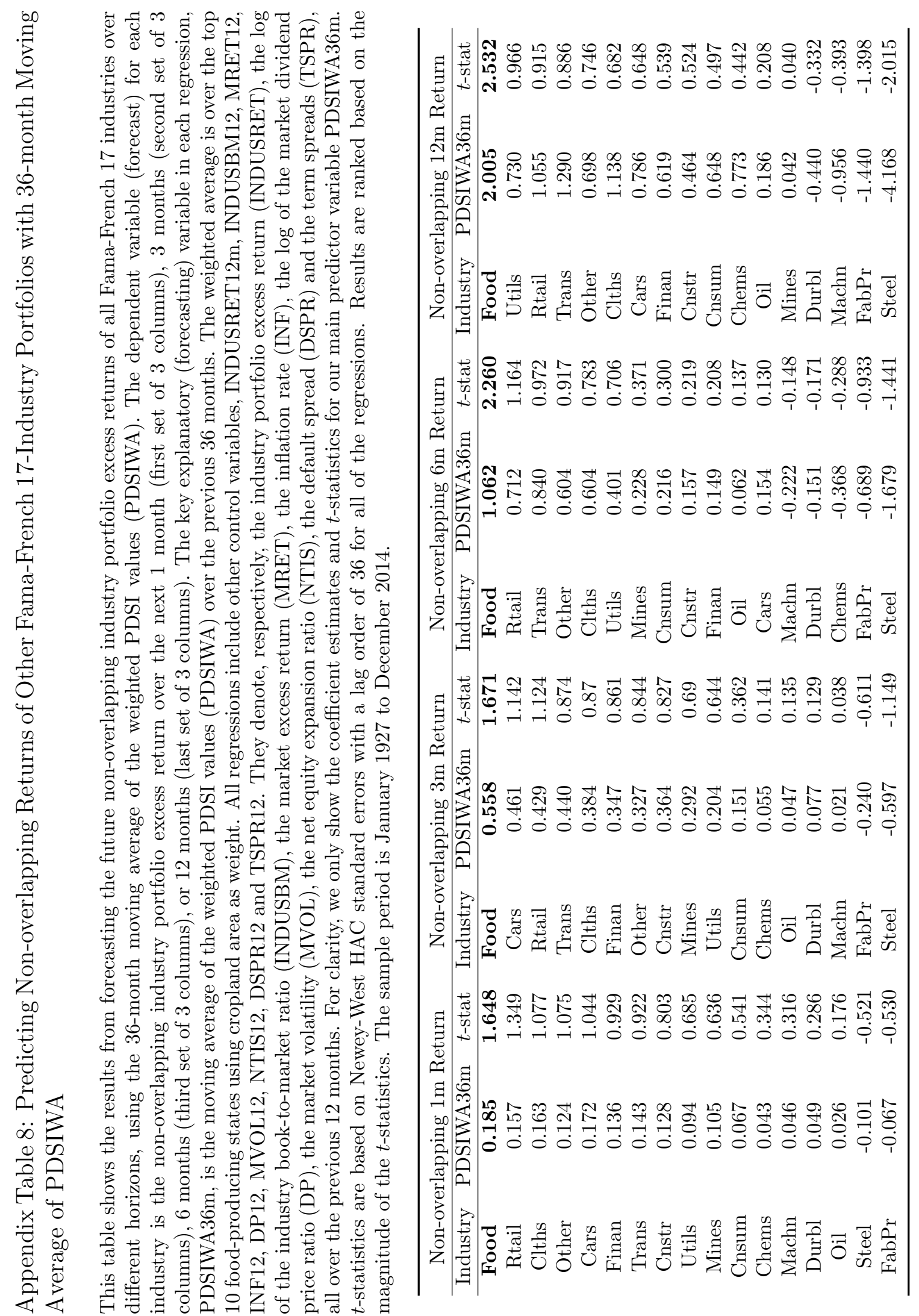


Appendix Table 9: Predicting Non-overlapping Food Portfolio Returns and Food Industry Change in Profitability with 36-month Moving Average of PMDIWA

This table presents the results from forecasting the future non-overlapping food industry portfolio excess returns (FOODRET) over different horizons and the future 1-year change in profitability of the food industry, using the 36-month moving average of the weighted PMDI (Modified Palmer Drought Severity Index) values. The dependent variables (forecasts) are the non-overlapping food portfolio excess returns (FOODRET) over the next 1 month, 3 months, 6 months and 12 months (Future FOODRET1m to Future FOODRET12m), the non-overlapping food portfolio return net of the return of the market excluding food (MXF) portfolio over the next 12 months (Future FOODXMRET12m), and the future change in the food industry profitability over the next year (Future CP1y). The key explanatory (forecasting) variable, PMDIWA36m, is the moving average of the weighted PMDI values (PMDIWA) over the previous 36 months. The weighted average is over the top 10 food-producing states using cropland area as weight. Other control variables, CP1y, FOODRET12m, FOODXMRET12m, FOODBM12, MRET12, INF12, DP12, MVOL12, NTIS12, DSPR12 and TSPR12 denote, respectively, the change in the food industry profitability (CP), the food portfolio return (FOODRET), the food portfolio net of market return (FOODXMRET), the log of the food industry book-to-market ratio (FOODBM), the market excess return (MRET), the inflation rate (INF), the log of the market dividend price ratio (DP), the market volatility (MVOL), the net equity expansion ratio (NTIS), the default spread (DSPR) and the term spreads (TSPR), all over the previous 12 months. CONST is the constant term. $t$-statistics based on NeweyWest HAC standard errors are shown in parentheses, with a lag order of 36 for all of the regressions. *, **, *** denote statistical significance at $10 \%, 5 \%, 1 \%$ respectively. The $R^{2}$ for each regression is also reported. $N$ is the number of observation points in each regression. The sample period is January 1927 to December 2014 for the return regressions and 1950 to 2014 for the change in profitability regression.

\begin{tabular}{|c|c|c|c|c|c|c|}
\hline & \multicolumn{6}{|c|}{ Dependent Variable } \\
\hline & (1) & $(2)$ & $(3)$ & $(4)$ & $(5)$ & $(6)$ \\
\hline & Future & Future & Future & Future & Future & Future \\
\hline & FOODRET1m & FOODRET3m & FOODRET6m & FOODRET $12 \mathrm{~m}$ & FOODXMRET12m & CP1y \\
\hline \multirow[t]{2}{*}{ PMDIWA36m } & 0.188 & 0.565 & $1.122^{* *}$ & $2.104^{* * *}$ & $1.344^{* * *}$ & $0.108^{* *}$ \\
\hline & $(1.635)$ & $(1.611)$ & $(2.368)$ & $(2.674)$ & $(2.941)$ & $(2.380)$ \\
\hline CP1y & & & & & & $\begin{array}{c}-0.132 \\
(-0.990)\end{array}$ \\
\hline \multirow[t]{2}{*}{ FOODRET12m } & -0.000 & -0.026 & -0.011 & -0.021 & & $-0.017^{* * *}$ \\
\hline & $(-0.029)$ & $(-0.488)$ & $(-0.129)$ & $(-0.185)$ & & $(-4.442)$ \\
\hline \multirow[t]{2}{*}{ FOODXMRET12m } & & & & & -0.009 & \\
\hline & & & & & $(-0.100)$ & \\
\hline \multirow{2}{*}{ FOODBM12 } & 0.489 & 1.935 & 6.672 & 17.095 & $10.917 * * *$ & 0.319 \\
\hline & $(0.717)$ & $(0.680)$ & (1.187) & (1.028) & $(2.687)$ & (1.449) \\
\hline \multirow[t]{2}{*}{ MRET12 } & 0.004 & -0.011 & -0.110 & -0.206 & $-0.203^{* * *}$ & 0.007 \\
\hline & $(0.236)$ & $(-0.211)$ & $(-1.352)$ & $(-1.096)$ & $(-2.984)$ & $(1.401)$ \\
\hline \multirow[t]{2}{*}{ INF12 } & -0.057 & -0.140 & $-0.339 * *$ & 0.032 & -0.002 & $-0.094 * * *$ \\
\hline & $(-0.884)$ & $(-0.812)$ & $(-2.054)$ & $(0.129)$ & $(-0.011)$ & $(-3.460)$ \\
\hline \multirow[t]{2}{*}{ DP12 } & 0.436 & 1.157 & -0.032 & -5.534 & $-13.744^{* *}$ & -0.083 \\
\hline & $(0.712)$ & $(0.489)$ & $(-0.007)$ & $(-0.411)$ & $(-2.386)$ & $(-0.336)$ \\
\hline \multirow[t]{2}{*}{ MVOL12 } & -0.007 & -0.038 & $-0.307 * * *$ & -0.355 & $-0.266^{*}$ & $0.026^{* * *}$ \\
\hline & $(-0.265)$ & $(-0.563)$ & $(-2.775)$ & $(-1.348)$ & $(-1.728)$ & $(2.819)$ \\
\hline \multirow[t]{2}{*}{ NTIS12 } & $-0.236^{* * *}$ & $-0.875^{* * *}$ & $-1.344^{* * *}$ & $-2.265^{* * *}$ & 0.315 & $0.089^{*}$ \\
\hline & $(-3.016)$ & $(-3.756)$ & $(-3.584)$ & $(-6.910)$ & $(0.316)$ & $(2.005)$ \\
\hline \multirow[t]{2}{*}{ DSPR12 } & -0.107 & -0.407 & -0.616 & 0.127 & $3.754^{* * *}$ & 0.271 \\
\hline & $(-0.293)$ & $(-0.463)$ & $(-0.508)$ & $(0.048)$ & $(2.698)$ & $(1.365)$ \\
\hline \multirow[t]{2}{*}{ TSPR12 } & 0.138 & $0.452^{* *}$ & $1.374^{*}$ & $2.742^{* * *}$ & -0.515 & 0.007 \\
\hline & (1.599) & $(2.039)$ & (1.868) & $(3.578)$ & $(-1.081)$ & $(0.229)$ \\
\hline \multirow[t]{2}{*}{ CONST } & 2.877 & 9.201 & 14.426 & 4.797 & $-37.436^{*}$ & -0.392 \\
\hline & (1.557) & (1.459) & (1.139) & $(0.138)$ & $(-1.804)$ & $(-0.565)$ \\
\hline$R^{2}$ & 0.02 & 0.06 & 0.14 & 0.26 & 0.11 & 0.29 \\
\hline$N$ & 1020 & 340 & 170 & 85 & 85 & 63 \\
\hline
\end{tabular}


Appendix Figure 1: Future Non-overlapping 12-month Food Portfolio Return Residual and Past 36-month Moving Average of PDSIWA, Scatter Plot

This figure depicts the scatter plot of the future non-overlapping 12-month food portfolio return residual against our main predictor variable PDSIWA36m, the past 36-month moving average of the weighted average (by cropland area) PDSI value of the top 10 food-producing states in the US. The sample period is January 1927 to December 2014. The plot starts in December 1929 as the first 36 months are used to obtain the first value of PDSIWA36m.

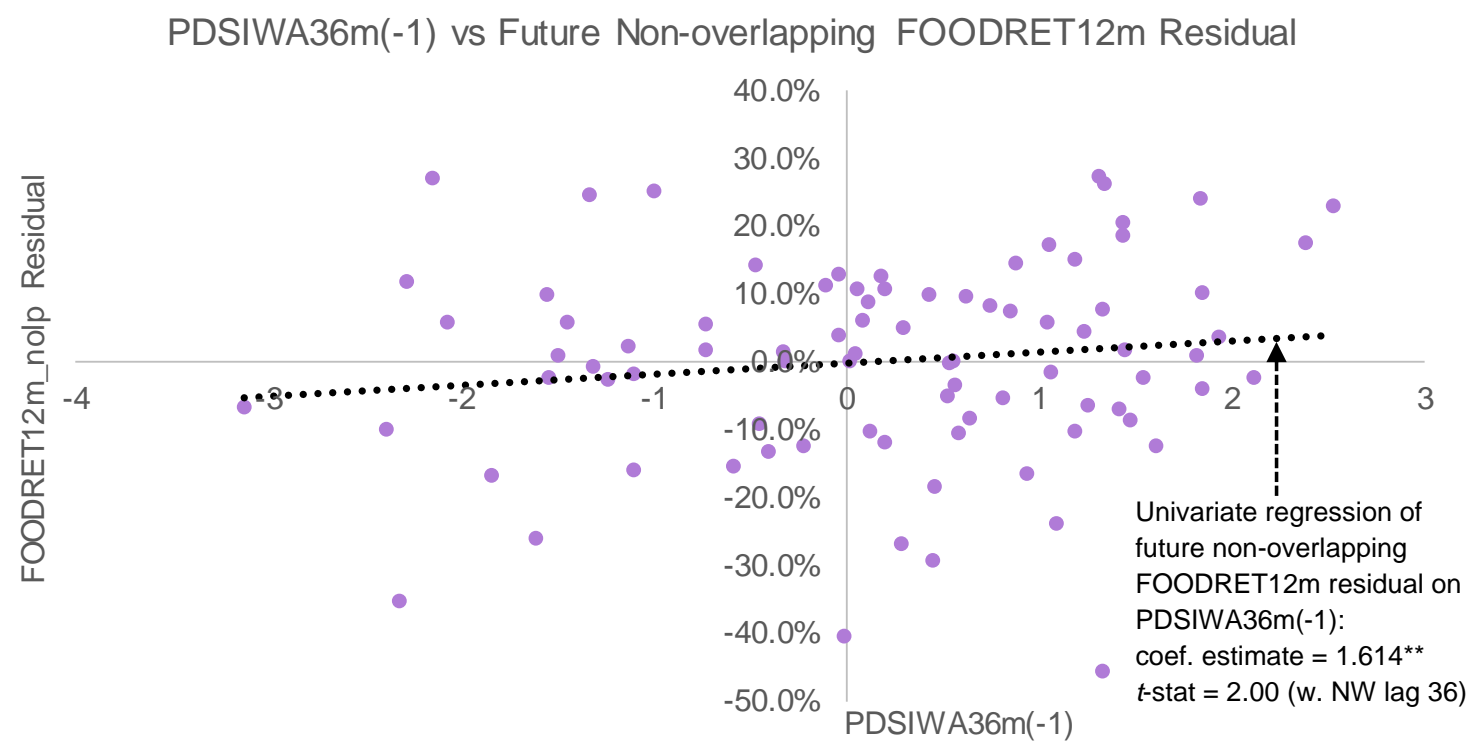


Appendix Figure 2: Future 1-year Change in Food Industry Profitability (CP) Residual and Past 36-month Moving Average of PDSIWA, Scatter Plot

This figure depicts the scatter plot of the future 1-year change in the food industry profitability (CP) residual against our main predictor variable PDSIWA36m, the past 36-month (3-year) moving average of the weighted average (by cropland area) PDSI value of the top 10 food-producing states in the US. The sample period is 1950 to 2014 .

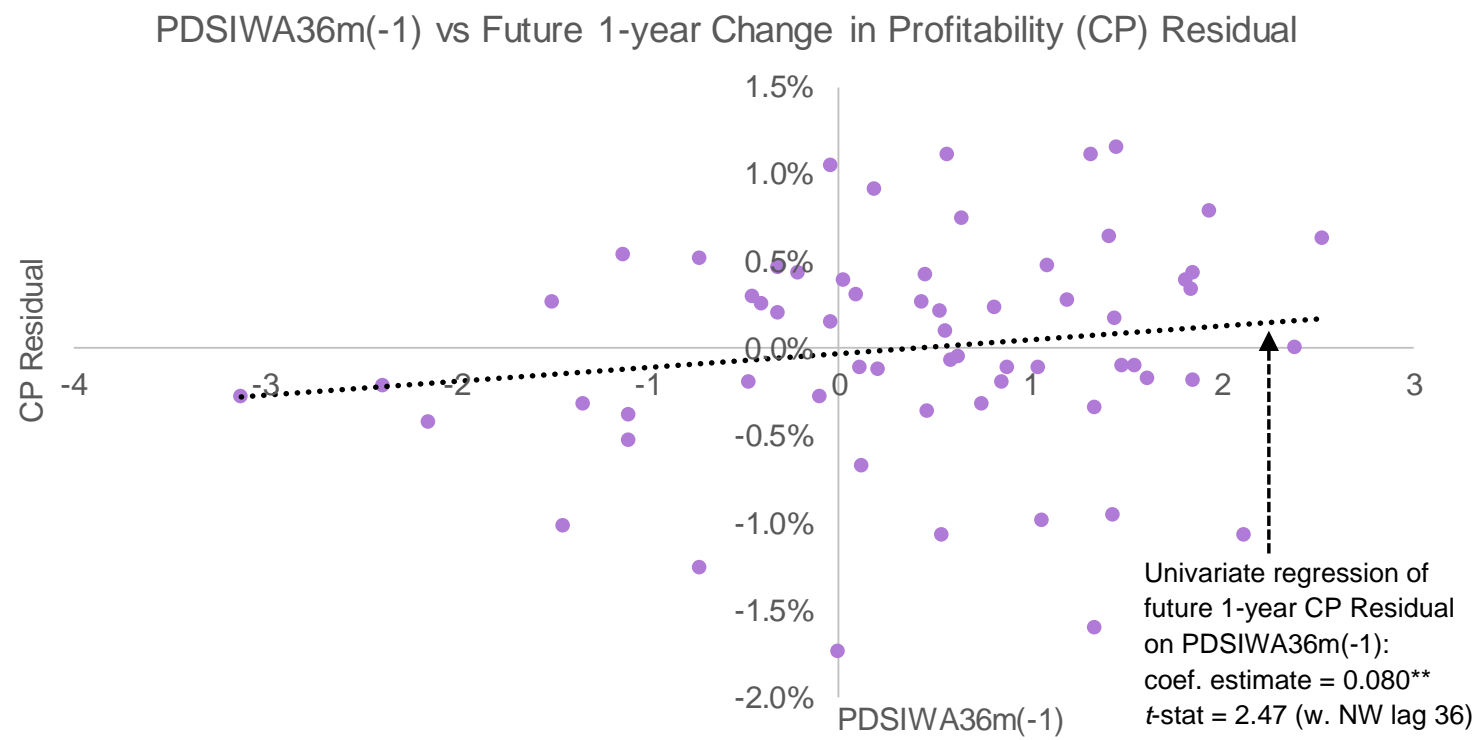

